Usando Serviços Web para integrar aplicações cientes de contexto

Carlos Henrique Odenique Jardim 



\title{
Usando Serviços Web para integrar aplicações cientes de contexto
}

\author{
Carlos Henrique Odenique Jardim \\ Orientadora: Profa. Dra. Maria da Graça Campos Pimentel \\ Dissertação apresentada ao Instituto de Ciências Mate- \\ máticas e de Computação - ICMC-USP, como parte dos \\ requisitos para obtenção do título de Mestre em Ciências \\ de Computação e Matemática Computacional.
}

USP - São Carlos

Fevereiro/2006 



\section{Dedicatória}

Aos meus pais Francisco e Aparecida, meus irmãos Rafael e Marina, a minha orientadora Graça Pimentel e aos meus amigos Renato Bulcão e Tacina Kudo pelo apoio incondicional. 


\section{Agradecimentos}

Agradeço a Graça pela orientação durante o mestrado, ajuda e pelas cobranças sempre bem vindas e ao Renato pela colaboração, incentivo e ajuda.

Agradeço aos meus amigos e companheiros ou ex-companheiros de Laboratório Intermídia e de Projeto TIDIA-Ae Graça, Renata Pontin, Renato, Taciana, Elaine, Pedro, Jane, Silvana, Renata Porto, Daniel Lobato, Renan, Valter, Hélder, Anselmo, Juliana, Toño e Alessandra pela ajuda, incentivo e companhia.

Aos meus amigos de república Bruno, Osvaldo, Carrijo, Bixo-L pelos momentos de diversão e pelas discussões filósoficas.

Deixo um agradecimento especial à Graça e Renato Bulcão pela revisão e contribuição para esta monografia e pela ajuda neste projeto.

Aproveito para agradecer aos meus pais pelos esforços que fizeram e fazem, em prol da minha formação, pela paciência e por sempre terem acreditado em mim.

Agradeço a FAPESP pelo apoio financeito (processo $n^{\circ}$ 04/08206-8).

Agradeço aos contribuidores da enciclopédia Wikipedia por compartilharem os seus conhecimentos os quais usualmente consulto.

Finalmente quero agradecer a Deus por sempre me dar forças para enfrentar as dificuldades. 


\section{Resumo}

A Computação Ubíqua está revolucionando a interação do ser-humano com os dispositivos computacionais ao disponibilizar tecnologias pouco intrusivas ao cotidiano das pessoas. A Computação Ciente de Contexto, um dos temas de pesquisa em Computação Ubíqua, tem contribuído para a construção de aplicações capazes de customizar-se e adaptar-se às necessidades do usuário sem a intervenção explícita deste. Suportar o desenvolvimento de aplicações Cientes de Contexto é um dos desafios da Computação Ubíqua. Desenvolvido no mesmo grupo de pesquisa que este trabalho está inserido, o Serviço Web Context Kernel, gerencia informações de contexto e explora as especificações e tecnologias da Web como plataforma de intercâmbio para a informação contextual. O trabalho aqui reportado teve como objetivo investigar a utilização de Serviços Web por meio do emprego da infra-estrutura Context Kernel na integração de aplicações em cenários de trabalho colaborativo e de aprendizado eletrônico. Como resultado, foi elaborado um conjunto de lições aprendidas provenientes do estudo e do emprego das especificações para Serviços Web. Outros resultados foram: as especificações de informações de contexto de grupo e de metadados educacionais em dimensões de contexto e exemplos de utilização do Context Kernel para tornar aplicações cientes de contexto. 


\section{Abstract}

Ubiquitous computing has became a revolution in terms of the user-computer interaction by providing technologies that seamlessly integrate themselves to people's everyday life. Context-aware computing, which is an important research theme in ubiquitous computing, has been contributing for the building of applications that are capable both to customize and adapt themselves aiming to support a user without disturb him. A great challenge in ubiquitous computing has been the support to build context-aware aplications. For that reason, the it has been developed the Context Kernel Web Service, which is a service infrastructure that makes use of Web-based specifications and technologies in order to promote the management and the interchange of context information. In this work the usage of Web Services was analyzed by using the Context Kernel to integrate applications in scenarios of cooperative work and e-learning. As a result, a list of lessons learned was ellaborated with respect to the use and the study of Web Services specifications for context-aware computing. Other results include a context information specifications for metadata about group and educational resources as well as examples of how to use the Context Kernel to leverage applications context-aware. 


\section{Publicações}

Publicações obtidas no contexto deste trabalho:

- Jardim, C. H. O., Neto, R. F. B., Godoy, R. P., Ribas, H. M. B., Arruda Jr., C. R. E., Munson, E. V., and Pimentel, M. G. C. (2005). Web Services Enabling Ubiquitous Computing Applications: Lessons Learned by Integrating Ubiquitous e-Learning Applications. International Journal of Web Services Practices, 1(12):142-152. ISSN: 1738-6535.

- Jardim, C. H. O., Bulcão Neto, R. F., Ribas, H. M. B., Munson, E. V., and Pimentel, M. G. C. (2005). Web Services Enabling Context-aware Applications: Lessons Learned by Integrating e-Learning Applications. In International Conference on Next Generation Web Services Practices, pages 400-405, Seoul, Korea. IEEE Computer Society Press. ISBN: 0-7695-2452-4.

- Macedo, A. A., Bulcão Neto, R. F., Camacho-Guerrero, J. A., Jardim, C. H. O., Cattelan, R. G., Inácio Jr, V. R., and Pimentel, M. G. C. (2005). Linking everyday presentations through context information. In 3rd IW3C2 Latin American Web Conference, pages 130-139, Buenos Aires, Argentina. IEEE Computer Society Press.

- Bulcão Neto, R. F., Jardim, C. H. O., Camacho-Guerrero, J. A., and Pimentel, M. G. C. (2004). A Web Service Approach for Providing Context Information to CSCW Applications. In Proceedings of 2nd IW3C2 Latin American Web Congress, pages 78-85, Ribeirão Preto, Brasil. IEEE Computer Society Press.

- Bulcão Neto, R. F., Jardim, C. H. O., Camacho-Guerrero, J. A., Lobato, D. C., and Pimentel, M. G. C. (2004). A Context-based Web Service Approach to Communities of Practice. XXXI Seminário Integrado de Software e Hardware, SEMISH. 15 pages.

- Bulcão Neto, R. F., Jardim, C. H. O., Camacho-Guerrero, J. A., and Pimentel, M. G. C. (2004). Provision of context information to CSCW Applications: A Web Service Approach. Technical report 227, Instituto de Ciências Matemáticas e de Computação - USP. 26 pages. 


\section{Sumário}

1 Introdução 1

1.1 Contextualização . . . . . . . . . . . . . . . . . . . . . . . . . . . . . . . .

1.2 Motivação . . . . . . . . . . . . . . . . . . . . 3

1.3 Objetivos e resultados obtidos . . . . . . . . . . . . . . 3

1.4 Estrutura do texto . . . . . . . . . . . . . . . . . 4

2 Computação Ciente de Contexto 5

2.1 Definição de informação de contexto . . . . . . . . . . . . 5

2.2 Definição de ciência de contexto . . . . . . . . . . . . 5

2.3 Dimensões de informações de contexto . . . . . . . . . . . . . 6

2.4 Desafios em computação ciente de contexto . . . . . . . . . . . 7

2.4 .1 Intercâmbio de informações de contexto . . . . . . . . . . . . 7

2.4 .2 Representação da informação contextual . . . . . . . . . . . 7

2.4 .3 Histórico de contexto . . . . . . . . . . . . . . . 8

2.4 .4 Privacidade e segurança . . . . . . . . . . . . . . 8

2.4 .5 Descoberta de recursos . . . . . . . . . . . . . . . . 9

2.4 .6 Interpretação de informações de contexto $\ldots \ldots \ldots$. . . . . . 10

2.5 Considerações finais . . . . . . . . . . . . . . . 11

\begin{tabular}{lll}
\hline 3 & Serviços Web & 13
\end{tabular}

3.1 Arquitetura Orientada a Serviços . . . . . . . . . . . . . . . . . . 14

3.2 Benefícios dos Serviços Web . . . . . . . . . . . . . . . 15

3.3 Arquitetura dos Serviços Web . . . . . . . . . . . . . . 16

3.4 Protocolos e tecnologias dos Serviços Web . . . . . . . . . . . . . 18

3.4 .1 Protocolo de empacotamento SOAP . . . . . . . . . . . . . . . . . . . . . . . . 18

3.4 .2 Linguagem de descrição WSDL . . . . . . . . . . . . . . . . . . 19

3.4 .3 Serviços Web orientados a chamada de procedimento remoto . . . 20 
3.4 .4 Serviços Web orientados a documento . . . . . . . . . . . 21

3.4 .5 Segurança, coordenação e administração de Serviços Web. . . . . 22

3.5 Registros para Serviços Web . . . . . . . . . . . . . . . . . 24

3.6 Considerações finais $\ldots \ldots \ldots \ldots \ldots \ldots \ldots$

\begin{tabular}{|lll}
\hline & Context Kernel & 27
\end{tabular}

4.1 O Serviço Web Context Kernel . . . . . . . . . . . . . . . . . . . . . . . 27

4.2 Modelo de armazenamento do Context Kernel . . . . . . . . . . . . . . 28

4.3 Operações disponibilizadas pelo Context Kernel . . . . . . . . . . . . . . . 29

4.3 .1 Registro de aplicações . . . . . . . . . . . . . . . . . . . . . . 29

4.3 .2 Armazenamento de informações de contexto . . . . . . . . . . . 30

4.3 .3 Recuperação de informações de contexto . . . . . . . . . . . . . . . . . . 31

4.3 .4 Consulta de informações de contexto . . . . . . . . . . . . . . . . . . . . 32

4.3 .5 Notificação de eventos e validação de regras . . . . . . . . . . . . . . . . . . 33

4.4 Limitações do Context Kernel . . . . . . . . . . . . . . . . . . . . . 34

4.5 Considerações finais $\ldots \ldots \ldots \ldots \ldots \ldots$

5 Trabalhos Relacionados $\quad 37$

5.1 Context Toolkit . . . . . . . . . . . . . . . . . . 37

5.2 Context Fabric . . . . . . . . . . . . . . . . . . . . 39

5.3 GaiaOS . . . . . . . . . . . . . . . . . . 40

5.4 Aura $\ldots \ldots \ldots \ldots \ldots \ldots \ldots \ldots$

5.5 Context Service . . . . . . . . . . . . . . . . . . . 43

5.6 Context Tailor . . . . . . . . . . . . . . . . . . . 44

5.7 one.world $\ldots \ldots \ldots \ldots \ldots \ldots \ldots \ldots$

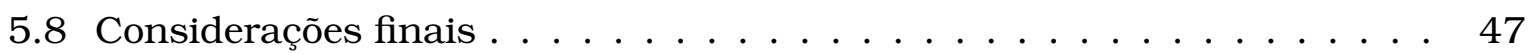

6 Serviços Web em Computação Ciente de Contexto 49

6.1 O Context Kernel em uso por aplicações CSCW . . . . . . . . . . . . . . . 49

6.1 .1 Aplicação WebLogin . . . . . . . . . . . . . . . . . 50

6.1 .2 Aplicação WebRegister . . . . . . . . . . . . . . . . . . 52

6.1 .3 A aplicação WebMemex . . . . . . . . . . . . . . . . . 53

6.1 .4 A aplicação WebChat . . . . . . . . . . . . . . . . . 55

6.1 .5 Discussão sobre a integração . . . . . . . . . . . . . . . 56

6.2 O Context Kernel em uso por aplicações de aprendizado eletrônico . . 57

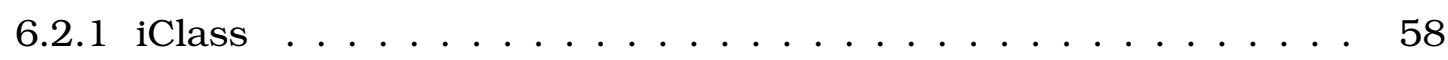

6.2 .2 AutorE . . . . . . . . . . . . . . . . . . 59

6.2 .3 coWeb . . . . . . . . . . . . . . . . . . 59

6.2 .4 Integrando aplicações de aprendizado eletrônico . . . . . . . . . 60

6.2 .5 Discussão sobre a integração . . . . . . . . . . . . . . 67 
6.3 Lições aprendidas ao utilizar Serviços Web. . . . . . . . . . . . . . . . 69

6.4 Considerações finais . . . . . . . . . . . . . . . 70

\begin{tabular}{lll}
\hline 7 & Conclusões & 73
\end{tabular}

7.1 Contribuições . . . . . . . . . . . . . . . . . . . 74

7.2 Publicações . . . . . . . . . . . . . . . . . . 74

7.3 Trabalhos futuros . . . . . . . . . . . . . . . . . 75

7.4 Considerações finais . . . . . . . . . . . . . . . . . 77 


\section{Lista de Figuras}

1.1 Exemplos de dispositivos computacionais ubíquos. . . . . . . . . . . . 2

3.1 Interação entre serviços, aplicação e serviço de registro em arquitetura orientada a serviços. Adaptado de Bond et al.|2004|. . . . . . . . . . . . 14

3.2 Arquitetura dos Serviços Web e tecnologias relacionadas. Adaptado de W3C|2004el. . . . . . . . . . . . . . . . . . 17

3.3 Diagrama de operação de um roteador SOAP. Adaptado de Bond et al.



4.1 Fluxo de informação no Context Kernel. . . . . . . . . . . . . . . . . . 28

5.1 Interações entre as aplicações e componentes da aquitetura do Context Toolkit. Adaptado de Dey et al.|2001]. . . . . . . . . . . . . . . . . 38

5.2 Arquittura do Context Fabric: sensores e serviços básicos são distribuídos entre aplicações e a infra-estrutura. Adaptado de Hong and Landay

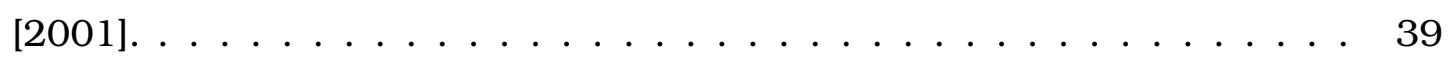





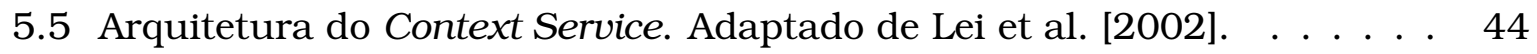

5.6 Arquitetura em alto nível ilustrando a interação entre os componentes adicionados ao Context Service pelo Context Tailor. Adaptado de Davis II et al. $|2003 a| . \ldots \ldots \ldots \ldots \ldots$. . . . . . . . . . . . . 45

5.7 Visão geral da arquitetura do one.world. Adaptado de Grimm et al.||2004|.|46

6.1 Aplicações WebLogin e WebRegister: (a) A informação do usuário será verificada com a registrada no Context Kernel; (b) ao se adicionar um novo usuário, deve-se fornecer informações de contexto de localização para o Context Kernel; (c) interface para registro de grupos. . . . . . . . . 50 
6.2 A interface do WebMemex (tela no canto inferior direito). . . . . . . . . . 54

6.3 A interface do WebChat. . . . . . . . . . . . . . . . 56

6.4 Aplicação iClass: (a) um instrutor usando o iClass para anotar sobre slides previamente preparados; (b) um documento HTML contento todos os slides apresentados e/ou anotados em uma aula; (c) tinta eletrônica sendo reproduzida sincronamente com o áudio capturado. . . . . . . . . 59

6.5 Exemplo de um slide sendo anotado durante uma aula com o iClass. . . 60

6.6 Exemplo de uma aula sobre Computação Gráfica sendo criada usando o

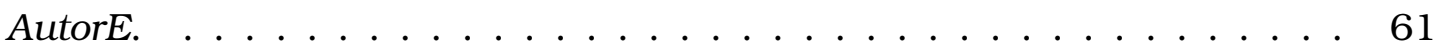

6.7 Exemplo de uma aula sendo documentada usando a CoWeb. . . . . . . . 62

6.8 Fluxo de informação: AutorE, iClass, CoWeb e o Serviço Web Context

\begin{tabular}{|l|}
\hline Kernel trocando metadados sobre registro e consultas de cursos e aulas. 63 \\
\hline
\end{tabular}

6.9 As informações consultadas no Exemplo 11 são usadas pelo iClass para iniciar a aula entitulada "Everyday computing" para o curso "Ubiquitous Computing" que é ministrada às segundas-feiras pelo instrutor Ethan. . 64

6.10 Lista de aulas do curso "Ubiquitous Computing" criado na CoWeb consultando o Context Kernel. A lista contém a data, o título e o assunto das aulas capturadas. . . . . . . . . . . . . . . . . . 66

6.11 Elemento SCORM ${ }^{T M}$ General com informações obtidas do Context Kernel. O iClass invoca as operações GetAny e GetInverse para obter metadados sobre aulas e cursos, respectivamente. . . . . . . . . . . . . 67

6.12Elemento SCORM ${ }^{T M}$ Relation com informações obtidas do Context Kernel. Este elemento representa relações de referência entre os slides capturados durante uma aula e as páginas correspondentes na CoWeb para o curso "Ubiquitous Computing". . 


\section{Lista de Abreviaturas}

API: Application Programming Interface

B2B: Business-to-Business

CORBA: Common Object Request Broker Architecture

CPA: Collaboration Protocol Agreements

CPP: Collaboration Protocol Profile

CSCW: Computer Supported Cooperative Work

DCOM: Distributed Component Object Model

FTP: File Transfer Protocol

HTTP: Hypertext Transfer Protocol

IIOP: Internet Inter-ORB Protocol

JMS: Java Message Service

OASIS: Organization for the Advancement of Structured Information Standards

ORB: Object Request Broker

OWL: Web Ontology Language

P2P: Peer-to-Peer

PKI: Public Key Infrastructure

RDF: Resource Descriptor Framework

RMI: Java Remote Method Invocation

RPC: Remote Procedure Call

SAML: Security Assertion Markup Language

SCM: Service Control Manager

SCORM: Sharable Content Object Reference Model

SMTP: Simple Mail Transfer Protocol

SOAP: Simple Object Access Protocol

SQL: Structured Query Language

SSL: Secure Socket Layer

TLS: Transport Layer Security

UDDI Universal Description, Discovery, and Integration

URI: Universal Resource Identifier

XML: eXtensible Markup Language

XSLT: eXtensible Style Sheet Language 
W3C: World Wide Web Consortium

WS-BPEL: Web Services Business Process Execution Language

WS-I: Web Services Interoperability

WS-Security: Web Services Security

WSDL: Web Services Description Language

WSDM: Web Services Distributed Management 


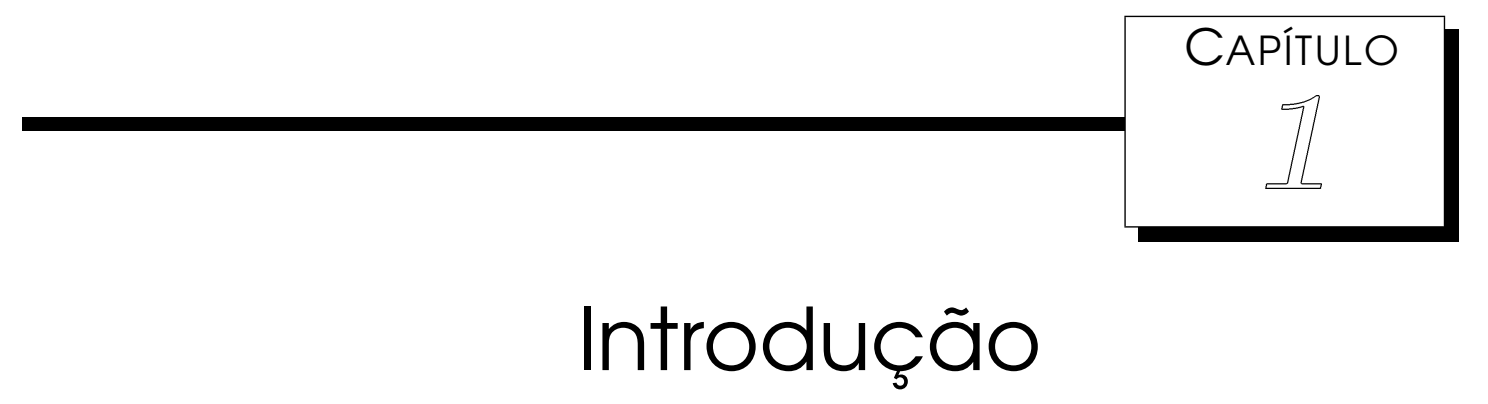

$\mathcal{A}$

té meados da década de 90 acreditava-se que com a evolução da computação pessoal, as funções dos dispositivos e aplicações estariam concentrados em um único equipamento e o ser-humano mudaria seus hábitos para utilizá-lo. No entanto, as pesquisas em computação guiaram a exploração da tecnologia do computador pessoal para dispositivos de uso cotidiano e abriram espaço para a criação de ambientes informatizados pouco intrusivos.

\subsection{Contextualização}

O visionário pesquisador Mark Weiser vislumbrou uma forma pouco intrusiva de utilizar dispositivos computacionais no cotidiano das pessoas. Segundo ele, facilidades computacionais devem ser incorporadas aos ambientes para auxiliar atividades humanas mudando minimamente a forma como as tarefas são originalmente realizadas |Weiser, 1991; 1993|. Weiser denominou computação ubíqua essa forma transparente de integrar tecnologias às atividades humanas diárias. Para a realização desse paradigma, Weiser previu o desenvolvimento de novos dispositivos computacionais que permitiriam a computação ser adaptada ao cotidiano do ser-humano e, conseqüentemente, o surgimento de novas aplicações computacionais para explorar o uso desses dispositivos. Os dispositivos computacionais foram classificados por Weiser em: pequenos e pessoais (inch-scale, Figura 1.1(a)), de médio porte (foot-scale, Figura 1.1(b)) e grandes e de uso coletivo (yard-scale, Figura 1.1(c)). As projeções de Weiser foram comprovadas, fazendo da computação ubíqua uma área de interesse da pesquisa em computação. Por exemplo, conferências como a International Conference 
on Ubiquitous Computing e a International Conference on Pervasive Computing, bem como o periódico IEEE Pervasive Computing, apresentam o estado da arte na área.



(a)

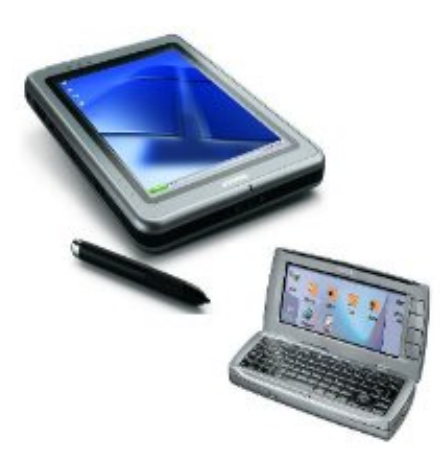

(b)

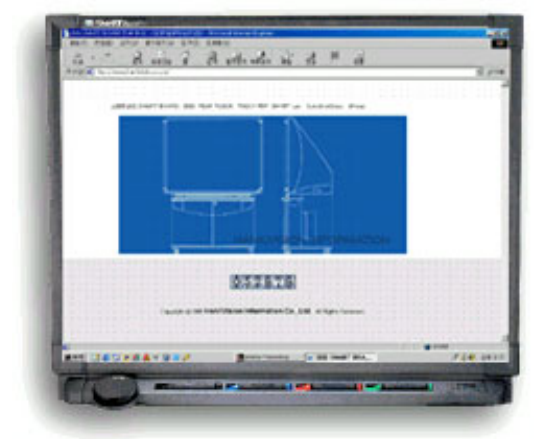

(c)

Figura 1.1: Exemplos de dispositivos computacionais ubíquos.

Abowd et al. 2002] destacam aplicações de captura e acesso de experiências ao vivo, interfaces naturais e computação ciente de contexto (do inglês context-aware) como principais temas de pesquisa em computação ubíqua em termos de aplicações.

Aplicações de captura e acesso visam registrar de modo automático uma experiência humana cotidiana utilizando ambientes instrumentados (por exemplo, salas com lousas eletrônicas, câmeras e microfones). O resultado da captura pode ser visto e entendido posteriormente por meio de documentos multimídia gerados automaticamente. Aplicações no domínio de reuniões |Pedersen et al., 1993; Chiu et al., 2001] e no domínio educacional Abowd, 1999; Müller and Ottmann, 2000; Cattelan et al., 2003c; Shi et al., 2003 tipicamente exploram interfaces naturais por meio de interação baseada em caneta e de captura de áudio e vídeo.

Interfaces naturais devem permitir ao ser-humano interagir com os dispositivos computacionais da mesma maneira como interagem com o mundo físico. Explorar a capacidade humana de se expressar por meio da fala, de gestos e da escrita objetiva um novo paradigma de interfaces menos intrusivo que substituirá o paradigma de interfaces gráficas tradicionais. Pesquisas nessa área têm proposto técnicas baseadas em voz [Witbrock and Hauptmann, 1998], em escrita Goularte et al., 2004; Schilit et al., 1998, manipulação de dispositivos eletrônicos [Ishii and Ullmer, 1997] e utilização de sensores em dispositivos computacionais para identificar a interação do ser-humano [Harrison et al., 1998.

Computação ciente de contexto habilita aplicações a adquirirem e utilizarem informação de contexto para fornecer serviços que sejam apropriados para uma situação particular. A relevância das informações de contexto dependem dos requisitos da aplicação no domínio que está sendo empregada. Aplicações cientes de contexto têm 
sido propostas para localização [Borriello et al., 2005], reuniões [Chen et al., 2004], hospitais [Bardram, 2004], residências [Kidd et al., 1999], ambientes com alta mobilidade de usuários [Amann and Guirchmayr, 2003; Dey et al., 1999b; 2001], escritórios [Want et al., 1992], guias turísticos [Burrell et al., 2002] e trabalho colaborativo apoiado por computador |Johanson et al., 2002; Fuchs, 1999], entre outras.

À medida que a computação não intrusiva passa a fazer parte do cotidiano das pessoas, surge um novo tema que se associa aos três anteriormente citados, a computação no cotidiano (do inglês everyday computing) Abowd et al., 2002; Abowd and Mynatt, 2000. Nesse tipo de interação, deve-se disponibilizar serviços vinte e quatro horas por dia, sete dias por semana, auxiliando computacionalmente atividades informais e não estruturadas comum no dia a dia dos indivíduos.

\subsection{Motivação}

Um dos desafios em computação ubíqua é desenvolver aplicações cientes do contexto que adaptam-se automaticamente a mudanças de contexto. Utilizar informações de contexto em aplicações, principalmente nas já existentes, é uma tarefa não trivial. Para amenizar essa tarefa, infra-estruturas para o gerenciamento de informação de contexto têm sido propostas. Desenvolvido pelo grupo de pesquisa no qual este trabalho está inserido, o Context Kernel é uma dessas infra-estruturas e destaca-se por adotar os Serviços Web como plataforma para invocação das operações fornecidas. Sua disponibilização motiva a análise da solução adotada por meio da experimentação em aplicações reais.

\subsection{Objetivos e resultados obtidos}

O trabalho de dissertação aqui reportado objetivou analisar o emprego da infraestrutura Context Kernel na integração de aplicações em cenários de trabalho colaborativo e de aprendizado eletrônico. As aplicações exploradas passaram a trabalhar em conjunto ao compartilhar informações de contexto. Após uma etapa de integração, foi realizada uma análise do uso dos Serviços Web como abordagem para combinar aplicações diversas e heterogêneas. Como resultado, foi elaborado um conjunto de lições aprendidas provenientes do estudo e do emprego das especificações para Serviços Web. Outros resultados foram a especificação de informações de contexto de grupo e de metadados educacionais em dimensões de contexto e os exemplos de utilização do Context Kernel para tornar aplicações cientes de contexto. As publicações obtidas no contexto deste trabalho foram:

- Jardim, C. H. O., Neto, R. F. B., Godoy, R. P., Ribas, H. M. B., Arruda Jr., C. R. E., Munson, E. V., and Pimentel, M. G. C. (2005). Web Services Enabling 
Ubiquitous Computing Applications: Lessons Learned by Integrating Ubiquitous e-Learning Applications. International Journal of Web Services Practices, 1(12):142-152. ISSN: 1738-6535.

- Jardim, C. H. O., Bulcão Neto, R. F., Ribas, H. M. B., Munson, E. V., and Pimentel, M. G. C. (2005). Web Services Enabling Context-aware Applications: Lessons Learned by Integrating e-Learning Applications. In International Conference on Next Generation Web Services Practices, pages 400-405, Seoul, Korea. IEEE Computer Society Press. ISBN: 0-7695-2452-4.

- Macedo, A. A., Bulcão Neto, R. F., Camacho-Guerrero, J. A., Jardim, C. H. O., Cattelan, R. G., Inácio Jr, V. R., and Pimentel, M. G. C. (2005). Linking everyday presentations through context information. In 3rd IW3C2 Latin American Web Conference, pages 130-139, Buenos Aires, Argentina. IEEE Computer Society Press.

- Bulcão Neto, R. F., Jardim, C. H. O., Camacho-Guerrero, J. A., and Pimentel, M. G. C. (2004). A Web Service Approach for Providing Context Information to CSCW Applications. In Proceedings of 2nd IW3C2 Latin American Web Congress, pages 78-85, Ribeirão Preto, Brasil. IEEE Computer Society Press.

- Bulcão Neto, R. F., Jardim, C. H. O., Camacho-Guerrero, J. A., Lobato, D. C., and Pimentel, M. G. C. (2004). A Context-based Web Service Approach to Communities of Practice. XXXI Seminário Integrado de Software e Hardware, SEMISH. 15 pages.

- Bulcão Neto, R. F., Jardim, C. H. O., Camacho-Guerrero, J. A., and Pimentel, M. G. C. (2004). Provision of context information to CSCW Applications: A Web Service Approach. Technical report 227, Instituto de Ciências Matemáticas e de Computação - USP. 26 pages.

\subsection{Estrutura do texto}

Neste capítulo foi apresentado o contexto no qual se insere o trabalho, a motivação para sua realização e os resultados obtidos. No Capítulo 2 são discutidos o tema computação ciente de contexto e os desafios nessa área; no Capítulo 3 são discutidos os Serviços Web e as tecnologias envolvidas; no Capítulo 4 é descrita a infra-estrutura Context Kernel e algumas de suas limitações; no Capítulo[5] são descritos os trabalhos relacionados ao Context Kernel; no Capítulo 6 é detalhado o trabalho realizado. No Capítulo 7] é apresentada a conclusão do trabalho com as contribuições, as publicações obtidas e os trabalhos futuros. Finalmente é apresentada a bibliografia utilizada e o glossário de termos. 


\section{- \\ Computação Ciente de Contexto}

eres humanos são muito eficientes em transferir e usar informações implicitamente durante um diálogo. No entanto, quando interagem com computadores, seres humanos não conseguem explorar tão bem as informações implícitas devido ao modesto mecanismo para fornecer entrada de informações ao computador [Dey, 2001]. A computação ciente de contexto visa melhorar o acesso de sistemas computacionais às informações de contexto incrementando a comunicação entre ser humano e sistemas computacionais, e assim permitir o desenvolvimento de serviços computacionais mais úteis e ubíquos [Dey, 2001].

\subsection{Definição de informação de contexto}

Uma definição clássica proposta por Dey [2001] é: “contexto" é qualquer informação que pode ser usada para caracterizar a situação de uma entidade. Uma entidade é uma pessoa, lugar, ou objeto que é considerado relevante para a interação entre o usuário e uma aplicação, incluindo os próprios usuários e aplicações. Por exemplo, em uma casa, informações como quem entra, quando entra, o que faz e para onde vai são informações de contexto que podem ser capturadas por fontes de contexto..$^{1}$

\subsection{Definição de ciência de contexto}

Um sistema é ciente de contexto se utilizar informações de contexto para fornecer informações e/ou serviços relevantes para o usuário, sendo a relevância dependente

\footnotetext{
${ }^{1}$ dispositivos capazes de capturar informações de contexto do ambiente.
} 
das tarefas do usuário [Dey, 2001]. Assim, espera-se que sistemas computacionais cientes de contexto não somente respondam quanto ao estado social e cognitivo do usuário, mas também antecipem suas necessidades [Siewiorek, 2002]. Por exemplo, em uma casa que possui dispositivos cientes de contexto, pode-se identificar que um determinado morador está procurando, na biblioteca, livros sobre determinado assunto e fazer sugestões de leitura. Ainda nesse cenário, a sala de leitura da casa pode adequar o ambiente (luz natural ou artificial, quantidade de luz, entre outros) para as preferências e ou necessidades de quem está lendo.

\subsection{Dimensões de informações de contexto}

A heterogeneidade das aplicações, e conseqüentemente das informações de contexto, dificulta a formalização de um único conjunto genérico e completo de informações de contexto para todas as aplicações. No entanto há um conjunto de seis dimensões básicas a partir das quais é possível contextualizar uma determinada atividade [Abowd and Mynatt, 2000; Truong et al., 2001]:

-Who (quem): É importante fornecer informações contextuais de todas as pessoas envolvidas em uma dada atividade assistida por computador;

- What (o que): Tem como função identificar o que o usuário está fazendo. Sistemas como os de captura e acesso são exemplos de sistemas que lidam com atividades variadas dos usuários nas quais é altamente desejável obter informações contextuais a respeito dessas atividades. Sendo assim, formas de explorar o contexto das atividades dos usuários são objetos de pesquisa em computação ubíqua;

- Where (onde): Informações de localização é o tipo de informação de contexto mais utilizado pelos sistemas sensíveis a contexto. Pesquisas apontam a utilização dessa informação contextual associada a outras como, por exemplo, quando, indicando que é relativamente fácil combinar os contextos temporais e espaciais para fornecer novas funções às aplicações;

- When (quando): O contexto temporal tem sido usado para indexar um registro capturado ou para informar por quanto tempo um usuário esteve em um determinado local. Por exemplo, determinar que um aluno entrou em um cinema em uma tarde de quarta-feira quando deveria estar na escola;

- Why (porquê): Mais difícil do que inferir o que o usuário está fazendo é entender o porquê da sua ação. Obter informações de contexto que explique o estado de uma pessoa talvez seja o mais complexo desafio da computação ciente de contexto; 
- How (como): Geralmente, associa-se à dimensão Why a dimensão How para inferir informações sobre Why. Para domínios mais específicos, como captura e acesso, essa dimensão especifica a forma segundo a qual são realizadas as atividades de captura e acesso.

\subsection{Desafios em computação ciente de contexto}

As pesquisas em computação ciente de contexto têm apontado problemas que devem ser abordados e para os quais deve-se propor soluções. Nesta seção estão descritos alguns desses problemas desafiadores.

\subsubsection{Intercâmbio de informaçōes de contexto}

Um requisito desejável em computação ciente de contexto é que a informação cotextual capturada em um ambiente esteja disponivel para aplicações em outros ambientes. Dey et al. [2001] argumentam que à medida que os ambientes tornam-se mais instrumentados, mais informações de contexto podem ser adquiridas e que podem vir de máquinas distribuídas conectadas via rede de computadores. As infra-estruturas para gerenciamento de contexto devem abstrair a localização e a recuperação de informação contextual, promovendo o intercâmbio de contexto entre aplicações não registradas na mesma instância da infra-estrutura.

Zimmer 2004 argumenta que se as informações de contexto estiverem exlusivamente codificadas dentro da lógica da aplicação elas não poderão ser reutilizadas por outras aplicações em geral. Isso conflita com a idéia da computação ubíqua, na medida em que os ambientes ubíquos dependem de informações de contexto compartilhadas entre aplicações que não necessariamente se conhecem a priori. Um sistema comum de representação e comunicação de contextos em ambientes de computação ubíqua seria mais interessante do que formas customizadas para fazer uso do contexto Zimmer, 2004.

\subsubsection{Representação da informação contextual}

Em computação ciente de contexto, diversos dispositivos computacionais, e conseqüentemente diversas aplicações, podem utilizar informação contextual em sua lógica computacional. A forma como elas representam a informação contextual varia, por exemplo, de linguagens de marcação a modelos baseados em lógica ou orientados a objetos. Formas de representação diferentes e/ou próprias dificultam, ou até mesmo inviabilizam, a troca de informações entre aplicações ou a notificação de uma aplicação sobre uma modificação em uma informação de contexto que foi capturada por outra aplicação. Assim, infra-estruturas de software que apoiam o desenvolvi- 
mento de aplicações cientes de contexto necessitam de modelos uniformes e extensíveis para representação de informação contextual [Bulcão Neto, 2003; Wang et al., 2004; Chen et al., 2004].

A representação da informação contextual na forma de regras tem sido amplamente empregada pelas infra-estruturas e aplicações cientes de contexto. As regras devem informar como os sistemas devem se comportar de acordo com os serviços disponíveis e com o contexto atual [Forstadius et al., 2005]. Os autores alertam para os desafios em representar a descrição de serviços, a informação contextual e as preferências dos usuários, e como descrever as regras para as quais essas informações podem ser utilizadas. Os autores ainda questionam, quem cria as regras e propõem três soluções: pré-construídas pelos provedores de serviço, criadas pelos usuários ou automaticamente coletadas de acordo com o comportamento e rotina dos usuários, o que seria uma abordagem mais sofisticada.

\subsubsection{Histórico de contexto}

O armazenamento da informação contextual para posterior uso tem sido proposto na literatura como forma de manter um histórico das informações de contexto [Dey et al., 2001; Davis II et al., 2003a. O histórico do contexto pode ser útil em predizer valores futuros de contexto e contribuir na inferência sobre um evento. Por exemplo, a análise do histórico de atividades cotidianas de uma pessoa no seu local de trabalho pode ser útil para prever quais as próximas tarefas. Esta mesma análise pode também permitir inferir que um dia de trabalho atípico está ocorrendo. A arquitetura de infra-estruturas de suporte à computação ciente de contexto devem suportar o armazenamento bem como a recuperação desse histórico de informações.

Ebling et al. 2001 observam que o seres humanos possuem hábitos que podem ser utilizados tanto para inferências no presente e futuro, quanto na ausência de informações atuais. Armazenar o histórico de contexto pode gerar uma quantidade muito grande de informações o que dificulta o acesso por dispositivos móveis |Spence et al. 2005]. Trabalhar com um subconjunto do histórico é uma abordagem, mas pode ser difícil definir esse subconjunto [Spence et al., 2005].

\subsubsection{Privacidade e segurança}

Um problema que aparece naturalmente no uso das informações de contexto está relacionado à privacidade do objeto cujo contexto está sendo representado e utilizado. Freqüentemente, usuários não querem que determinadas informações estejam disponíveis para todas as aplicações ou, ainda, há a necessidade de diferentes níveis de privacidade para as informações dependendo de quem pode acessá-las. Por exemplo, no cenário de uma casa, as ações que lá ocorrem são de interesse da casa, mas al- 
gumas também podem ser de interesse externo. Definir níveis de privacidade para as informações de contexto e assegurar que nenhuma informação sigilosa será compartilha é uma questão difícil de ser resolvida. Deve-se ainda considerar que aplicações cientes de contexto precisam assumir que as informações estarão disponiveis a qualquer hora e qualquer lugar, não importando onde o objeto esteja no momento. Assim, as informações sobre o objeto precisam estar disponíveis para serem acessadas de qualquer lugar, o que alerta para o problema de garantir a segurança dessas informações de modo a impedir que essas sejam utilizadas por sistemas não autorizados. Alguns sistemas para suporte ao desenvolvimento de aplicações cientes de contexto contêm mecanismos para garantir a privacidade da informação contextual |Lei et al., 2002; Davis II et al., 2003a.

Segundo Lahlou et al. [2005], à medida que os objetos e ambientes inteligentes tornam-se menos intrusivos, uma quantidade maior de informações está sendo coletada, podendo compreender desde preferências passadas, atividades atuais e planos futuros. Os autores lembram que não somente informações do que fazemos, onde e como fazemos, mas também como nos sentimos ao fazer algo - monitorando batimentos cardíacos, respiração, padrão de caminhada - estarão disponíveis e serão utilizadas pelos sistemas. Dessa forma, privacidade e segurança do ser humano parecem ser conflitantes se não consideradas no projeto de sistemas cientes de contexto.

\subsubsection{Descoberta de recursos}

A computação integrada ao cotidiano do ser-humano deve atender ao cenário de mobilidade de usuários e de aplicações, permitindo a aquisição e o compartilhamento de informações de contexto em ambientes ubíquos. Esse cenário deve utilizar e fornecer serviços móveis [Doulkeridis et al. 2005] de modo que as aplicações devem conhecer o tipo de informação fornecida pelos serviços, onde ela está localizada e como recuperá-la (protocolo e linguagem, por exemplo) |Dey et al., 2001|. Em computação ciente de contexto, o serviço responsável por encontrar os serviços distribuídos é denominado serviço de descoberta (discovery service).

Serviços de descoberta devem ser capazes de descobrir recursos (serviços e fontes de informações) relevantes para o contexto das aplicações. Exemplos de uso seriam: (a) quando um serviço que fornece determinada informação não está disponível, encontrar automaticamente outros serviços e fornecer mecanismos de acesso a eles; (b) se um determinado serviço não é capaz de responder por completo uma requisição, pode-se procurar por outros serviços e até mesmo utilizar de composição dos serviços de modo a elaborar uma resposta adequada. Um cenário interessante é o de um pronto-socorro de um hospital, no qual a demanda e a urgência na transfusão de sangue são altas. No caso de falta de um tipo de sangue, pode-se localizar o banco de sangue mais próximo com a quantidade necessária para atender uma emergência. 
Automatizar a descoberta, a invocação e a composição de serviços é um requisito de cenários com mobilidade de usuários e aplicações, nos quais os serviços distribuídos, trabalhando em conjunto ou suprindo carências mais específicas por informações, devem melhorar a qualidade dos serviços prestados.

Com o crescente número de serviços sendo disponibilizados, um problema para os serviços de descoberta é o de localizar o recurso mais apropriado para uma tarefa específica |Forstadius et al., 2005; Czerwinski et al., 1999]. Além disso, surge também questões relativas a segurança, pois geralmente é necessário utilizar serviços confiáveis e estes precisam saber se podem confiar nos clientes [Friday et al., 2001]. Há ainda que se considerar questões como: interoperalidade entre as diversas e heterogêneas tecnologias para descoberta de recursos; escalabilidade devido o crescente número de clientes e provedores de serviços; questões temporais, tais como recursos já utilizados; e quais são os metadados utilizados na descoberta [Friday et al., 2001].

\subsubsection{Interpretação de informações de contexto}

Interpretar as informações de contexto de uma forma inteligente é um dos desafios em computação ciente de contexto, sendo geralmente referenciado como raciocínio de contexto. Este raciocínio pode ser obtido combinando contexto de baixo nive ${ }^{2}$ para conseguir contexto de alto nível, em um processo denomidado inferência de contexto. Essa não é uma tarefa simples, pois envolve questões como: obter, representar e préprocessar contexto de baixo nível; combinar contexto obtidos de sensores; utilizar máquinas de inferência adequadas e eficientes.

As máquinas de aprendizado podem utilizar contexto de baixo nível e o histórico de contexto para o raciocínio de contexto de alto nível. Porém, Nurmi and Floréen [2004] discutem que o projeto e a implementação de sistemas baseados em máquinas de aprendizado não são tarefas triviais. Há um bom número de máquinas de inferência disponíveis e as classes de algoritmos são apropriadas para um tipo de problema em particular. Além disso, o processo de implementação requer modelos de representação eficientes que podem ser eficientemente aplicados quando processando novos dados.

Przybilski and Nurmi [2005] questionam que, embora as máquinas de inferência possam ser avaliadas com dados simulados, não há garantias de que elas são eficientes com dados reais. Segundos ao autores, combinar diversas e diferentes fontes de contexto e raciocinar sobre os seus relacionamentos pode auxiliar na inferência de contexto. Por outro lado, quantidades pequenas de dados podem ser utilizadas como histórico de contexto derivados em padrões para predizer irregularidades, tais como uso anormal de cartões de créditos |Davis II et al., 2003a|.

\footnotetext{
${ }^{2}$ Contexto de baixo nível são os dados obtidos diretamente do ambiente por fontes de contexto, tais como sensores.
} 


\subsection{Considerações finais}

A computação ciente de contexto é um tema de pesquisa essencial para que a computação suporte vários níveis de ubiqüidade, permitindo que aplicações sejam integradas aos ambientes de maneira transparente, ou seja, integradas de modo a não despender a atenção das pessoas. A computação ciente de contexto é um tema desafiador e importante para o desenvolvimento da computação ubíqua, porque disponibiliza às aplicações informações que estão implícitas na interação dos seres humanos com os dispositivos computacionais utilizados. No entanto, para atingir esse objetivo, vários problemas relativos ao conjunto de informações de contexto, ao intercâmbio, à representação, ao histórico de contexto, privacidade e segurança, descoberta de recursos e interpretação de informações de contexto precisam ser solucionados.

Uma importante questão a ser considerada na pesquisa em computação ciente de contexto é que ela herda os problemas da computação ubíqua em geral. Esta, por sua vez, herda os desafios que abrangem outras áreas da computação, tais como hipermídia, sistemas distribuídos, banco de dados, engenharia de software e interface humano-computador. Os desafios ainda extrapolam a computação e dependem de considerar o estado social e cognitivo do ser-humano, envolvendo ciências como a a pisicologia e sociologia e, ainda, desafios relativos a apoiar pessoas com necessidades especiais. Dessa forma, trata-se de uma área de pesquisa multidisciplinar e com muito trabalho a ser realizado ainda. 


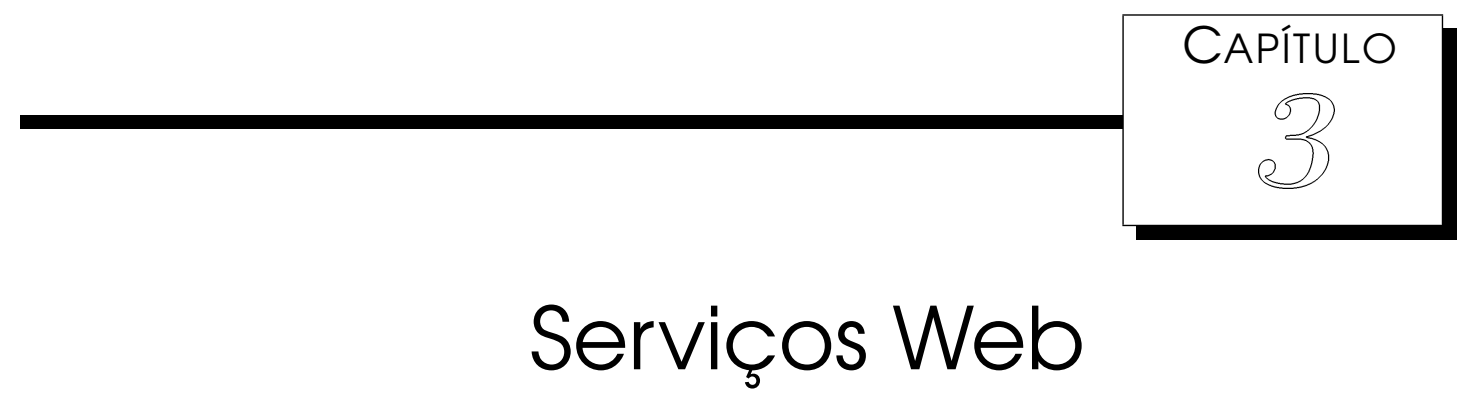

O uso de Serviços Web [W3C, 2002] na World Wide Web está se expandindo rapidamente devido a necessidade crescente de comunicação e interoperabilidade entre aplicações. Em um estudd 11 publicado em 2005, o IDC 2 estima que foram investidos em Serviços Web 2,3 bilhões de dólares em 2004 e em 2009 estima-se que o investimento será de aproximadamente 14,9 bilhões de dólares. Serviços Web disponibilizam um meio de comunicação padronizado entre diferentes aplicações, promovendo interoperabilidade entre elas, e permitindo que sejam combinadas para executar operações mais complexas [Burner, 2003]. O World Wide Web Consortium 3 (W3C) define Serviços Web como sistemas de software identificados por uma URI e especificados por um documento de descrição baseado na linguagem XML |W3C, 2003a]. A partir dessa descrição, outros sistemas podem identificar o sistema especificado e interagir com o mesmo. A comunicação é feita por meio de mensagens XML e conduzidas por protocolos Internet |W3C, 2002|.

Assim, Serviços Web [Stal, 2002] utilizam a infra-estrutura da Internet para uma comunicação transparente entre aplicações e independem de diferenças de tecnologia de rede, dispositivos, sistemas operacionais e linguagens de programação. Esses serviços são baseados no protocolo $\mathrm{HTTP}^{5}$ e em especificações baseadas em XML como o SOAP [W3C, 2003b] (Simple Object Access Protocol) e a WSDL [W3C, 2006] (Web Service Description Language) - linguagem de descrição de Serviços Web.

\footnotetext{
${ }^{1}$ http://www.idc.com/getdoc.jsp?containerId=prUS00190705

${ }^{2}$ Empresa de consultoria em tecnologia da informação (http://www.idc.com).

${ }^{3}$ http://www.w3c.org

${ }^{4}$ http://www.w3.org/Addressing/

${ }^{5}$ http://www.w3.org/Protocols/
} 


\subsection{Arquitetura Orientada a Serviços}

A Arquitetura Orientada a Serviços (Service Oriented Architecture - SOA) é uma abordagem baseada em serviços disponibilizados na rede, por exemplo na Web. Nessa arquitetura, aplicações são desenvolvidas para utilizar serviços, aplicações são disponibilizadas como serviços para serem utilizadas por outras aplicação, ou ambos. Essa estratégia permite conectar aplicações, expostas como serviços, e compartilhar suas funções de forma flexível. Os serviços podem ser localizados em registros e sua descrição, é utilizada por aplicações para invocá-los, como ilustrado na Figura 3.1.

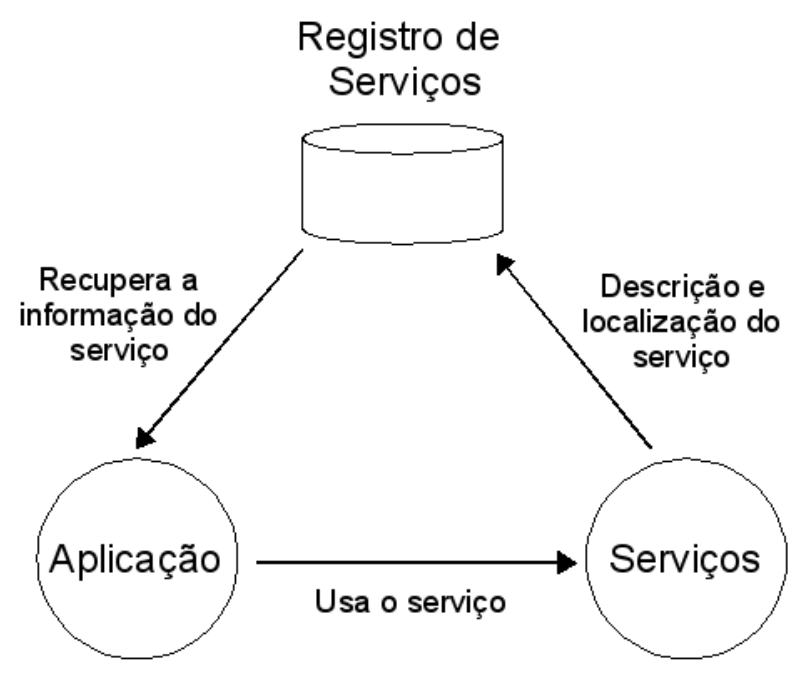

Figura 3.1: Interação entre serviços, aplicação e serviço de registro em arquitetura orientada a serviços. Adaptado de Bond et al. [2004].

A abordagem SOA é caracterizada como de acoplamento fraco, pois clientes são independentes dos serviços utilizados. O cliente não conhece a plataforma de desenvolvimento e nem a linguagem usada para codificar o serviço. Mudanças na implementação do serviço não podem afetar o cliente, pois este se comunica com o primeiro de acordo com uma interface bem definida. A interface deve continuar a mesma embora a implementação das regras de negócio possa mudar.

O fraco acoplamento, por sua vez, permite que serviços sejam orientados a documentos. Assim, os serviços aceitam um documento como entrada e os clientes não se preocupam com a forma como as funções de negócio do serviço processarão o documento. O serviço determina que funções serão utilizadas com base no conteúdo do documento.

A tecnologia Jini [Sun Microsystems, 2006], é um exemplo de implementação de uma Arquitetura Orientada a Serviços. Jini fornece uma plataforma que, entre outras funções, permite encontrar um serviço por meio de um serviço de localização, o que 
possibilita ao serviço e ao cliente serem transparentes quanto à localização.

Um outro exemplo de SOA e dos benefícios do fraco acoplamento são os Serviços Web, que fornecem os beneficios de fraco acoplamento e mecanismos para localizar, conectar e invocar dinamicamente serviços.

\subsection{Benefícios dos Serviços Web}

A abordagem SOA e, mais especificamente, a abordagem baseada em Serviços Web oferecem vários benefícios. Segundo Orti [2005], entre os benefícios estão: reuso, interoperabilidade, escalabilidade, flexibilidade e eficiência de custo.

O reuso de funções que já existem, ao invés de desenvolver código que reproduz essas funções, tende a diminuir o custo e o tempo de desenvolvimento de aplicações. O benefício do reuso aumenta à medida que mais serviços são construídos e incorporados em aplicações diferentes. Entretanto, o reuso é prejudicado ou mesmo inviabilizado quando soluções são codificadas em diferentes linguagens, executam em sistemas operacionais diferentes e utilizam protocolos e interfaces de programação diferentes. Entender como e onde os sistemas e as aplicações executam para se comunicar com elas envolve esforço que pode consumir muito tempo. Em Arquitetura Orientada a Serviços somente a interface pública dos serviços deve ser conhecida. Isso facilita o acesso e simplifica a integração de aplicações e sistemas, mesmo os legados.

A interação entre clientes e serviços com fraco acoplamento promove a interoperabilidade, isto é, clientes e serviços se comunicam não importando em que plataforma eles estão executando. Com Serviços Web, esse objetivo é conseguido devido ao conjunto de protocolos e tecnologias amplamente aceitos e usados, e ao meio de comunicação padronizado e consistente através de plataformas, sistemas e linguagens independentes. Uma organização que objetiva promover a interoperabilidade de Serviços Web (Web Services Interoperability Organization ${ }^{6}$ ) definiu um perfil básico, nomeado WS-I |Web Service Interoperability Organization, 2004|, que identifica um núcleo principal de tecnologias que, quando implementadas em diferentes plataformas e sistemas, ajudam a garantir que serviços possam se comunicar.

O fraco acoplamento dos serviços em SOA facilita a escalabilidade das aplicações. Como há pouca dependência entre a aplicação e o serviço requisitado, a escalabilidade da aplicação depende menos do serviço do que em sistemas fortemente acoplados. Os Serviços Web tendem a ser de granulosidade alta, orientados a documento e assíncronos [Orti, 2005]. Serviços com granulosidade alta oferecem um conjunto de funções ao invés de uma única função, como fazem os de granulosidade baixa. Um serviço orientado a documento aceita um documento como entrada, ao invés de algo mais

\footnotetext{
${ }^{6}$ http://www.ws-i.org/
} 
específico, como objetos de uma linguagem de programação orientada a objetos. Um serviço assíncrono realiza o seu processamento sem obrigar o cliente a esperar o processamento terminar, enquanto o serviços síncronos forçam a espera. A interação mais limitada necessária para clientes que se comunicam com serviços de granulosidade alta, assíncronos e orientados a documento permite às aplicações que usam esses serviços escalarem sem sobrecarregar a comunicação na rede.

A flexibilidade em serviços com acoplamento fraco é maior do que naqueles com acoplamento forte. Em arquiteturas com acoplamento forte, os diferentes componentes de uma aplicação são fortemente ligados ao outro e compartilham semântica, biblioteca e, às vezes, estado. As características de fraco acoplamento, comunicação baseada em documento e comunicação assíncrona de SOA flexibilizam o suporte a modificações nos requisitos.

Soluções customizadas são custosas para desenvolver, porque requerem mais esforço, análise extensiva e tempo de desenvolvimento maior. Elas são custosas também para manter e estender, pois são tipicamente fortemente acopladas, de forma que mudanças em um componente de soluções integradas requerem mudanças em outros componentes. Os Serviços Web por sua vez, não requerem codificação única da solução customizada e são de fraco acoplamento, sendo então, menos custosos de se manter e mais fáceis de estender que soluções customizadas. Além disso, SOA é empregada no reuso de funções de negócio expostas como serviços de granulosidade alta.

\subsection{Arquitetura dos Serviços Web}

Ao se construir um Serviço Web, informações sobre sua interface e localização podem ser armazenadas em um registro. Os consumidores do serviço devem recuperar essas informações e utilizá-las para invocar o Serviço Web. As informações da interface e do contrato de serviço são necessárias para os desenvolvedores codificarem o uso do Serviço Web em suas aplicações. Em tempo de execução, a aplicação pode localizar o Serviço Web em registros de serviços ou, simplesmente, o documento de descrição pode ser fornecido para potenciais clientes manualmente. No servidor, um adaptador e um roteador são necessários para aceitar as mensagens SOAP e entregálas ao serviço apropriado. Estes fazem o papel [Bond et al., 2004] do intermediador de requisição de objeto (Object Request Broker — ORB) no CORBA |Object Management Group, 2004] e RMI [Sun Microsystems, 2003] e do gerente de controle do serviço (Service Control Manager - SCM) no DCOM |Microsoft, 1999].

A forma como as aplicações interagem com os Serviços Web depende dos próprios serviços. Os serviços podem utilizar uma interface no estilo de chamada a procedimento remoto (Remote Procedure Call - RPC) baseada em operações de requisição e 
resposta, as quais são encapsuladas em mensagens SOAP (ver Sub-seção 3.4.3). Os serviços podem também utilizar o estilo orientado a mensagem por meio da troca de documentos baseados em XML (ver Sub-seção 3.4.4). Em ambos os casos, a interação pode ser síncrona ou assíncrona, o que permite quatro combinações: RPC síncrono, RPC assíncrono, orientado a mensagem síncrono e orientado a mensagem assíncrono.

A Figura 3.2 ilustra a arquitetura dos Serviços Web e algumas das tecnologias envolvidas. Na camada mais abaixo estão os protocolos de comunicação de aplicação que podem ser utilizados, como o HTTP, SMTP ${ }^{7}$, FTP 8 , JMS 9 , IIOP 10 , embora o primeiro seja o mais empregado. As camadas superiores utilizam como base as tecnologias XML, DTD ${ }^{11}$ e XML Schema |W3C, 2004f] (Schema na figura). Essas são as tecnologias utilizadas pelo protocolo de troca de mensagens SOAP - e suas extensões - e pela linguagem de descrição dos Serviços Web. Na camada mais acima e com nível de abstração e semântica maior, estão as especificações de processos, por exemplo, para a descoberta e para a composição de serviços. As duas camadas laterais envolvem segurança e administração dos serviços, cujas soluções podem sem adotadas ao longo das demais camadas

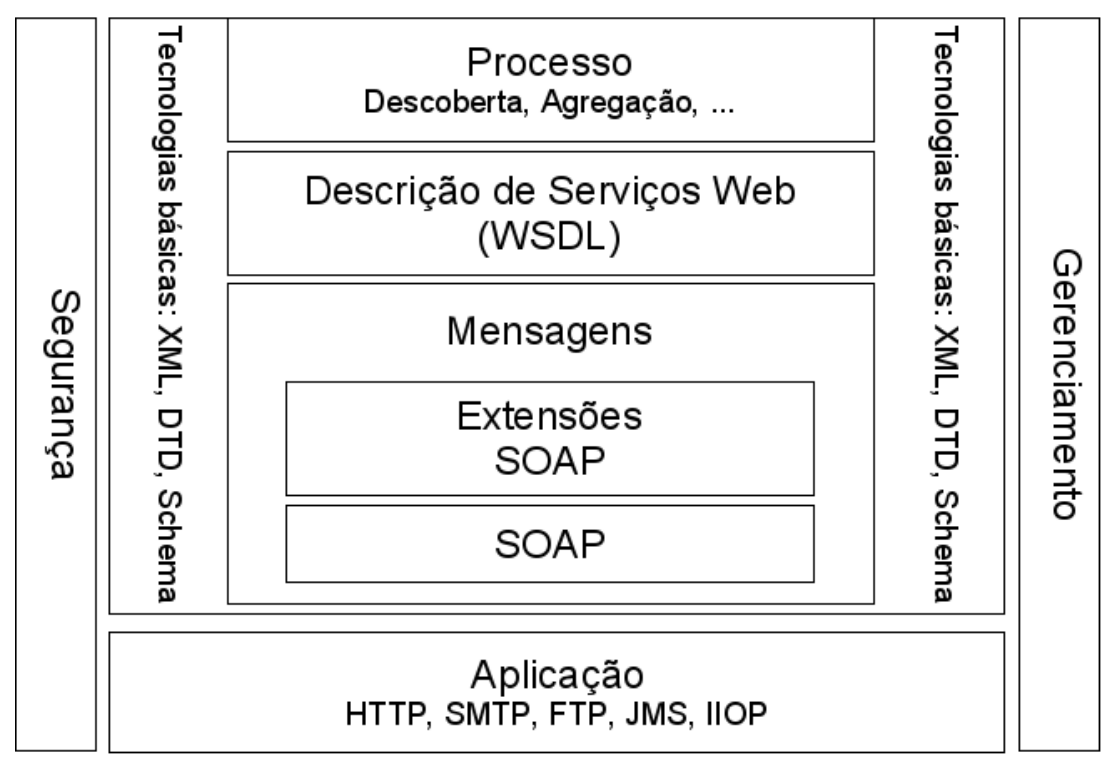

Figura 3.2: Arquitetura dos Serviços Web e tecnologias relacionadas. Adaptado de W3C 2004e.

\footnotetext{
${ }^{7}$ http://www.ietf.org/rfc/rfc0821.txt

${ }^{8}$ http://www.ietf.org/rfc/rfc0959.txt

${ }^{9}$ http://java.sun.com/products/jms/

${ }^{10}$ http://www.omg.org/technology/documents/formal/corba_iiop.htm

${ }^{11}$ http://www.w3.org/TR/REC-xml/
} 


\subsection{Protocolos e tecnologias dos Serviços Web}

Nesta seção estão descritas algumas das tecnologias principais no emprego de Serviços Web. Há inúmeras outras tecnologias especificadas e outras ainda em desenvolvimento ainda. Para uma referência mais completa, pode se consultar o documento W3C 2004a.

\subsubsection{Protocolo de empacotamento SOAP}

Para o intercâmbio de dados através da Web, não é suficiente entender o significado e a estrutura das marcações XML: é necessário um protocolo para formatar o documento XML de modo que o receptor possa entender o que ele significa - que parte é o corpo da mensagem, que parte contém instruções adicionais, entre outros. Para os Serviços Web, o protocolo especificado é o SOAP.

O protocolo SOAP define uma sintaxe baseada em XML, a semântica e a ordem das mensagens trocadas entre as aplicações e os serviços, além de usar geralmente o protocolo básico de troca de informações na Web, o HTTP, como protocolo de comunicação de aplicação. A sua unidade básica de transmissão é a mensagem SOAP, que consiste dos elementos obrigatórios envelope e body, e dos opcionais header e fault. $\mathrm{O}$ envelope especifica um namespace ${ }^{12}$ XML e o estilo de codificação. O namespace XML especifica os nomes que podem ser usados em uma mensagem SOAP para evitar ambigüidade, de modo que um mesmo nome possa ser utilizado em diferentes elementos com diferentes namespaces. O estilo identifica os tipos de dados reconhecidos pela mensagem SOAP.

O elemento header contém informações que estendem a mensagem. Na transmissão da mensagem SOAP do cliente para um serviço, ela pode passar por um conjunto de nós intermediários ao longo do caminho. Um nó intermediário pode fornecer serviços adicionais, como por exemplo, transformar os dados ou realizar operações relacionadas a segurança. O elemento header pode ser utilizado para indicar processamento adicional para nós intermediários, diferente do processamento feito no destino. O elemento body contém a parte principal da mensagem, que é a parte direcionada para o receptor final da mensagem SOAP. O elemento fault é opcional e fornece informações sobre os erros ocorridos durante o processamento da mensagem.

Há um padrão relacionado ao SOAP para transmissão de mensagens com anexos (SOAP Messages With Attachments [W3C, 2000]) - por exemplo, para transmissão de imagens. De qualquer forma, as mensagens SOAP - com ou sem anexos - não dependem de qualquer sistema operacional ou plataforma e podem ser transportadas usando vários protocolos.

\footnotetext{
${ }^{12} \mathrm{O}$ W3C |W3C, 2004b] define namespace como um documento unicamente identificado na Web e que é utilizado para estabelecer a estrutura lógica de outro documento.
} 
O protocolo SOAP define um perfil para troca de mensagens no qual aplicações podem criar interações mais elaboradas por meio da combinação de requisição e resposta simples ou requisições e respostas múltiplas. SOAP apresenta duas características principais:

- interoperabilidade: ao não restringir a forma de implementação dos serviços;

- simplicidade: ao estabelecer a linguagem XML para formatar suas mensagens.

\subsubsection{Linguagem de descrição WSDL}

A linguagem de descrição WSDL (Web Services Description Language) viabiliza a descrição completa dos serviços oferecidos por um Serviço Web [W3C, 2006]. A linguagem WSDL permite que um Serviço Web publique a interface de suas funções, ou seja, o formato das mensagens de requisição e das mensagens de resposta.

Para a descrição de um Serviço Web, WSDL define uma estrutura baseada em XML e composta de elementos e atributos. O elemento definitions é o elemento principal da estrutura e pode conter os elementos type, message, portType, binding e service. $\mathrm{O}$ elemento definition possui uma série de namespaces como atributos. $\mathrm{O}$ atributo targetNamespace é obrigatório e contém a definição dos elementos e dos atributos principais da descrição.

Uma interface é uma definição abstrata dos serviços que pode ser reutilizada por múltiplas definições de implementação. A interface compreende os elementos type, message, portType e binding. O elemento type é opcional e utilizado para a formatação das mensagens. Esse elemento define os tipos dos dados, uma vez que a WSDL não implementa seus próprios tipos. Um ou mais elementos message definem a modelagem das mensagens que serão trocadas entre sistemas de software, contendo as informações de entrada e saída para uma determinada operação.

O elemento portType é o elemento mais importante do documento WSDL, pois descreve um Serviço Web, suas operações e as mensagens envolvidas na sua utilização. Cada portType pode apresentar um conjunto de elementos operation, que especificam se as mensagens definidas previamente são mensagens de requisições ou mensagens de resposta. Cada elemento operation possui ao menos um elemento input ou um elemento output, ou ambos, que definem, respectivamente, a mensagem de entrada e a de saída de cada operação. Uma combinação desses elementos é possível das seguintes formas:

- input-output: são necessárias mensagens de entrada e de saída, nessa ordem. Quando a mensagem de entrada é recebida, a mensagem de saída é gerada;

- input-only: apenas a mensagem de entrada é necessária e não é produzida nenhuma mensagem de saída; 
- output-only: apenas a mensagem de saída é necessária. O serviço envia a mensagem, mas não espera nada como resposta;

- output-input: são necessárias as mensagens de saída e entrada, nessa ordem. O serviço envia a mensagem de saída e espera uma mensagem de resposta.

Nos elementos binding são representados os mapeamentos entre um elemento portType e um protocolo de comunicação. Esses elementos descrevem o formato das mensagens de requisição e de resposta e indicam um único protocolo de transporte a ser utilizado. Cada elemento binding fornece a ligação entre o modelo lógico e o modelo físico da descrição ao relacionar as operações definidas pelo elemento abstrato portType com a descrição física de como elas são transmitidas ao serviço. Para esse fim, deve-se definir o protocolo de transporte e o protocolo de comunicação a serem utilizados.

O protocolo SOAP utiliza extensões de sua definição para descrever como as mensagens serão enviadas. A extensão do protocolo SOAP utilizada no elemento binding possui dois atributos: style e transport. O primeiro é opcional e descreve a natureza das operações dentro do elemento binding. O segundo atributo define o protocolo de transporte utilizado pelo serviço nessa operação.

Os elementos service agrupam um ou mais elementos de definição de endereço que determinam o endereço específico de cada uma das operações do Serviço Web. Cada elemento service possui pelo menos um elemento port, que é o responsável por definir as particularidades de um endereço no qual um dado serviço é disponibilizado.

\subsubsection{Serviços Web orientados a chamada de procedimento remoto}

O uso de chamada a procedimento remoto (RPC) sobre protocolos Web não difere muito de outros protocolos como o IIOP, DCOM ou RMI. As chamadas são normalmente síncronas, zero ou mais parâmetros são passados na chamada, e zero ou mais valores de retorno são gerados. A chamada ao método remoto é entregue para algum distribuidor no servidor que determina qual método deve ser invocado e cuida do fluxo da passagem de parâmetros e dos valores de retorno. Mesmo esse estilo de operação faz uso do SOAP, sendo a diferença com outros mecanismo de RPC em utilizar protocolos padronizados, de propósito geral, como o HTTP e descrição textual do método em XML. No estilo RPC, a estrutura do corpo da mensagem deve conter o nome do método e um conjunto de parâmetros, semelhante ao exemplo a seguir:

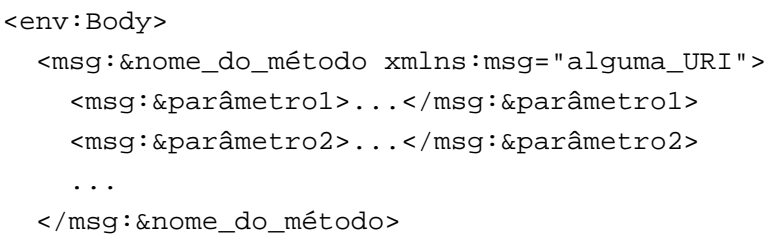


$</ e n v:$ Body $>$

A mensagem SOAP é entregue a um roteador, como ilustrado na Figura 3.3, que examina o cabeçalho da mensagem e decide como passar adiante o corpo da mensagem. O roteador é o responsável pela conversão dos parâmetros baseados em XML na representação especifica da plataforma que foi implementada o serviço e as primitivas que podem ser passadas como parte da invocação do serviço.



Figura 3.3: Diagrama de operação de um roteador SOAP. Adaptado de Bond et al. |2004|.

Segundo Bond et al. |2004], o uso de HTTP e XML fornece um protocolo comum que não é restrito a uma empresa, enquanto protocolos de objetos distribuídos (CORBA, RMI e DCOM) têm suas correntes e seguidores. Além disso, esses protocolos RPC tradicionais têm grandes dificuldades com bloqueio por firewalls, enquanto esse problema é menor com HTTP. No entanto, utilizar Serviços Web não implica em substituir ou não usar RMI, CORBA ou DCOM, que podem ser utilizados para distribuir funções nas diversas camadas de um sistema - os Serviços Web são empregados normalmente somente nos limites do sistema e não no seu interior.

\subsubsection{Serviços Web orientados a documento}

Serviços Web orientados a documento utilizam uma única operação com um único parâmetro, que é um documento XML a ser processado o qual pode ser estruturado tanto quanto necessário. O exemplo a seguir, ilustra um operação para inserir usuários e indica o documento XML Schema que descreve o documento de cadastro:

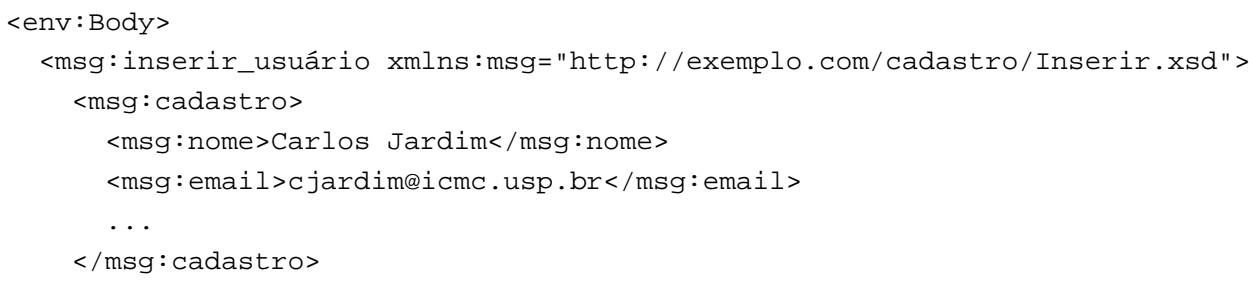


$</$ msg:inserir_usuário>

$</ e n v$ :Body $>$

A mensagem de resposta contém uma estrutura similar com o valor de retorno e parâmetros de saída. Em geral, pode-se representar as informações a serem passadas ao serviço em ambos os estilos. A grande diferença entre o estilo RPC e o orientado a documento está na codificação da mensagem. O estilo documento utiliza codificação literal, enquanto o estilo RPC utiliza codificação SOAP. Codificação literal define que o corpo da mensagem deve respeitar um XML Schema específico. A codificação SOAP utiliza os tipos de dados do XML Schema, mas a mensagem não respeita um XML Schema em particular. Respeitar um XML Schema permite que a mensagem seja validada e mesmo até transformada usando XSLT [W3C, 2005b].

\subsubsection{Segurança, coordenação e administração de Serviços Web}

Como discutido anteriormente, os padrões XML, SOAP, UDDI |OASIS, 2004a e WSDL fornecem uma base para interoperabilidade de serviços. Porém, outros padrões ainda são necessários para que Serviços Web sejam amplamente empregados. Mecanismos de segurança, de coordenação e de administração são necessários para evitar soluções ad-hoc, que prejudiquem a interoperabilidade |W3C, 2004e]. Ainda não há especificações para segurança, coordenação ou administração de Serviços Web amplamente empregadas, mas padrões como o WS-Security [OASIS, 2004b], o SAML OASIS, 2005a], o WS-BPEL [OASIS, 2005b] e o WSDM [OASIS, 2005c] estão em desenvolvimento e são discutidos a seguir.

O padrão WS-Security (Web Services Security) foi proposto pelo consórcio OASIS13 em Março de 2004. Ele descreve melhorias de segurança em mensagens SOAP para garantia de integridade e de confidência para mensagem. Integridade significa que a mensagem não é violada durante o seu trafego até o destino final. Confidência significa que a mensagem é vista somente por receptores pretendidos. O WS-Security utiliza tokens de segurança para garantia de segurança e integridade. Um token de segurança é uma coleção de reivindicações feitas pelo remetente da mensagem SOAP (como a identidade do remetente). O remetente é autenticado combinando um token de segurança com uma assinatura digital - a assinatura é usada como prova de que o remetente está associado ao token de segurança. O padrão também fornece um mecanismo de propósito geral para associar tokens de segurança com mensagens, e descreve como codificar tokens binários. O padrão WS-Security é flexível e pode ser usado com uma grande variedade de modelos de segurança e tecnologias de encriptação, como infra-estruturas de chave pública (Public-key infrastructure - PKI),

\footnotetext{
${ }^{13}$ http://www.oasis-open.org
} 
Kerberos ${ }^{14}$, protocolos SSL ${ }^{15}$ (Secure Socket Layer) e TLS ${ }^{16}$ (Transport Layer Security), que fornecem comunicação segura na Internet.

Outras tecnologias na área de segurança estão em desenvolvimento, como a SAML ${ }^{17}$ (Security Markup Assertion Language) |OASIS, 2005a|. Segundo o comitê técnico do consórcio OASIS responsável pela SAML, esta é um arcabouço para intercâmbio de informações de segurança. As informações de segurança são expressadas na forma de asserções sobre assuntos, no qual um assunto é uma entidade (ser-humano ou computador) que tem uma identidade em algum domínio de segurança. O consórcio Liberty Alliance Project ${ }^{18}$ desenvolveu especificações [Liberty Alliance Project, 2004 para serviços de identidade. A conformidade com estes padrões permitirão aos Serviços Web usar um único arcabouço para identidade. Isso suportará, por exemplo, que usuários se autentiquem uma única vez, mesmo se invocarem vários serviços, cada um requerendo autenticação.

Processos de negócio geralmente requerem múltiplos passos em uma seqüência específica, envolvendo a invocação e a interação de múltiplos serviços. A linguagem WS-BPEL(Web Services Business Process Execution Language) [OASIS, 2005b] foi desenvolvida para coordenar 19 Serviços Web por meio de um único processo de negócio. A WS-BPEL utiliza a WSDL para descrever os Serviços Web que participam em um processo e como os serviços interagem |Fu et al., 2004|. Um comitê técnico do consórcio OASIS ${ }^{20}$ tem continuado o trabalho de especificação do WS-BPEL.

O gerenciamento [W3C, 2004e] de Serviços Web permite monitorar, controlar e reportar uso e qualidade de serviços. Entre atributos de qualidades de serviços estão disponibilidade (presença e número de instâncias do serviço), performance (latência e taxa de falhas) e acessibilidade dos destinatários. Quanto ao uso, pode-se considerar o atributo de freqüência, duração, escopo e autorização de acesso. Para que Serviços Web se tornem gerenciáveis são necessários um conjunto de operações e um modelo de informações que representem os vários tipos de uso e de qualidade de serviço. O consórcio OASIS está desenvolvendo uma especificação para o gerenciamento de Serviços Web, a WSDM (Web Services Distributed Management) |OASIS, 2005c, que define um protocolo para a interoperabilidade do gerenciamento de informações e capacidades por meio de Serviços Web [Papazoglou and Heuvel, 2005]. A WSDM aborda o gerenciamento usando Serviços Web OASIS, 2005e (Management Using Web Services - MUWS) e o gerenciamento de Serviços Web [OASIS, 2005d] (Management Of Web Services - MOWS). O MUWS define como descrever o gerenciamento de recursos

\footnotetext{
${ }^{14}$ http://web.mit.edu/kerberos/

${ }^{15}$ http://wp.netscape.com/eng/ssl3/

${ }^{16}$ http://www.ietf.org/rfc/rfc2246.txt

${ }^{17} \mathrm{http}: / / \mathrm{xml}$.coverpages.org/saml.html

${ }^{18}$ http://www.projectliberty.org/

${ }^{19} \mathrm{~A}$ coordenação de serviços é conhecida também como orquestração (orchestration).

${ }^{20} \mathrm{http}$ ///www.oasis-open.org/committees/wsbpel/charter.php
} 
usando documentos WSDL [Papazoglou and Heuvel, 2005] e o MOWS está baseado no MUWS e define como acessar via Serviços Web os recursos de gerenciamento OOASIS, 2005d.

\subsection{Registros para Serviços Web}

Serviços Web trabalham em ambientes distribuídos de modo que para serem utilizados, se faz necessário o uso de registros (ou repositórios), nos quais os metadados e informações de localização são disponibilizados. Os clientes dos serviços recuperam as informações que precisam de um registro, tais como: detalhes sobre a organização que fornece o serviço, informações técnicas de acesso (interface e transporte) e onde encontrar o serviço.

As especificações UDDI (Universal Description, Discovery, and Integration) OASIS, 2004a definem - por meio de um esquema e uma API - como publicar e descobrir informações sobre os serviços em registros em conformidade com UDDI. O esquema UDDI identifica os tipos de estruturas de dados XML que compõem uma entrada no registro para o serviço. Os registros UDDI são como páginas amarelas para os Serviços Web, que fornecem: o nome do serviço, uma breve descrição do que ele faz, um endereço onde o serviço pode ser acessado e a descrição da interface para acessar o serviço.

O UDDI define um modelo de informações para o registro de Serviços Web e um conjunto de mensagens SOAP para acessar essas informações, que pode ser dividido em duas partes:

- informações de negócio: fornece o nome e contato para o negócio. Fornece também a lista de categorias por meio das quais o negócio deve ser registrado para ajudar usuários a encontrá-lo;

- informações de serviço: fornece as informações de quais Serviços Web são oferecidos pelo negócio, suas interfaces e localizações.

$\mathrm{O}$ ebXML $L^{22}$ é um arcabouço B2B (business-to-business) que inclue um registro e outras informações necessárias para colaboração do negócio em um mercado eletrônico global. O arcabouço foi desenvolvido pelo consórcio OASIS e pela organização UN/CEFAT 23 (United Nations Centre for Trade Facilitation and Electronic Business). O ebXML contém os protocolos CPP (Collaboration-Protocol Profile) e CPA (CollaborationProtocol Agreement). Um CPP é um documento XML que contém informações sobre

\footnotetext{
${ }^{21}$ http://www.uddi.org/specification.html

${ }^{22}$ http://www.ebxml.org

${ }^{23}$ http://www.unece.org/cefact/
} 
um negócio e como ele troca informações. Um CPA é um documento XML que descreve as capacidades específicas a serem acordadas para colaboração no negócio.

\subsection{Considerações finais}

Os Serviços Web vêm sendo utilizados com sucesso em ambientes com heterogeneidade de aplicações, linguagens de programação e sistemas operacionais. Essas são características dos ambientes de computação ubíqua em geral, o que inspira a sua utilização nessa área de pesquisa. No Capítulo 6 é discutido o seu uso na integração de aplicações em computação ciente de contexto e também é discutida a viabilidade em adotar uma solução orientada a serviços.

Pesquisas atuais em Serviços Web têm trabalhado no desenvolvimento de especificações para suprir as necessidades de segurança, coordenação e administração. No entanto, ainda não há padrões nessa linha tão amplamente aceitos e empregados como os padrões básicos. Uma outra linha de pesquisa direciona os esforços para a Web Semântica [Berners-Lee et al., 2001], com o intuito de promover os Serviços Web Semânticos. Com a adoção de tecnologias da Web Semântica espera-se automação no fornecimento e uso dos Serviços Web, incluindo descoberta, seleção, composição, invocação e monitoramento de serviços. 




$\mathrm{O}$

Context Kernel |Arruda Jr., 2003; Arruda Jr. et al., 2003| é um Serviço Web [W3C, 2002| dedicado ao armazenamento e à recuperação de informações de contexto, que permite à aplicações gerenciarem informações com base nas seis dimensões amplamente discutidas na literatura: who (identificação), where (localização espacial), when (localização temporal), how (modo de captura ou de acesso), what (atividades) e why (motivação) Abowd et al., 2002; Truong et al., 2001.

\subsection{O Serviço Web Context Kernel}

O Context Kernel Arruda Jr., 2003; Arruda Jr. et al., 2003 permite que aplicações não somente armazenem e recuperem, mas também compartilhem informações de contexto por meio da Web. Assim, beneficia-se da especificação SOAP para estruturar o formato das mensagens, da linguagem WSDL para definir as mensagens e da linguagem XML Schema para evitar ambigüidade na representação dos tipos de dados em diferentes plataformas que processarão as mensagens.

A Figura 4.1 ilustra o fluxo de informação no Context Kernel por meio dos passos numerados de 1 a 5. No passo 1, o Context Kernel publica a descrição de seus serviços em um documento público WSDL. No passo 2, o desenvolvedor de aplicações recupera o conteúdo do documento WSDL. Analisando esse documento, o desenvolvedor obtém a descrição dos serviços disponibilizados pelo Context Kernel, suas localizações na Web e o formato das mensagens para invocá-los. Com base nessas informações, a aplicação é construída de modo a enviar requisições HTTP utilizando 
o protocolo SOAP para o empacotamento das mensagens. No passo 3, a aplicação requisita os serviços disponibilizados pelo Context Kernel. No passo 4, o Context Kernel comunica-se com sua base de dados e armazena/recupera as informações que são enviadas/requisitadas pelas aplicações. Dependendo do resultado da análise dessas informações e do sucesso no armazenamento ou recuperação da base de dados, o Context Kernel envia uma mensagem de retorno apropriada no passo 5.

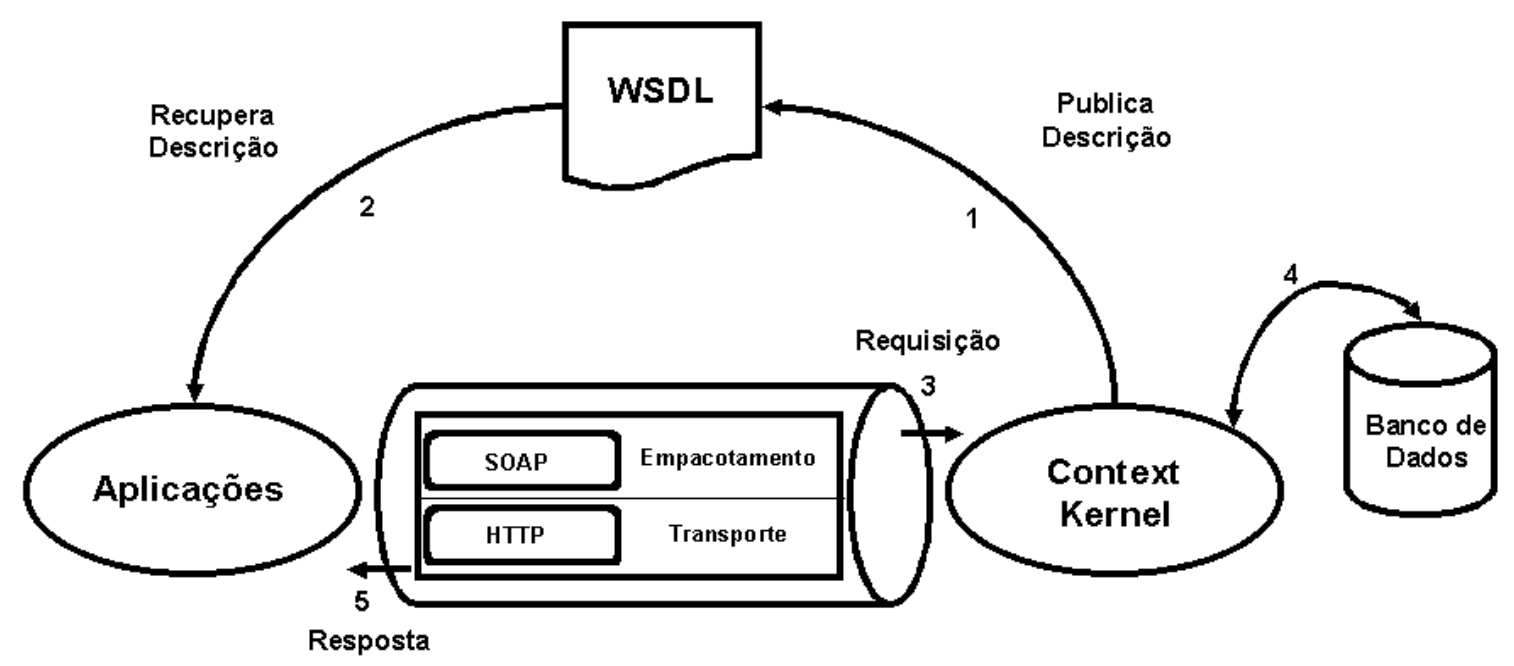

Figura 4.1: Fluxo de informação no Context Kernel.

O Context Kernel usa as dimensões de contexto com uma modelagem baseada em dimensões primitivas e derivadas Arruda Jr. et al., 2003. As dimensões primitivas podem ser armazenadas e recuperadas independentemente de outras dimensões. Qualquer uma das dimensões pode ser utilizada como dimensão primitiva ou derivada.

\subsection{Modelo de armazenamento do Context Kernel}

O Context Kernel (daqui em diante referenciado por CK) formaliza as dimensões primitivas na forma de quádruplas dimensão-tipo-valor-qualificador, nas quais as dimensões devem ser restritas às dimensões definidas no modelo do CK. O tipo identifica a categoria do valor, que é determinada pela aplicação. O qualificador é um atributo opcional utilizado para restringir o valor. As dimensões derivadas são determinadas por meio de regras que contêm pelo menos uma premissa e uma inferência. Premissas são quádruplas no formato dimensão-tipo-valor-qualificador e inferências são triplas dimensão-tipo-valor, sendo o tipo um atributo opcional para inferências. As regras são inferidas pelas aplicações e armazenadas no CK para consultas |Arruda Jr., 2003; Arruda Jr. et al., 2003. Por exemplo, uma regra pode ser baseada nas 
premissas:

(dimensão=who; tipo=pessoa; valor=Carlos;)

(dimensão=where; tipo=sala; valor=Intermídia;)

(dimensão=when; tipo=date; valor= Segunda-feira;)

e determinar a inferência:

(dimensão=what; tipo=tarefa; valor=Trabalhando no Context Daemon)

As informações contextuais, representadas no formato XML, são mapeadas pelo CK para o Modelo Relacional, de modo a armazená-las em um Sistema Gerenciador de Banco de Dados (SGBD) Relacional.

\subsection{Operações disponibilizadas pelo Context Kernel}

Atualmente as operações disponibilizadas pelo Context Kernel são as de registro, armazenamento, consulta, recuperação e notificação. A seguir estão descritos cada uma dessas operações. Informações mais completas estão disponíveis em Arruda Jr. 2003 e Jardim 2003.

\subsubsection{Registro de aplicações}

O registro de informações, disponibilizado pela operação InfoApp, permite que aplicações se registrem como usuárias do CK. Uma aplicação deve informar seu nome, uma descrição, seu endereço na Web, o número e data da sua última versão, o domínio (comercial, acadêmico, demonstração, gratuito ou versão para avaliação) e o nome e o endereço eletrônico dos seus desenvolvedores. A aplicação pode informar um endereço (“callback_address") para receber as notificações de eventos (descrito adiante). O fragmento XML do Exemplo 1 descreve as informações da aplicação iClass Cattelan et al. 2003al que devem ser enviadas via operação InfoApp para ser registrada.

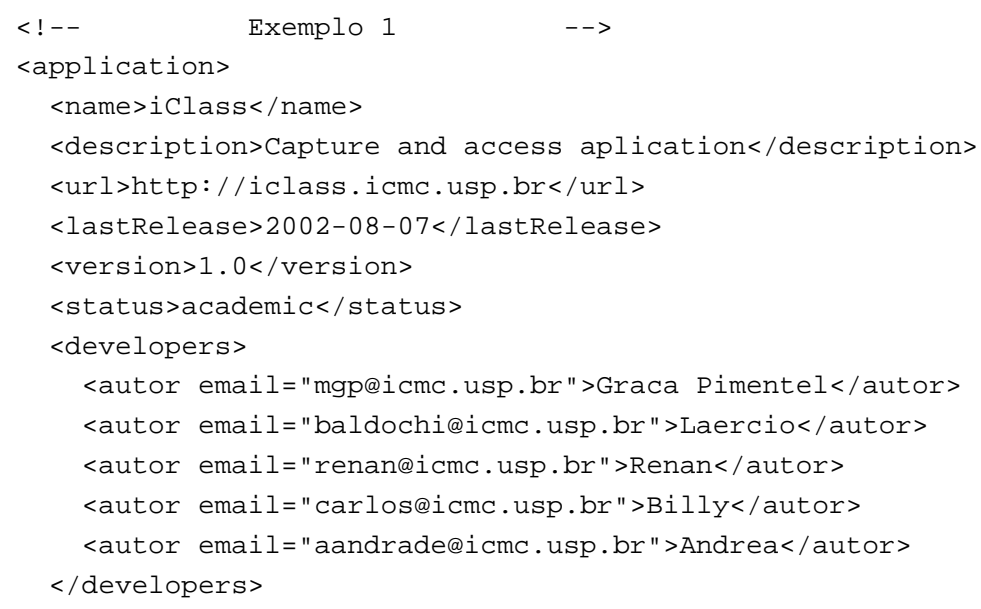






Na operação InfoApp, essas informações são registradas na base de dados e a aplicação recebe dois identificadores, um público e um outro privado. O identificador público é utilizado para acesso às informações contextuais armazenadas pela aplicação, enquanto o identificador privado é usado para armazenar informações de contexto. O identificador público é a chave que permite compartilhar as informações com outras aplicações. Uma vez que uma aplicação A possui o identificador público de uma aplicação B, A pode usar os serviços do CK para obter as informações armazenadas por B. O fragmento XML do Exemplo 2 mostra uma mensagem de registro bem sucedido recebido pela aplicação.

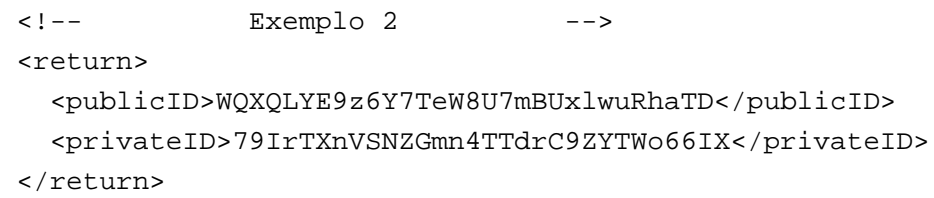

\subsubsection{Armazenamento de informações de contexto}

A operação PutData é a responsável pelo armazenamento das informações primitivas, enquanto a operação PutRules é a responsável pelo armazenamento das regras de contexto. A operação PutData permite que aplicações enviem várias sentenças sobre as dimensões. No fragmento XML do Exemplo 3, uma aplicação está armazenando que "a professora Graça está na sala 3-009 em uma Guarta-feira de manhã”.

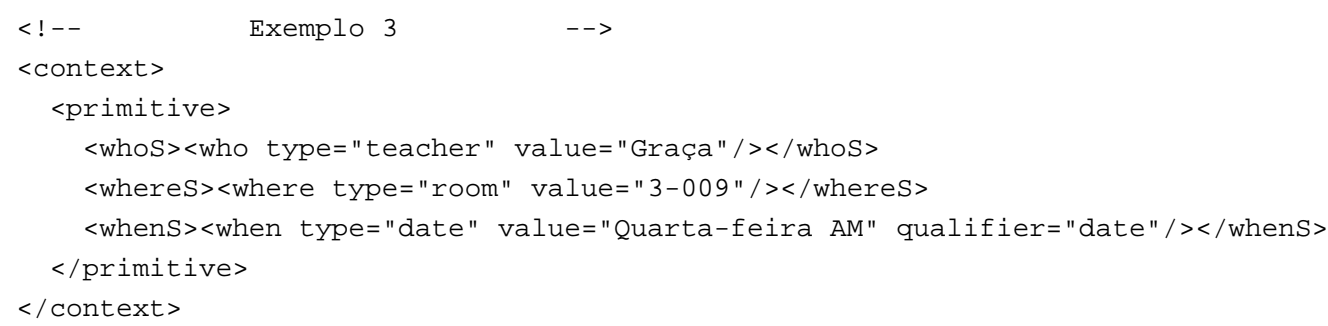

Já a operação PutRules requer que as aplicações enviem um ou mais dados primitivos que fazem parte da premissa, ou um ou mais dados derivados que fazem parte da inferência da regra. No fragmento XML do Exemplo 4, uma aplicação está armazenando a seguinte regra: "a professora Graça está todas as Quartas-feira de manhã na sala 3-009 ministrando o curso de Hipermídia”. Essa regra é válida somente para o primeiro semestre de 2004 como indicado pelos atributos "begin" e "end". O uso do 
atributo "notify" do elemento "rule" com valor "true" (o valor padrão é "false") demonstra o interesse da aplicação que registrou a regra em receber notificações de eventos se essa regra for validada (a validação está definida mais adiante).

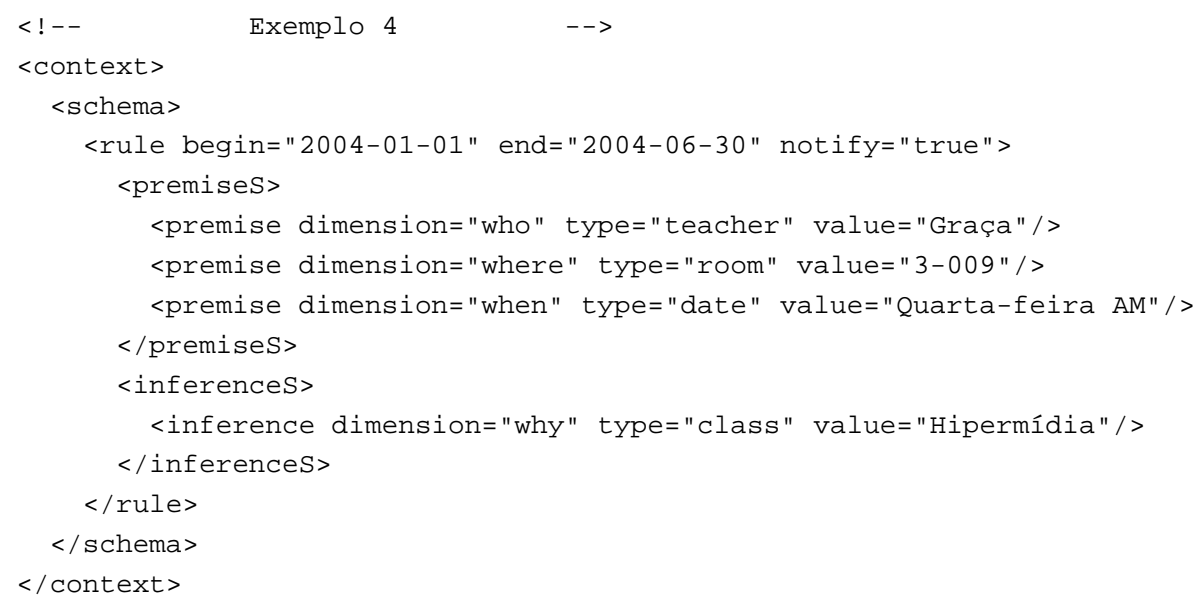

\subsubsection{Recuperação de informações de contexto}

O CK disponibiliza três operações para a recuperação de informações de contexto: StatusApp, StatusApps e GetRules. As operações StatusApp e StatusApps permitem a recuperação das informações de registro de uma dada aplicação e de todas as aplicações registradas no CK, respectivamente. Por motivos de segurança o identificador privado não é recuperado, apenas o identificador público.

A operação GetRules é a responsável pela recuperação das regras de contexto armazenadas na base de dados, sendo necessário, para isso, informar o identificador público da aplicação. O fragmento XML do Exemplo 5 mostra uma mensagem com a regra recuperada de uma aplicação, na qual os estudantes Carlos, Valter e Renan estão todas as terças-ferias na sala 100-8 apresentando seminários. Neste exemplo, a aplicação tem apenas uma regra registrada.

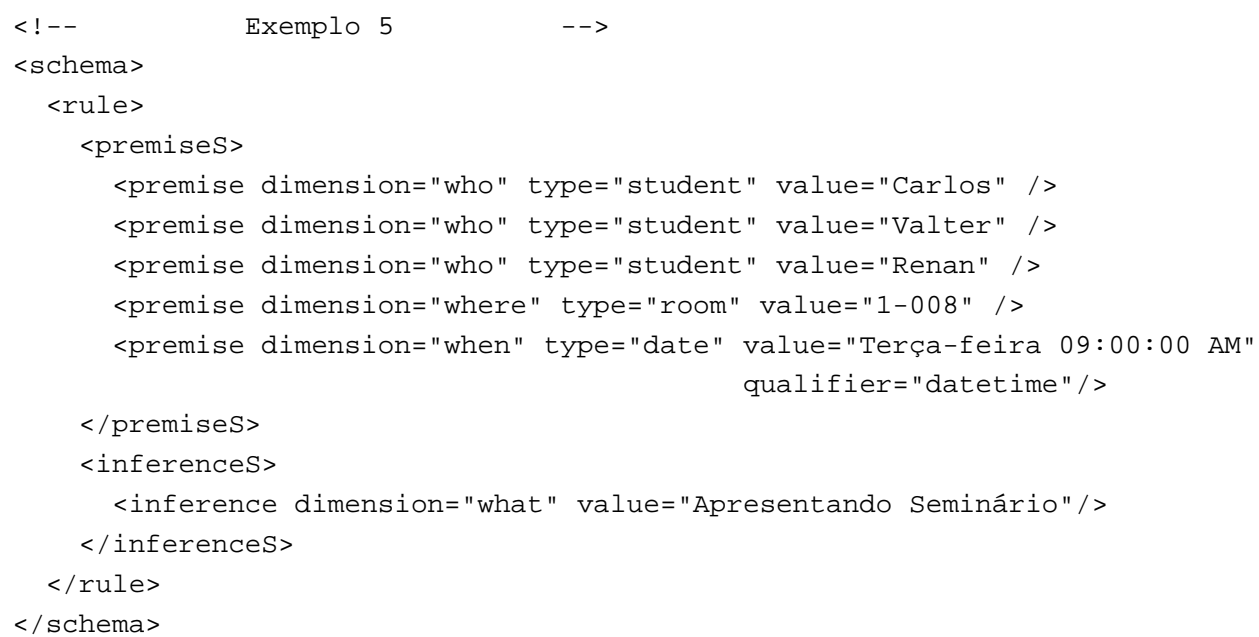




\subsubsection{Consulta de informações de contexto}

As operações GetAny e Getlnverse são as responsáveis pelas operações de consultas. A operação GetAny permite às aplicações realizarem consultas com base nos valores das premissas associando dimensões primitivas e derivadas. Ainda, pode-se requisitar o número máximo de respostas retornadas, quais as dimensões de resposta, especificar o tipo da dimensão e usar os operadores booleanos AND e OR.

No fragmento XML do Exemplo 6, uma aplicação quer saber "qual foi a última atividade que uma pessoa chamada Carlos fez no Intermídia no dia 27 de Julho de 2004".

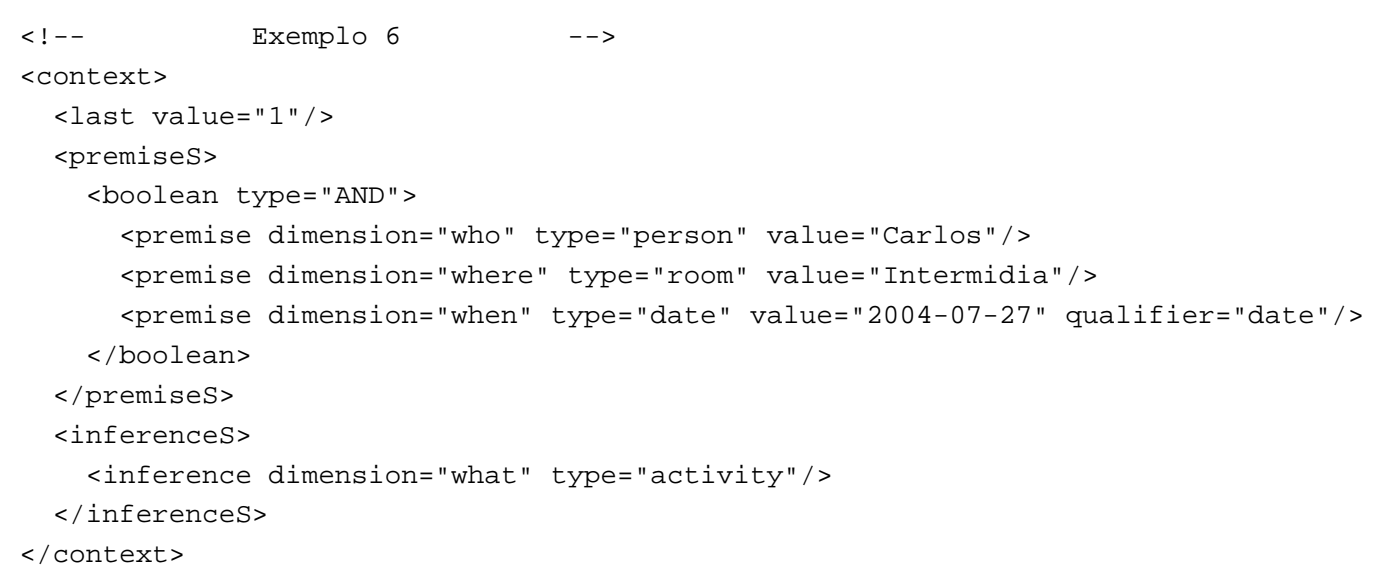

O fragmento XML do Exemplo 7 mostra um possível retorno para a consulta anterior.

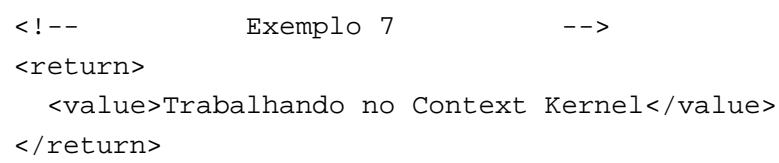

A operação Getlnverse permite às aplicações recuperarem informações de contexto utilizando uma inferência para obter as correspondentes premissas. Essa operação permite uma semântica de raciocínio "para trás", enquanto a operação GetAny segue um raciocínio "para frente”. No fragmento XML do Exemplo 8, uma aplicação quer saber "quem está na sala Intermídia".

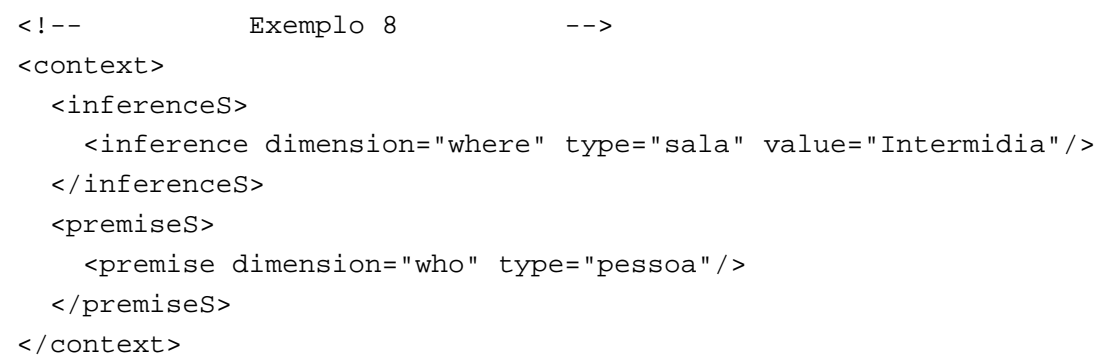


O fragmento XML do Exemplo 9 mostra um possível retorno para a consulta anterior.

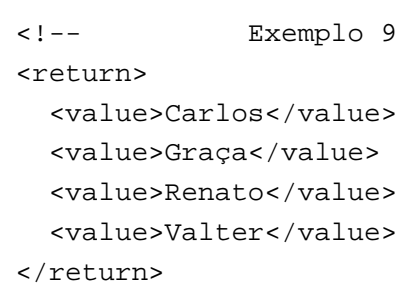

Ambas as operações GetAny e Getlnverse permitem o uso de caracteres coringas no valor das premissas. Por exemplo, no Exemplo 6, pode ser útil consultar a atividade sem especificar a sala na dimensão when de modo a tornar a consulta mais geral. Esse recurso pode ser usado ao atribuir o valor “*” à premissa:

<premise dimension="where" type="room" value="*"/>

\subsubsection{Notificação de eventos e validação de regras}

O Context Daemon (a partir daqui referenciado por CD) é uma operação de notificação de eventos que estende o modelo de gerenciamento de informações de contexto proposto pelo CK JJardim, 2003|. Esse modelo baseia-se nos conceitos de regras de contexto e de informações primitivas. Uma notificação de evento é decorrente da validação de uma regra. Definimos validação de uma regra como o processo resultante da igualdade léxica decorrente da comparação das premissas de uma informação primitiva com as premissas de uma regra de contexto. A notificação consiste em tornar uma aplicação ciente que uma regra registrada por ela foi validada.

Uma aplicação poderia armazenar a regra do Exemplo 4. No CK a regra é armazenada na base de dados, mas como ela contém o atributo "notify" com valor "true", o que indica que a aplicação tem interesse em receber notificação de eventos para essa regra, essas informações contextuais são enviadas ao CD. As informações recebidas pelo serviço PutData, não importando qual a aplicação as originou, também são enviadas para o CD para tentativa de validação das regras. Se a informação primitiva do Exemplo 3 fosse recebida pelo CK, ela validaria a regra do Exemplo 4, resultando em uma notificação do evento ocorrido, realizada pelo CD, para a aplicação que registrou a regra.

A mensagem de notificação enviada pelo CD contém as premissas e inferências da regra, porque não é o objetivo aqui deixar sobre responsabilidade do CK as inferências sobre as regras de contexto. 


\subsection{Limitações do Context Kernel}

O Context Kernel é um trabalho interessante por explorar a Web como plataforma de intercâmbio de informações de contexto. No entanto, é ainda um trabalho recente, possuindo limitações relativas a interpretação de contexto, segurança e privacidade, modelo centralizado, acesso ao histórico de contexto, descoberta de recursos e comparação textual. A seguir há uma breve descrição dessas limitações:

- Interpretação da informação contextual: ausência de um mecanismo de inferência sobre a informação contextual. Logo, não é possível atualmente inferir contexto de mais alto nível, como discutido na Sub-seção 2.4.6.

- Comparação textual: as operações de consulta consideram apenas comparação textual exata, o que restringe o conteúdo das informações de contexto a uma única representação. Dessa forma, a aplicação precisa saber exatamente como outra está armazenando as informações de contexto, para poder consultá-la.

- Segurança e privacidade: ausência de mecanismos para garantir a segurança e a privacidade das informações. Embora o Context Kernel utilize os identificadores público e privados, essa abordagem é limitada. O identificador privado garante o acesso restrito à aplicação, mas os dados trafegam pela rede em texto puro, isto é, sem mecanismos de criptografia. Por sua vez, o identificador público garante o acesso às informações de contexto de uma aplicação e precisa ser compartilhado com outras aplicações. Não há uma forma de separar categorias de informações que podem ou não ser compartilhadas.

- Histórico de contexto: embora o Context Kernel mantenha o histórico dos contextos, o acesso a essas informações é feito somente por meio de consultas, e em sua maioria de consultas a regras. Não é possível consultar dados de contexto e nem utilizar o histórico para predizer valores presentes e futuros, tal como discutido na Sub-seção 2.4.3.

- Modelo de armazenamento e consulta centralizado: o modelo da infra-estrutura Context Kernel centraliza o armazenamento e recuperação da informação contextual. Essa questão pode ser amenizada em termos de escalabilidade e desempenho, de acordo com a adoção de uma plataforma de desenvolvimento para aplicações distribuídas. Porém, o modelo proposto não contempla a interação entre as instâncias distribuídas da infra-estrutura, de modo a considerar o contexto armazenados nas demais instâncias.

- Descoberta de recursos: ausência de um mecanismo para descoberta de recursos. A importância deste mecanismo para a computação ciente de contexto foi 
discutido na Sub-seção 2.4.5. Uma discussão preliminar com respeito a investigar uma solução para o Context Kernel está proposta na Seção 7.3 .

\subsection{Consideraçōes finais}

A literatura tem reportado esforços que objetivam apoiar o processo de desenvolvimento de infra-estruturas computacionais para suporte ao desenvolvimento de aplicações cientes de contexto (ver Capítulo [5). Nesse sentido, foi desenvolvido no contexto de um projeto de mestrado o Serviço Web Context Kernel |Arruda Jr., 2003|, que permite a aplicações armazenarem, recuperarem e compartilharem informações de contexto utilizando a Web como plataforma de intercâmbio.

O conjunto de operações fornecidas originalmente pelo Context Kernel Arruda Jr., 2003| é um conjunto mínimo de serviços para atender à aplicações sensíveis ao contexto e o autor do trabalho aqui reportado tem ampliado e empregado essas operações em aplicações de computação ubíqua. Nesse contexto, implementou o serviço de notificação de eventos Jardim, 2003. Os trabalhos reportados em Jardim et al., 2005b;a; Macedo et al., 2005; Bulcão Neto et al., 2004c/a;b] mostram a viabilidade de empregar o Serviço Web Context Kernel de modo a tornar aplicações cientes de contexto. Um outro trabalho de mestrado em andamento tem utilizado com sucesso essa infra-estrutura para integração de uma aplicação de agendamento de compromissos com um sistema de captura |Vieira, 2004a|b|. 


\section{Trabalhos Relacionados}

uportar o desenvolvimento de aplicações cientes de contexto é um dos desafios da Computação Ubíqua |Abowd et al., 2002]. A seguir estão descritos

alguns esforços em pesquisa de aplicações que facilitam o desenvolvimento de aplicações cientes de contexto e uma breve comparação de suas características com as do Context Kernel (referenciado por CK). Esses trabalhos relacionados tratam de desafios para construção de aplicações cientes de contexto com suporte para vários níveis de heterogeneidade, distribuição de responsabilidades entre as aplicações e infra-estruturas e serviços para gerenciamento de informações de contexto.

\subsection{Context Toolkit}

O Context Toolkit |Dey et al., 1999a; Salber et al., 1999a|b| oferece um arcabouço com serviços genéricos e abstrações - componentes de interfaces (widget), agregadores e interpretadores - com o intuito de superar a ausência de um padrão de desenvolvimento de aplicações cientes de contexto baseadas em sensores. A arquitetura do Context Toolkit é ilustrada na Figura 5.1, na qual pode-se observar as interações entre aplicações e componentes da arquitetura.

Os componentes de interface são blocos básicos que gerenciam a aquisição de fragmentos particulares de contexto, como por exemplo sensores de presença, identidade e atividade. Esses componentes podem ser combinados de modo a fornecer às aplicações um modelo baseado em múltiplos tipos de informação contextual. Agregadores são componentes que encapsulam um único sensor ou um conjunto de sensores relacionados e o software que adquire informações dos sensores. Os interpretadores 


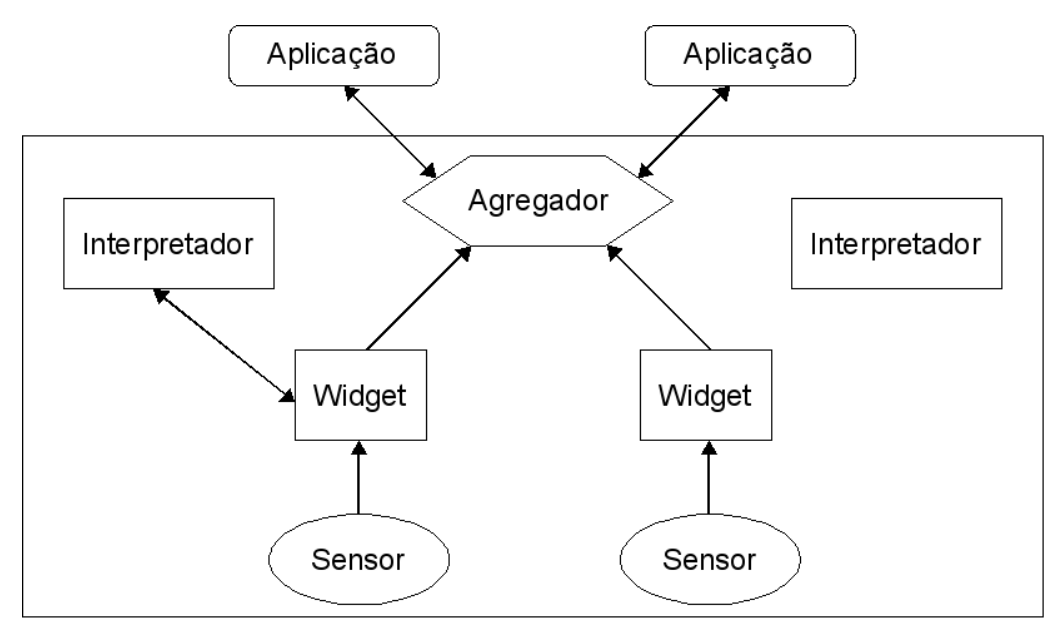

Figura 5.1: Interações entre as aplicações e componentes da aquitetura do Context Toolkit. Adaptado de Dey et al. [2001].

usualmente utilizam informações de mais de uma fonte de contexto, fornecendo uma abstração para a informação contextual em um nível mais alto do que os sensores podem produzir. O histórico de cada tipo das informações de contexto é armazenado em uma base de dados relacional pelo seu componente de interface correspondente, disponibilizando as informações a qualquer aplicação interessada. O Context Toolkit pode fornecer padronização e generalização às aplicações, possibilitando o reuso de métodos de desenvolvimento na construção de novas aplicações.

No Context Toolkit, os componentes compartilham um mecanismo de comunicação comum (XML sobre HTTP) que permite a transparência no processo de aquisição de contexto. Com isso, as aplicações não necessitam saber se os componentes responsáveis pelo contexto estão sendo executados local ou remotamente. Ao se utilizar os componentes de interface do Context Toolkit, obtém-se uma padronização na representação dos tipos de contexto. Sendo baseado nas dimensões de contexto descritas anteriormente, o Context Kernel não limita as aplicações a uma representação específica para informação contextual. Essa característica do Context Toolkit é conseqüência da abstração proposta para o uso de sensores, enquanto o Context Kernel objetiva, até o presente momento, não tratar de modo diferenciado fontes de contexto de aplicações consumidoras de contextos.

Os trabalhos de Dey et al. 2001] ainda contribuíram para a definição de informação de contexto e de ciência de contexto, além de requisitos para suportar o desenvolvimento de aplicações cientes de contexto e o uso da informação contextual [Dey, 2000.

O Context Toolkit foi utilizado para construir várias aplicações, como a Conference Assistant, que permite o acesso a informações capturadas de palestras em uma conferência com base em informações de contexto de localização [Dey et al., 1999c]. Outra 
aplicação construída utilizando essa infra-estrutura foi a Family Intercom, que permite a comunicação entre pessoas de uma residência instrumentada com sensores de presença e de localização |Nagel et al., 2001|.

\subsection{Context Fabric}

O Context Fabric |Hong and Landay, 2001] é um infra-estrutura para aplicações cientes de contexto com foco no modelo de armazenamento para informações de contexto flexíveis e distribuídas. Essa infra-estrutura permite a separação de aquisição, processamento e utilização dessas informações, liberando as aplicações desse gerenciamento. O Context Fabric consiste de um modelo lógico e de um modelo físico para armazenamento de informações. O modelo lógico é responsável por armazenar entidades, como pessoas e lugares. O modelo físico é o responsável por gerenciar as informações de contexto armazenadas. Essa infra-estrutura fornece uma linguagem declarativa e quatro serviços básicos: serviço de gerenciamento de sensores, serviço de criação automática de caminho, serviço de eventos e o serviço de consultas, ilustrados na Figura 5.2 .



Figura 5.2: Arquittura do Context Fabric: sensores e serviços básicos são distribuídos entre aplicações e a infra-estrutura. Adaptado de Hong and Landay |2001]. 
O serviço de gerenciamento de sensores é o responsável por gerenciar os sensores locais utilizados pelos outros serviços e fornece um formato uniforme de dados de sensores para os serviços de consulta e de eventos. O serviço de criação automática de caminho combina o fluxo de dados de sensores e os componentes de software necessários para inferir contexto em alto nível. O serviço de eventos permite às aplicações registrarem eventos de seu interesse e recebem a notificação do evento via callback. A notificação via callback é realizada de forma assíncrona para que as aplicações não precisem ficar consultado informações de contexto para saber sobre eventos de interesse. Guando necessitarem consultar sobre determinada informação de contexto, as aplicações podem utilizar o serviço de consulta, cuja comunicação é síncrona. A Linguagem de Especificação de Contexto (Context Specification Language - CSL) é baseada no padrão XML para a representação de informações de contexto e de eventos em alto nível. As sentenças em CSL são processadas pelo serviço de contexto local se todo os dados necessários estão disponíveis, ou utiliza outros serviços de contexto se necessário |Hong, 2002|.

O Context Fabric diferencia-se do Context Kernel fornecendo um serviço de gerenciamento de sensores e por inferir contexto em alto nível. A idéia da notificação fornecendo comunicação assíncrona e de consultas síncronas é a mesma em ambas as infra-estruturas.

O Context Fabric foi utilizado na construção de uma aplicação que localiza e disponibiliza email e páginas Web de pessoas que estão na mesma sala. Essa infraestrutura foi utilizada também em uma aplicação que permite aos usuários especificarem situações sobre as quais gostariam de serem notificadas [Heer et al., 2003].

\subsection{GaiaOS}

O GaiaOS |Hess et al., 2002; Román et al., 2002| é um middleware projetado para fornecer suporte para um "Espaço Virtual de Usuário", uma abstração que compreende informações de contexto, tarefas e dispositivos associados a cada usuário. $\mathrm{O}$ GaiaOS objetiva desafios herdados de ambientes computacionais ubíquos, tais como gerenciamento de contexto, comunicação, mobilidade e adaptabilidade. O serviço de armazenamento é disponibilizado por um sistema gerenciador de dados ciente de contexto que organiza o espaço virtual do usuário em servidores de arquivos distribuídos, com cada servidor de arquivo gerenciando seu próprio dado. Por meio dessa arquitetura, outros serviços podem ser implementados no topo do middleware GaiaOS. Segundo Román et al. [2002], o GaiaOS oferece cinco serviços básicos: o gerenciador de eventos distribui eventos (modificações no contexto) nos espaços virtuais de usuário; o serviço de contexto permite que aplicações consultem e se registrem para acessar a informação contextual; o serviço de presença detecta e mantém informações 
sobre o estado de componentes de software, dispositivos e pessoas; o repositório de espaços armazena informações sobre todas as entidades de software e hardware no espaço e permite que as aplicações recuperem entidades com base em atributos que os identificam; o sistema de arquivos de contexto: (a) disponibiliza automaticamente dados pessoais, condicionados na presença do usuário, (b) organiza os dados para facilitar a localização de material relevante para aplicações e usuários e (c) recupera dados no formato preferido do usuário ou baseado nas características do dispositivo. A Figura 5.3 ilustra a estrutura dos componentes do núcleo do middleware GaiaOS.

\begin{tabular}{|c|c|c|c|c|}
\hline \multicolumn{7}{|c|}{ Aplicações de espaços ativos } \\
\hline \multicolumn{3}{|c|}{ Arcabouço para aplicações } \\
\hline $\begin{array}{c}\text { Serviço de } \\
\text { gerência } \\
\text { de eventos }\end{array}$ & $\begin{array}{c}\text { Serviço de } \\
\text { contexto }\end{array}$ & $\begin{array}{c}\text { Serviço de } \\
\text { presença } \\
\text { de entidades }\end{array}$ & $\begin{array}{c}\text { Serviço de } \\
\text { repositório } \\
\text { de espaços }\end{array}$ & $\begin{array}{c}\text { Serviço de } \\
\text { arquivos } \\
\text { de contexto }\end{array}$ \\
\hline \multicolumn{3}{|c|}{ Núcleo de gerenciamento de componentes } \\
\hline
\end{tabular}

Figura 5.3: Componentes do middleware GaiaOS. Adaptado de Román et al. [2002].

O modelo de distribuição do GaiaOS está baseado na tecnologia CORBA, enquanto o Context Kernel propõe o uso de Serviços Web. Diferentemente da implementação atual do Context Kernel, o GaiaOS pode inferir contexto em alto nível combinando os contextos de sensores (baixo nível). Na representação do contexto, GaiaOS e Context Kernel propõem modelos diferentes para representar o tipo de contexto, objetos e o relacionamento entre eles, pois o GaiaOS utiliza o conceito de predicados, mas as duas infra-estruturas permitem a combinação de informações de contexto utilizando lógica booleana.

Aplicações que utilizam o middleware GaiaOS incluem a Music Player, que executa arquivos de música considerando as preferências de um usuário e sua mobilidade entre espaços virtuais |Román and Campbell, 2003, a ConChat, uma aplicação de chat em que usuários se comunicam por meio da troca de informações de contexto [Ranganathan et al., 2002, e um gerenciador de apresentações que permite aos usuários apresentarem slides em múltiplas telas simultaneamente [Román et al., 2002].

\subsection{Aura}

O Projeto Aura Garlan et al., 2002] fornece um arcabouço arquitetural para mobilidade dos usuários em ambientes computacionais ubíquos que permitem a adaptação para as necessidades e contextos dos usuários. O componente principal inclui uma representação das tarefas dos usuários como uma coleção de descrições de serviços que podem ser mapeadas em "fornecedores de serviços", atualmente disponíveis 
no ambiente. Os demais serviços do arcabouço são o "gerenciador de tarefas", o "gerenciador de ambiente" e os "observadores de contexto" [Sousa and Garlan, 2002].

Os fornecedores de serviço fornecem serviços abstratos para encapsular serviços ou aplicações já existentes. Os encapsuladores relacionam a descrição dos serviços abstratos com as características específicas das aplicações. Assim, os fornecedores podem extrair as informações das aplicações em um formato que eles reconhecem. Para essa representação, os fornecedores de serviços utilizam marcações no formato XML para descrever os serviços relacionados a uma tarefa. O gerenciador de tarefas coordena a migração das informações sobre as tarefas do usuário para novos ambientes. Esse componente monitora o ambiente e se o fornecedor de um serviço para determinada tarefa falhar ou se tornar incompativel com os requisitos da tarefa, o gerenciador de tarefas pode consultar o gerenciador de ambiente a procura de uma configuração alternativa adequada. Se o usuário decidir interromper a sua tarefa atual para iniciar uma nova, o gerenciador de tarefas salva as informações de contexto referentes à tarefa interrompida e cria a configuração para a nova tarefa. Dessa forma, o gerenciador de tarefas aplica o conceito de "aura pessoal" ao dar suporte transparente e dinâmico às tarefas de um usuário mesmo com as variações e alterações no ambiente. Os observadores de contexto fornecem informações sobre o contexto físico e reportam eventos ao gerenciador de ambiente, tais como localização do usuário, autenticação, atividade e presença de outras pessoas. A implementação desses componentes é dependente dos tipos de sensores disponíveis em um ambiente, e para cada tipo das informações de contexto há um observador de contexto. Esses componentes são colocados nas três camadas definidas pela arquitetura do Aura Cheng et al., 2002, , como ilustrado na Figura 5.4.

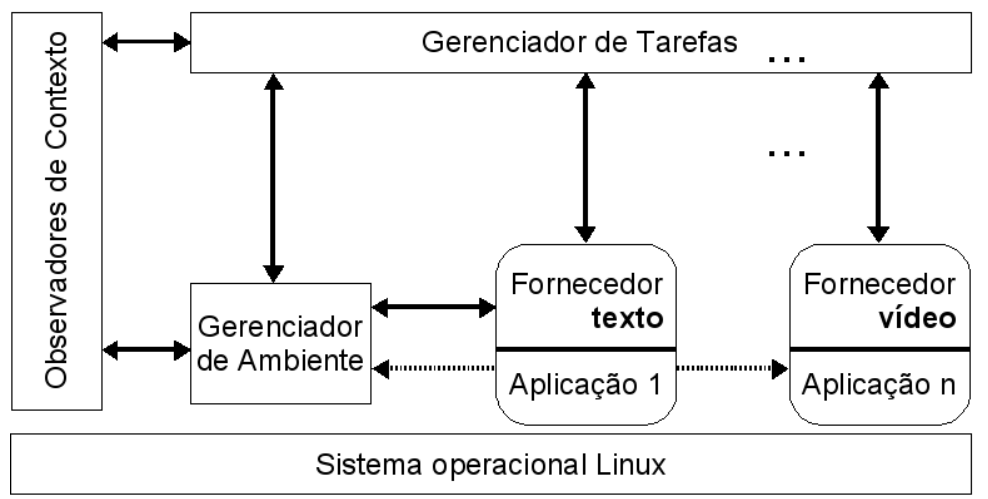

Figura 5.4: Arquitetura do Aura. Adaptado de Cheng et al. |2002].

O Projeto Aura e Context Kernel diferem nas características dos seus serviços. O serviços do CK são orientados a aplicações e não a tarefas dos seres humanos, ou seja, o relacionamento do contexto com as tarefas deve ser realizado pelas aplicações 
usuárias da infra-estrutura CK. Ainda entre as diferenças, destaca-se a função do Aura obtida pelo gerenciador de ambiente em escolher o melhor serviço para um tarefa.

Aplicações que utilizam a infra-estrutura Aura são a Portable Help Desk, uma aplicação ciente de localização que permite a alunos encontrarem colegas de trabalho em um campus universitário, e a Idealink, uma aplicação de lousa eletrônica para handhelds que suporta reuniões informais locais ou remotas Garlan et al., 2002.

\subsection{Context Service}

O Context Service |Lei et al., 2002] é uma infra-estrutura para coleta e disseminação de informações de contexto. A infra-estrutura é constituída por um distribuidor, um conjunto de drivers de contexto configuráveis e uma coleção de componentes. O distribuidor é responsável pelo roteamento das requisições das aplicações para os drivers de contextos apropriados. Cada driver gerencia um tipo de informação de contexto e abstrai os detalhes da interação com as fontes de contexto. Um driver, além de receber informação contextual via uma interface de registro, pode também requisitar explicitamente informações das fontes. Dentre as funções da coleção de componentes úteis, estão entidades responsáveis por cache de contexto, mecanismo de eventos e mecanismo de privacidade. O mecanismo de cache armazena em memória contextos recentemente acessados por razões de performance; o mecanismo de privacidade controla o acesso as informações de contexto baseado em políticas definidas pelos controladores de contexto; o controlador de ritmo de trabalho organiza a consulta das fontes de contexto para evitar a sobrecarga destes. A organização dos serviços e componentes da infra-estrutura é ilustrada na Figura 5.5 .

O Context Service destaca-se por ele próprio poder consultar fontes de contexto, ao invés de apenas aguardar que as fontes registrem o contexto, sendo essa uma característica que diretamente o difere do Context Kernel. Além disso, o mecanismo de cache e de políticas de privacidade no acesso ao contexto são características que o CK atualmente não contempla. O mecanismo de eventos compara eventos de contexto com o interesse das aplicações registradas, de modo semelhante ao serviço de notificação de eventos do CK. Uma limitação dessa infra-estrutura está no modelo adotado para adquirir as informações de contexto por meio de drivers, que devem ser implementados especificamente para um tipo de aplicação limitando o seu uso, ao invés de adotar um modelo padronizado como é feito pelo CK.

Uma aplicação que utiliza o Context Service é a Notification Dispatcher, que envia mensagens para um dos possíveis dispositivos de comunicação (por exemplo, celular e email) baseado no contexto do receptor e na urgência da mensagem. Uma outra aplicação que utiliza essa infra-estrutura é a Pervasive Content Distribution, que pré- 


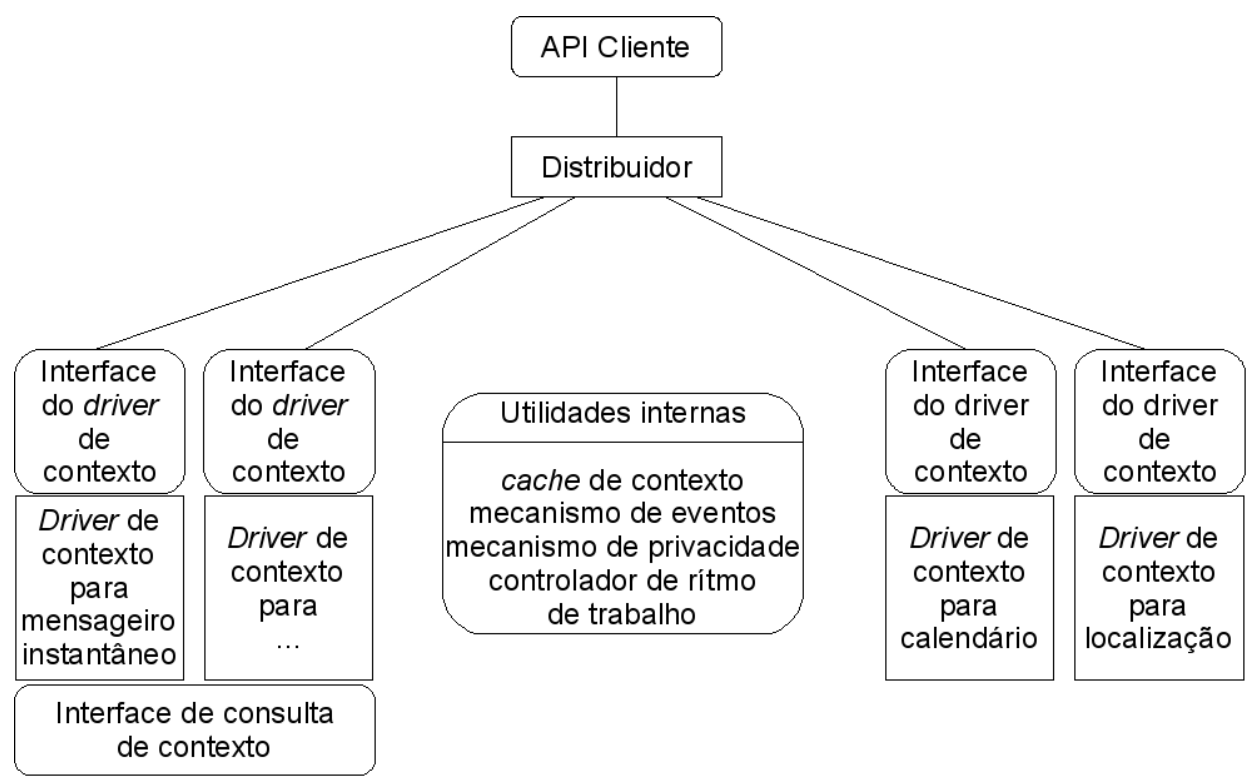

Figura 5.5: Arquitetura do Context Service. Adaptado de Lei et al. [2002].

processa e pré-distribui conteúdo em uma localização na rede próxima ao dispositivo do usuário com o objetivo de reduzir a latência no acesso ao conteúdo [Lei et al., 2002.

\subsection{Context Tailor}

O Context Tailor [Davis II et al., 2003a] é um middleware projetado sobre o Context Service [Lei et al., 2002]. O Context Service coleta, mantém e fornece informações de contexto para aplicações sobre numerosos assuntos. Assuntos podem dizer respeito a usuários ou objetos (por exemplo, equipamentos ou pacotes). O Context Tailor adiciona à arquitetura do Context Service um conjunto de fontes de contexto, um repositório de registros de contexto, uma máquina de aprendizado, um repositório de padrões de contexto e um ativador de padrões. Todas as requisições de contexto são registradas pelo serviço de contexto em um repositório de registro de contexto. Utilizando os registros de contexto, a máquina de aprendizado deriva padrões de contexto e os armazena no repositório de padrões de contexto. Os padrões derivados pela máquina de aprendizado podem ser usados para aumentar a confiabilidade das inferências sobre as informações de contexto, sendo essa a principal contribuição do Context Tailor. A Figura 5.6 ilustra a interação entre os componentes adicionados pelo middleware.

O Context Kernel não possui atualmente um mecanismo de inferência, impossibilitando-o de notificar aplicações sobre condições de eventos com base nos padrões derivados pela máquina de aprendizado, como realizado pelo Context Tailor. O projeto 


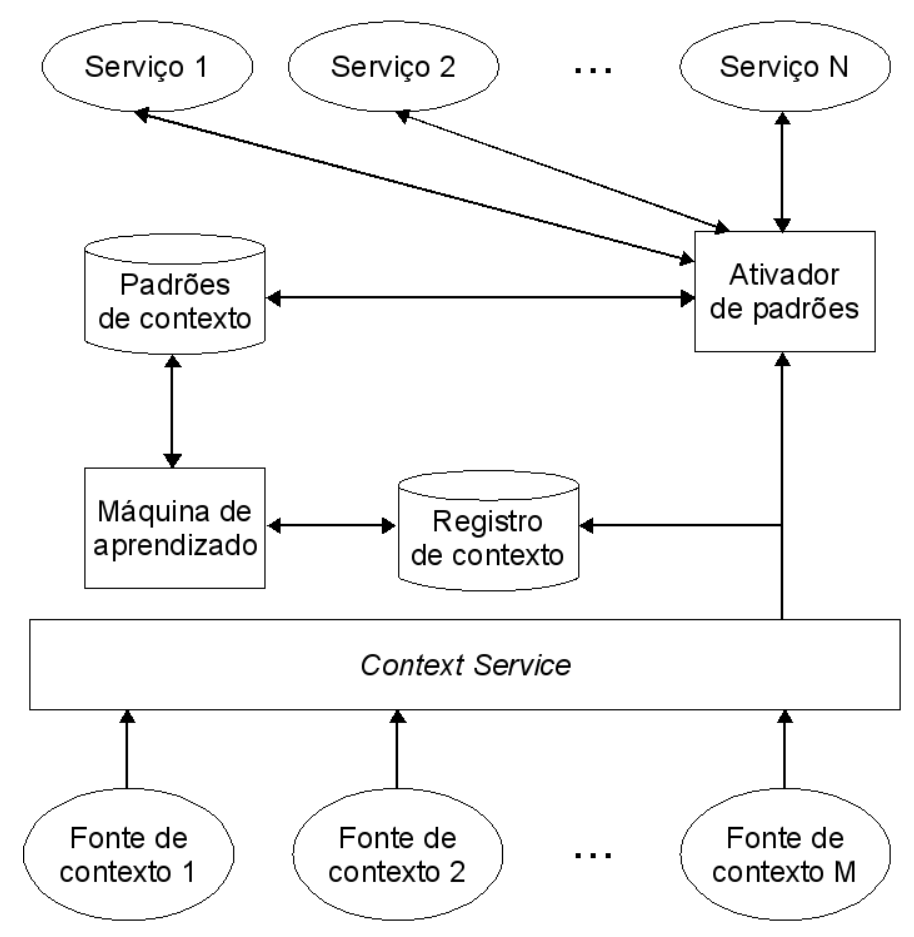

Figura 5.6: Arquitetura em alto nível ilustrando a interação entre os componentes adicionados ao Context Service pelo Context Tailor. Adaptado de Davis II et al. [2003a].

de Doutorado de Bulcão Neto [2003], em andamento no ICMC-USP, tem como um de seus objetivos construir uma infra-estrutura para processar e interpretar relacionamentos com base no conteúdo e descrições semânticas das entidades envolvidas, especialmente aqueles relacionamentos que não estão explicitamente definidos. O trabalho de Bulcão Neto está baseado em tecnologias para Web Semântica [W3C, 2001], como a Linguagem de Ontologia para Web (OWL) [W3C, 2004d] e o Toolkit Jena 2 |McBride, 2002], enquanto o Context Tailor baseia-se no uso de Lógica Fuzzy para realizar inferências sobre a informação contextual.

Um exemplo de utilização da infra-estrutura Context Tailor é aplicação Invoker, que utiliza informações de contexto para agendar tarefas computacionalmente custosas (por exemplo, replicação de dados) para executar em momento conveniente para o usuário do computador |Davis II et al., 2003b|.

\section{7 one.world}

A arquitetura one.world |Grimm, 2004| fornece um arcabouço compreendendo serviços que ajudam a estruturar aplicações e simplificar a tarefa de se adaptar continuamente a movimentação de pessoas através de ambientes físicos ou troca de dispositivos. Entre os serviços fornecidos, o de descoberta e migração são os mais 
interessantes com respeito ao Serviço Web Context Kernel. O serviço de descoberta ajuda os desenvolvedores a construirem aplicações para localizar e se conectar a serviços em outros dispositivos, e o serviço de migração ajuda com aplicações que devem seguir os usários conforme eles se movimentam pelo ambiente físico. Entretanto, o CK apresenta duas vantagens: (a) ele está baseado em um modelo centrado em dados e codificado em XML que fornece um compartilhamento mais eficiente das informações entre as aplicações, enquanto o one.world explora um modelo proprietário, com modelo de dados programático; (b) como um Serviço Web, o CK pode ser facilmente integrado com outros serviços na Internet independente da plataforma, enquanto é difícil integrar aplicações ao one.world - especialmente se elas não forem escritas em $\mathrm{Java}^{T M}$ - porque ele usa protocolos de rede não padronizados na forma de eventos remotos e de descoberta. A Figura 5.7 ilustra a arquitetura do one.word Os serviços de base e de sistema constituem o núcleo, enquanto as bibliotecas, utilitários de sistema, e aplicações executam no espaço do usuário. A seguir há uma breve descrição dos serviços fornecidos, segundo Grimm et al. [2004].

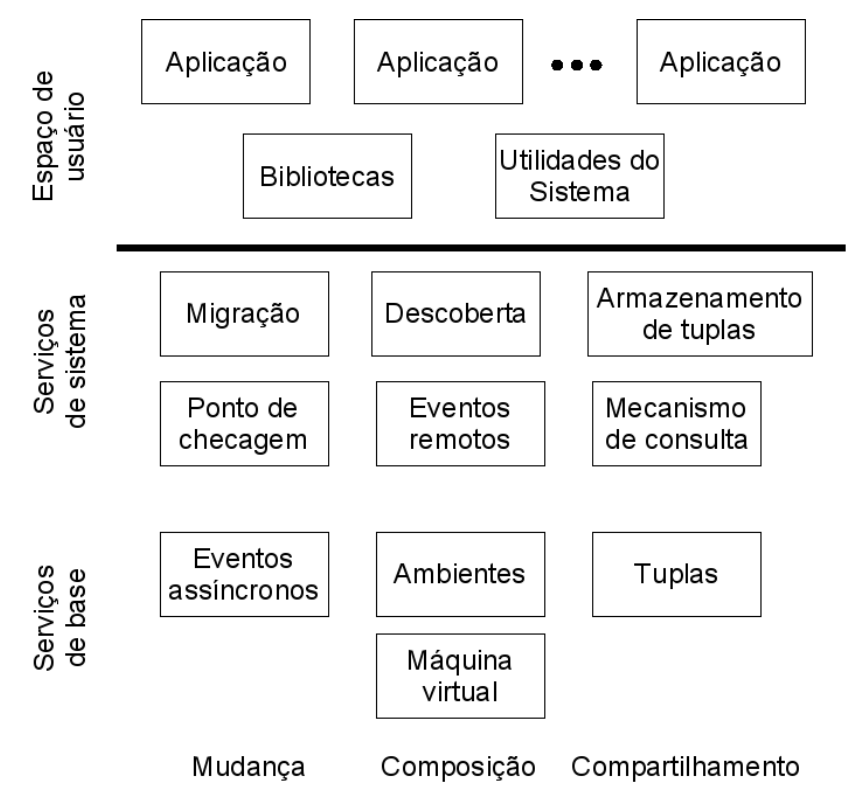

Figura 5.7: Visão geral da arquitetura do one.world. Adaptado de Grimm et al. [2004].

Segundo Grimm et al. [2004 os serviços de base lidam com os requisitos de mudança, composição ad hoc e compartilhamento em ambiente pervasivos. A máquina virtual garante a composição entre as aplicações e dispositivos, uma vez que não se pode prever todos os dispositivos que serão utilizados. As tuplas definem um modelo de dados comum, facilitando às aplicações compartilharem informações. Os eventos assíncronos são utilizados para toda comunicação, local ou remota, e objetivam notificar aplicações para se adaptarem às mudanças no ambiente físico ou de dispositivos. Os ambientes são o mecanimo central para estruturação e composição de aplicações, 
servindo como contâiners para armazenar tuplas, componentes da aplicação e outros ambientes. Um ambiente controla ambientes aninhados e pode interromper suas interações com o núcleo do sistema one.world e o mundo exterior.

Os serviços de sistema fornecem os serviços que podem ser usados como blocos de construção de aplicações. O mecanismo de consulta disponibiliza a consulta de tuplas pela instanciação de filtros. A E/S estruturadd 11 permite às aplicações acessarem as tuplas armazenadas nos ambientes. O mecanismo de consulta e a E/S estruturada simplificam o acesso a dados porque as aplicações podem acessar diretamente itens de dados relevantes. A passagem de eventos remotos envia eventos para serviços remotos, sendo o mecanismo básico de comunicação por meio da rede. O serviço de descoberta localiza serviços com localizações desconhecidas, sendo muito útil para aplicações que migram ou executam em dispositivos móveis e precisam encontrar recursos locais. Os pontos de checagem capturam o estado de execução de uma árvore de um ambiente e salvam-o como uma tupla, possibilitando reverter, posteriormente, o estado de execução da árvore do ambiente. Esse serviço facilita a tarefa de reativar uma aplicação após ela ter sido desativada ou após uma falha no dispositivo, por exemplo. A migração permite mover ou copiar um ambiente e seu conteúdo, incluindo tuplas armazenadas, componentes da aplicação, e ambientes aninhados, tanto localmente ou para um outro dispositivo. Essa abordagem é útil para aplicações que seguem uma pessoa de dispositivo para dispositivo conforme ela se move no mundo físico, por exemplo.

No espaço de usuário, fora do núcleo do one.world, a arquitetura fornece bibliotecas que incluem funções para construção de interfaces com o usuário e para a execução de controladores de eventos.

Uma aplicação construída utilizando a infra-estrutura one.world é a Emcee, que permite aos usuários mover ou copiar aplicações e seus dados do dispositivo atual para outros dispositivos e de outros para o atual. Outra aplicação construída utilizando essa infra-estrutura é a Labscape, que permite que dados de experimentos sigam pesquisadores conforme eles se movem no laboratório. Essa aplicação utiliza sensores para capturar os dados e atualizar a informação de localização, que por sua vez é utilizada para direcionar os dados para o serviço mais próximo do pesquisador.

\subsection{Considerações finais}

As infra-estruturas descritas neste capítulo oferecem, de modo geral, serviços de distribuição, armazenamento persistente, privacidade e segurança, inferência de contexto e mecanismos de descoberta de recursos. No entanto, elas não exploram a Web como plataforma de intercâmbio de informações de contexto. A adoção de represen-

\footnotetext{
${ }^{1}$ Entrada e saída estruturada.
} 
tações proprietárias e programáticas dificultam compartilhar e reusar contextos, enquanto que com o uso de padrões e protocolos abertos, como proposto pelos Serviços Web, promovem a interação entre aplicações e serviços.

Umas das características de ambientes de computação ubíqua é a heterogeneidade de tecnologias utilizadas, principalmente de software. Tecnologias diferentes implicam na dificultade de integrar essas infra-estruturas com outros serviços e aplicações, enquanto a uniformidade na representação, fraco acoplamento e contrato de serviço de Serviços Web são características úteis em tais ambientes.

As infra-estruturas descritas foram utilizadas na construção de aplicações cientes de contexto em vários cenários. A maioria delas foi construída para avaliar os benefícios das infra-estruturas. No Capítulo 6 é detalhada a integração de aplicações utilizando o Context Kernel em um cenário de trabalho colaborativo e um de aprendizado eletrônico e as lições aprendidas na utilização de Serviços Web em aplicações cientes de contexto. 


\section{Serviços Web em Computação Ciente de Contexto}

uas das principais características de ambientes de computação ubíqua são a heterogeneidade de tecnologias de software e hardware e a diversidade de aplicações. Para a concepção desses ambientes, espera-se que aplicações possam trabalhar colaborativamente com o objetivo de fornecer serviços mais úteis. Neste capítulo estão descritos os trabalhos de integração de aplicações utilizando o Serviço Web Context Kernel, incluindo as especificações das informações de contexto que foram utilizadas. Como resultado dos trabalhos de integração, é apresentado um conjunto de lições aprendidas ao se utilizar a abordagem dos Serviços Web em aplicações cientes de contexto.

\subsection{O Context Kernel em uso por aplicações CSCW}

Nesta seção é ilustrada como aplicações CSCW podem se beneficiar do fraco acoplamento fornecido pelos Serviços Web. Nesse trabalho foi utilizado um conjunto de aplicações que exploram informações de usuários e grupos armazenadas por uma das aplicações no Context Kernel. Para cada aplicação, há uma breve apresentação e os detalhes de uso do Context Kernel. O desenvolvimento de algumas aplicações e o processo de integração - que inclui a modelagem de informações de contexto - foi realizado juntamente com os autores dos artigos nos quais foi reportado o trabalho realizado e os resultados obtidos: 
- Bulcão Neto, R. F., Jardim, C. H. O., Camacho-Guerrero, J. A., and Pimentel, M. G. C. (2004). A Web Service Approach for Providing Context Information to CSCW Applications. In Proceedings of 2nd IW3C2 Latin American Web Congress, pages 78-85, Ribeirão Preto, Brasil. IEEE Computer Society Press.

- Bulcão Neto, R. F., Jardim, C. H. O., Camacho-Guerrero, J. A., Lobato, D. C., and Pimentel, M. G. C. (2004). A Context-based Web Service Approach to Communities of Practice. XXXI Seminário Integrado de Software e Hardware, SEMISH. 15 pages.

\subsubsection{Aplicação WebLogin}

A aplicação WebLogin (Figura 6.1(a)], é uma aplicação usada como ponto de entrada para outras aplicações no ambiente CSCW. Ao iniciar uma aplicação no ambiente, o usuário é direcionado para a aplicação WebLogin de modo que ele possa ser autenticado no ambiente.

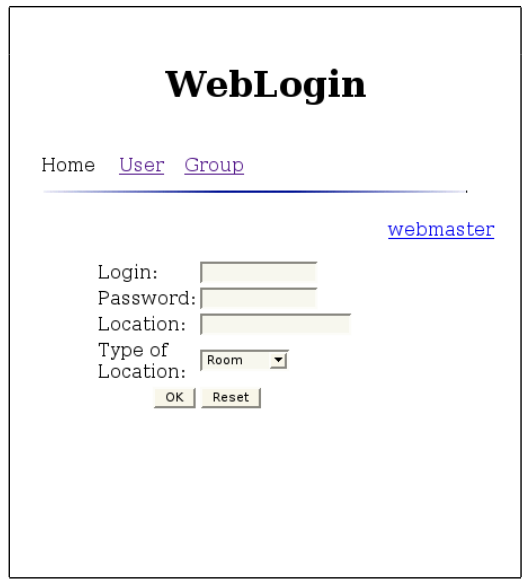

(a)



(b)

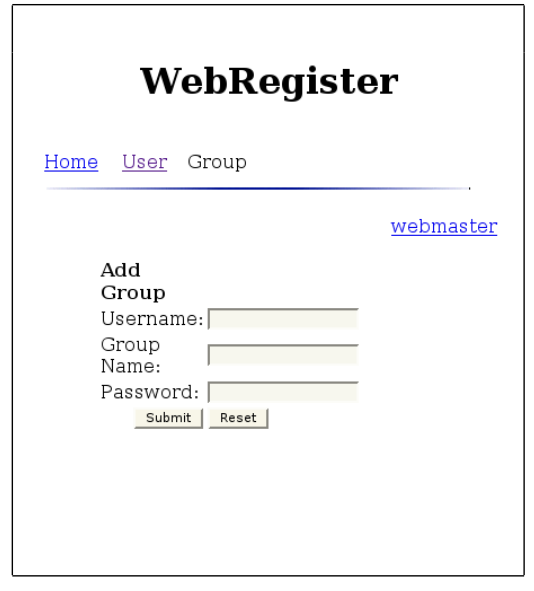

(c)

Figura 6.1: Aplicações WebLogin e WebRegister: (a) A informação do usuário será verificada com a registrada no Context Kernel; (b) ao se adicionar um novo usuário, deve-se fornecer informações de contexto de localização para o Context Kernel; (c) interface para registro de grupos.

Para utilizar o Context Kernel (daqui em diante referenciado como CK), a aplicação WebLogin se registra com o serviço, invocando a operação InfoApp e obtém seus identificadores público e privado. Em futuras interações, o WebLogin fornece um desses identificadores para se comunicar com o CK. No seguinte trecho XML (Exemplo 1), a aplicação WebLogin registra seus metadados no CK utilizando a operação InfoApp. 




Quando um usuário tenta se autenticar na aplicação WebLogin, é necessário verificar se o usuário já foi registrado na base de dados do CK por outra aplicação. Para recuperar informações de contexto de outras aplicações é necessário obter seus identificadores públicos. Neste caso, as informações sobre usuários e grupos são armazenadas pela aplicação WebRegister (descrita a seguir). A WebLogin precisa invocar a operação STATUSAPPS para obter o identificador público da aplicação WebRegister. De forma similar, todas as aplicações com intenção de consultar informações de usuários e grupos devem incluir o identificador público da aplicação WebRegister.

Como decisão de projeto, ficou definido que cada usuário registrado com o CK tem um grupo com seu próprio nome uma vez que o usuário pode trabalhar por ele próprio tanto quanto em grupos. A informação de grupo é armazenada como uma inferência what, enquanto a informação de usuário como premissas who. A aplicação WebLogin invoca a operação GetAny para pesquisar por alguma regra que inclua a inferência what onde o tipo tem o valor "group" e as premissas incluem nome de usário e senha correspondente ao usuário atual. Se há um grupo para o usuário, implica que ele está registrado e pode ser autenticado. O trecho do Exemplo 2, a seguir, descreve um usuário send autenticado na aplicação WebLogin. Durante o registro, cada usuário é associado a seu próprio grupo, como discutido a seguir.

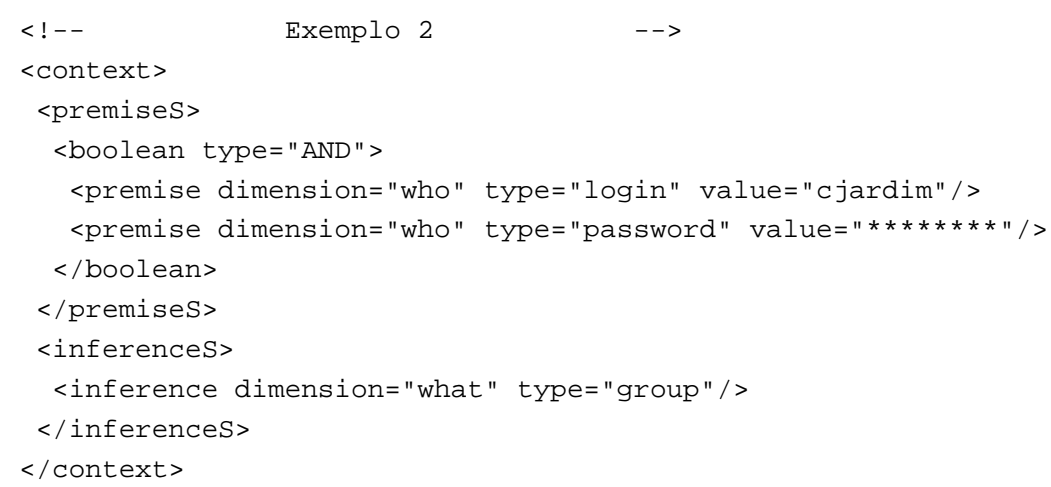




\subsubsection{Aplicação WebRegister}

A aplicação WebRegister é uma aplicação desenvolvida para gerenciar informações de usuários (Figura 6.1(b)) e grupos (Figura 6.1(c)). De acordo com o exemplo anterior, a aplicação WebLogin recebe uma mensagem que, ao ser analisada, indica se um dado usuário já existe ou não. Se for um novo usário, a WebRegister é iniciada pela WebLogin. A WebRegister fornece a informação sobre o novo usuário como parâmetro de entrada para invocar a operação PutRules. As premissas correspondentes ao novo usuário são então registradas no CK bem como as inferências correspondendo ao seu próprio grupo, como ilustrado no Exemplo 3.

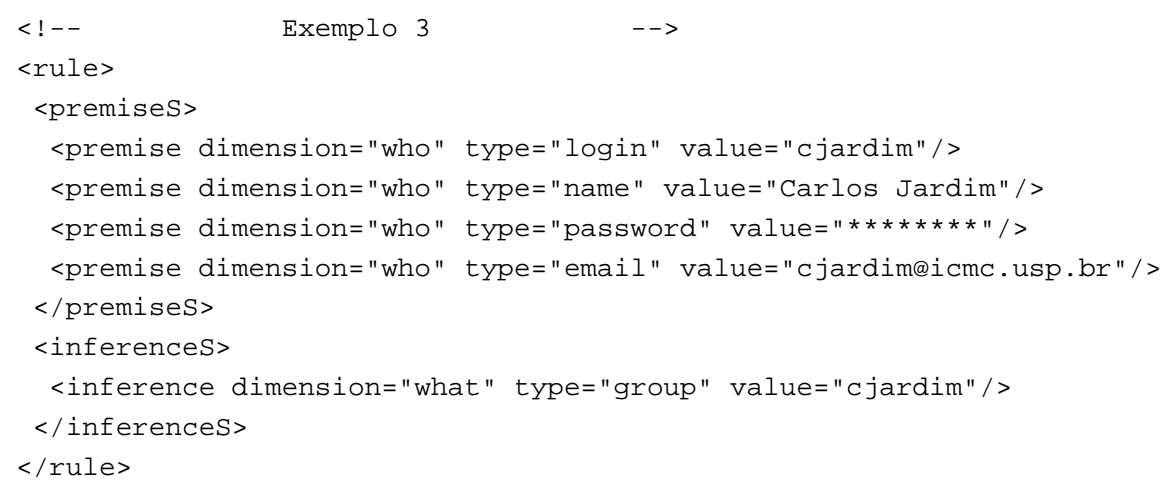

Se um usuário quiser criar um grupo (Figura 6.1(c)] - ou ser incluído em um grupo já existente - a WebRegister precisa verificar se o usuário e o grupo já foram registrados no CK. Para isso, a WebRegister invoca a operação Getlnverse de modo que o CK verifica a existência de alguma inferência what onde o tipo é "group" e o valor é igual ao nome do grupo dado como parâmetro de entrada (exemplo "intermidia"). O seguinte fragmento XML (Exemplo 4) ilustra essa situação.



Se o grupo não existe, a WebRegister invoca a operação PutRules com os seguintes parâmetros de entrada: seu identificador privado, uma tripla correspondente a premissa e a inferência what para grupos. Por exemplo, a premissa (dimension = "who", type $=$ "login", value $=$ "cjardim") e a inferência (dimension = "what", type = "group", value $=$ "intermidia") - como detalhado no seguinte trecho XML do Exemplo 5.

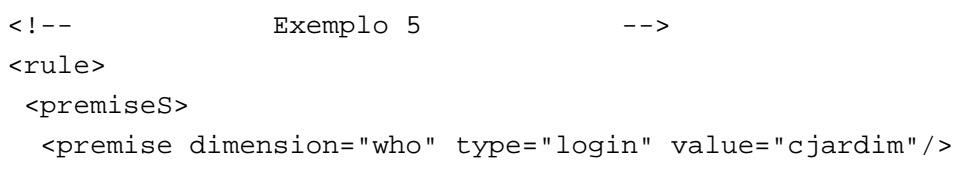




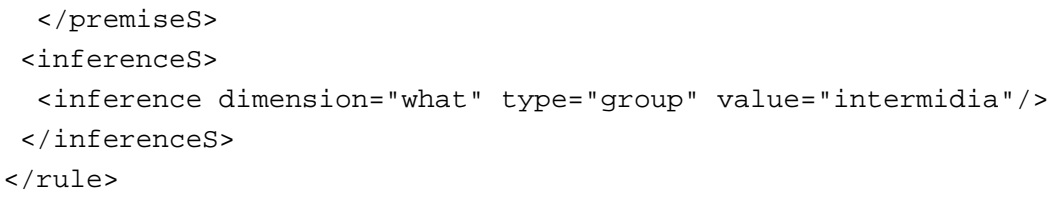

Dessa maneira, o nome cujo valor é "cjardim" pertence a dois grupos: ao seu próprio grupo e ao grupo "intermidia”. No caso das aplicações ilustradas nesta seção, informações de usuário e grupo são o núcleo da comunicação entre o CK e as aplicações integradas tais como o WebMemex e o WebChat, conforme detalhado a seguir.

\subsubsection{A aplicação WebMemex}

Vários sistemas de recomendação para a Web têm sido propostos na literatura, sendo muitos aqueles nos quais membros de um grupo são estimulados a recomendar uns aos outros referências apropriadas. Ribak et al. [2002] construíram e avaliaram o ReachOut [Ribak et al., 2002], um sistema que apóia usuários em grupos de interesse para explicitamente recomendar conhecimento a outros membros do grupo. Em outra abordagem, McNee et al. 2002] utilizam a rede de referências na pesquisa de artigos para apoiar a construção de sistemas para recomendar citações e artigos de pesquisa - neste caso o grupo é formado pelo correspondente conjunto de autores dos artigos.

O WebMemex |Macedo et al., 2003] é uma aplicação que recomenda páginas Web relacionadas àquela que o usuário está visitando no momento. Ela foi desenvolvida sobre uma aquitetura de alto nível que fornece autenticação de usuário, captura de navegação, identificação de relacionamentos, armazenamento, recuperação e capacidade de acesso. A aplicação WebMemex captura e recomenda páginas Web para grupos de usuários por meio do seu próprio servidor proxy Web. De modo a identificar usuários e membros de grupos, o nagevador Web estabelece uma conexão com o servidor de proxy Web para cada requisição HTTP. A inteface de usuário do WebMemex é apresentada na Figura 6.2.

Quando um usuário tenta se autenticar no WebMemex por meio da aplicação WebLogin, é necessário verificar se o usuário atual já foi registrado na base de dados do CK. O WebMemex pode ser informado assim que um usuário registrado fica online, recebendo essa demanda pela operação de notificação Context Daemon. Quando o WebMemex foi registrado usando o InfoApp, informou o seu endereço de callback para permitir notificações. Isso significa que o CK tentará validar as regras do WebMemex que foram registradas toda vez que houver uma atualização da informação relacionada no CK e realizar a notificação se necessário. O Exemplo 6 ilustra que o WebMemex precisa ser notificado quando o usuário "cjardim" tornar-se ativo após sua autenticação no WebLogin. 


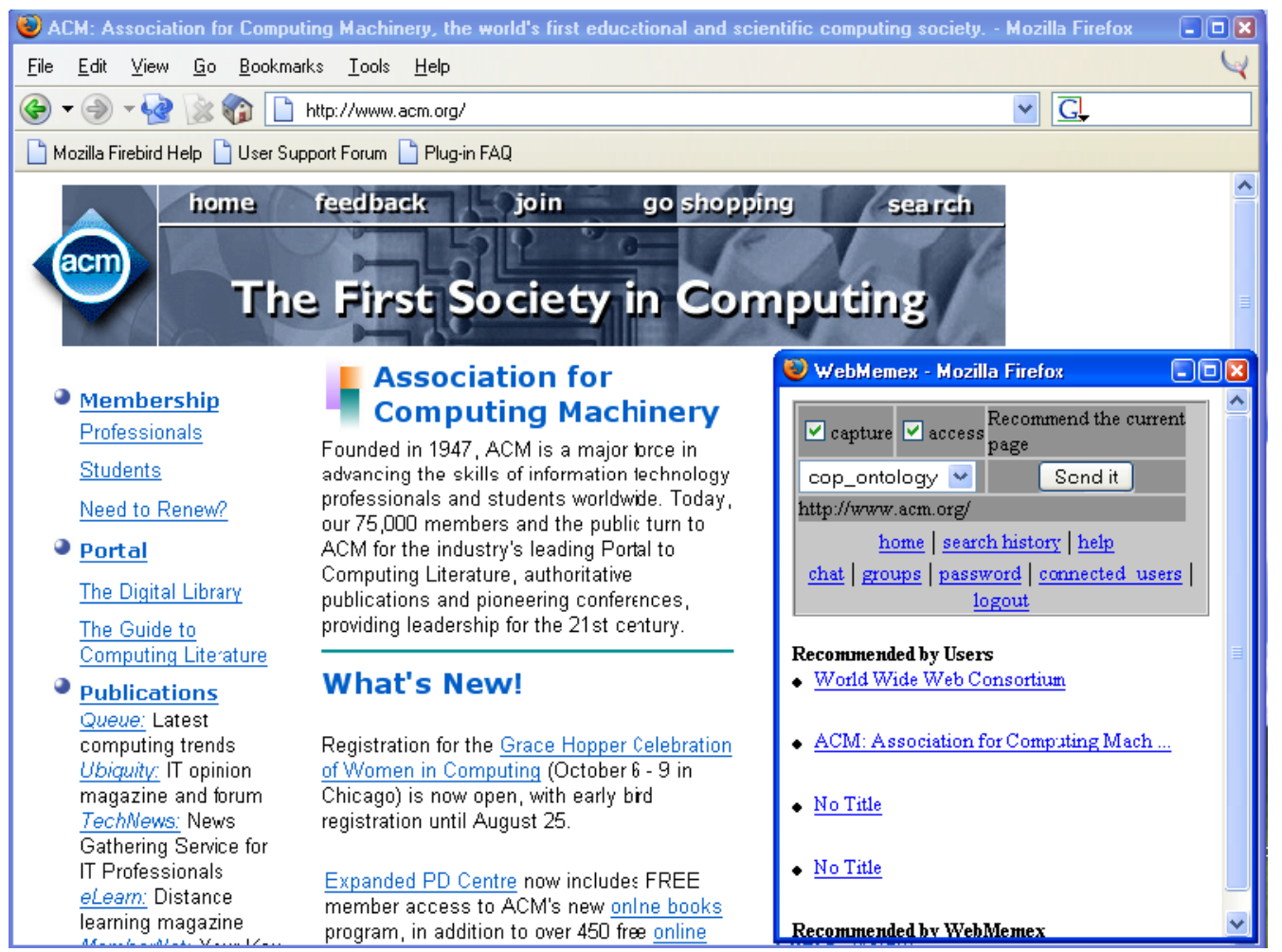

Figura 6.2: A interface do WebMemex (tela no canto inferior direito).

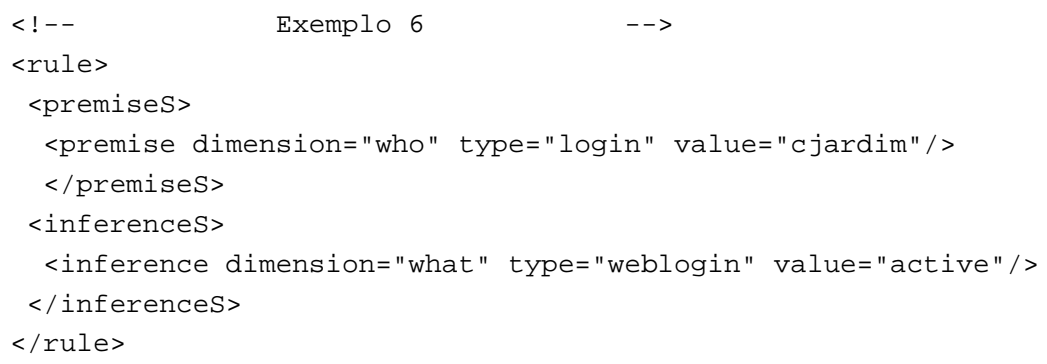

Quando um usuário se registra no WebLogin, a aplicação invoca a operação PutData para armazenar que o usuário "cjardim" está ativo (trecho do Exemplo 7). O Context Daemon valida essas informações de contexto contra as regras armazenadas no CK. Assim, a aplicação WebMemex que registra as regras será notificada de que o usuário já está ativo.

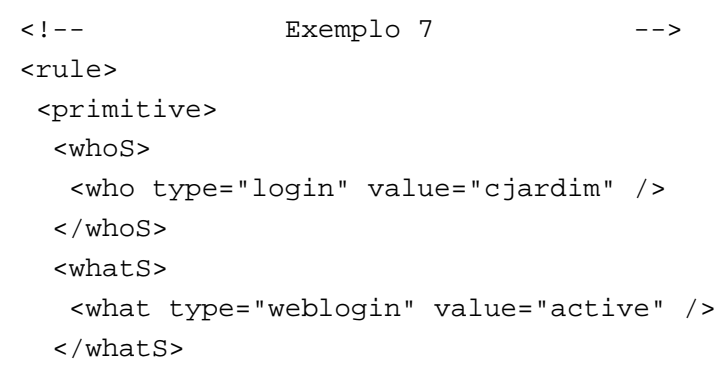


$</$ primitive $>$

$</$ rule $>$

Ao usar o WebMemex, um usuário precisa estar ciente do conjunto de grupos, o que permite a ele recomendar páginas para um grupo ou trocar de grupos. Sabendo quem o usuário é, o WebMemex invoca a operação GetAny, que por sua vez pesquisa por todas (last value = "ALL") as inferências what com o tipo "group" e a premissa com informação que coincide com o nome de usuário. No Exemplo 8, a tripla (dimension = "who", type = "login", value = "cjardim") representa essa premissa, enquanto (dimension $=$ "what", type = "group") descreve o grupo. O Exemplo 8 mostra a mensagem da requisição correspondente a operação GetAny.

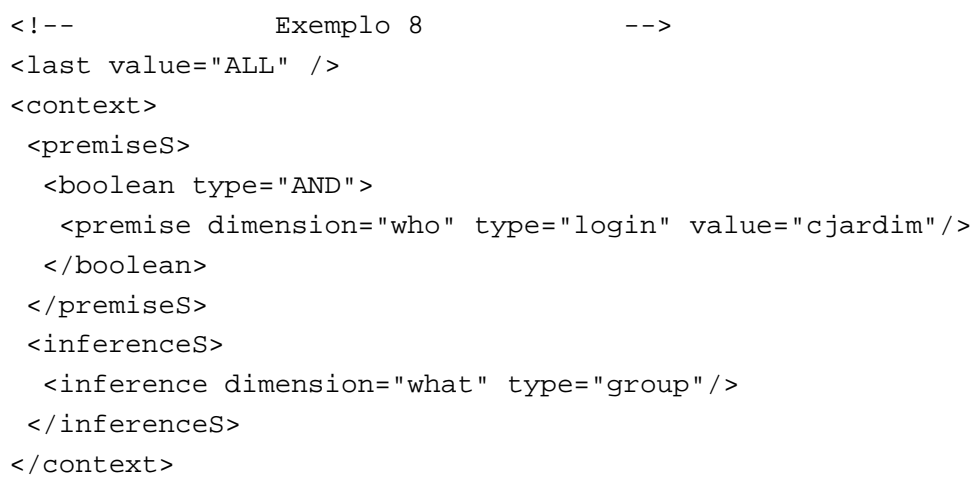

Com a lista de todos os usuários que fazem parte de um grupo, a aplicação WebMemex oferece a oportunidade para o usuário entrar em uma sessão de chat com os demais usuários do grupo que estiverem online. O usuário pode ativar o WebChat (descrito a seguir) para abrir uma sessão de chat com estes usuários.

\subsubsection{A aplicação WebChat}

Para ilustrar a comunicação entre os usuários de um grupo foi utilizada a aplicação WebChat, que é um sistema de chat para Web. Um cenário típico é um usuário iniciando uma sessão de chat com os membros de um dos grupos a que ele pertence - aqueles que estão online. Por exemplo, se um usuário recomenda uma página Web para um amigo usando a aplicação WebMemex, é possivel que eles queiram conversar sobre ela (Figura 6.3). O WebChat invoca a operação Getlnverse, que pesquisa por todas as premissas que tenham a inferência what com o tipo "group" e o valor igual ao nome de cada grupo do qual o usuário é membro. O seguinte fragmento XML (Exemplo 9) ilustra essa situação.

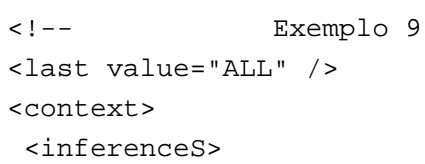




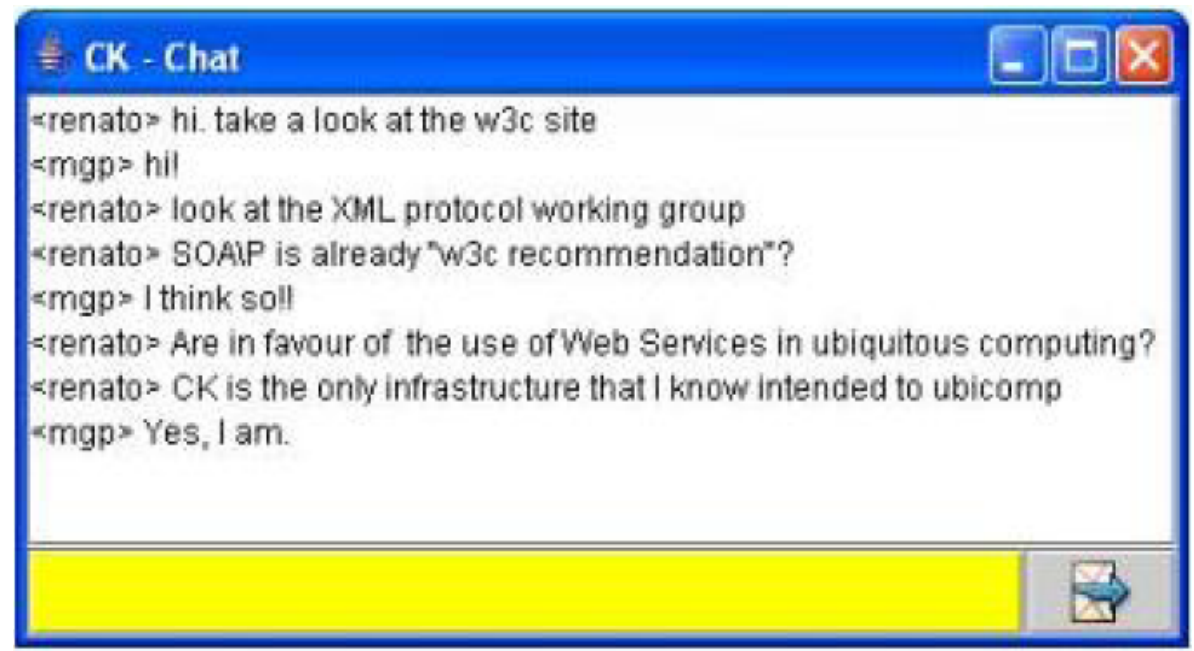

Figura 6.3: A interface do WebChat.



Neste caso, o Context Kernel devolve as seguintes triplas: (dimension = "who", type $=$ "login", value $=$ "cjardim"), (dimension = "who", type $=$ "login", value $=$ "rbulcao") $\mathrm{e}$ (dimension $=$ "who", type = "login", value = "jcamacho"), isto é, usuários "cjardim", "rbulcao" e "jcamacho" pertencem ao grupo "intermidia". O WebChat também fornece opções para um usuário criar uma sessão de chat com todos os usuários do seu grupo ou com usuários específicos que estão online.

\subsubsection{Discussão sobre a integração}

O trabalho de integração das ferramentas foi realizado em conjunto com os demais autores dos artigos citados no começo desta seção. As aplicações WebMemex e WebChat utilizadas são modificações das aplicações WebMemex |Macedo et al., 2003| e Chat Server [Cattelan, 2001]. As aplicações WebLogin e WebRegister foram desenvolvidas para o ambiente CSCW criado. Nas sub-seções anteriores foi descrito o trabalho reportado em ambos os artigos, mas eles diferem principalmente na abordagem de explorar os grupos. No artigo publicado no SEMISH 2004, foi explorado o conceito de comunidades de práticas em conjunto com informação de localização para criação de grupos. Os grupos são criados como comunidades de práticas ao reunir grupos não estruturados de pessoas com interesse em comum.

A versão original da aplicação WebMemex manipula usuários autenticados pelo serviço "Yahoo! Messenger" |Macedo et al., 2003|. Quando os usuários iniciavam 
o uso do WebMemex, o serviço "Yahoo! Messenger" era invocado para autenticar o usuário e fornecer suas listas de contatos. A aplicação foi modificada para utilizar os usuários de grupos registrados no CK. As informações de usuários e grupos representada como informações de contexto são compartilhadas no ambiente e promovem a interoperabilidade entre aplicações que não foram inicialmente desenvolvidas para trabalhar em conjunto. As aplicações podem compartilhar informação de contexto, promovendo a ciência de grupo. A interoperabilidade é beneficiada pelo uso de protocolos padronizados tanto para a invocação das operações, quanto para a modelagem e o intercâmbio de informações de contexto.

Durante o desenvolvimento desse cenário foi necessário estender o CK com a operação Getlnverse. Com essa operação houve a possibilidade de recuperar informações de contexto utilizando uma inferência para obter as correspondentes premissas. O Exemplo 9 ilustra a utilização dessa operação e recupera os usuários de um grupo. O desenvolvimento da operação Getlnverse permite observar o benefício da flexibilidade conseguida ao se utilizar Serviços Web. Uma mudança de requisito na infra-estrutura CK foi facilmente exposta no contrato de serviço, sem afetar o uso das demais operações. Mesmo a mudança ocorrida na operação PutRules para inclusão do atributo notify a uma regra de contexto - que define se a regra será validada (ver Sub-seção 4.3.5 - não causou problema, pois a interface de serviços não é alterada mas sim somente o modelo das informações de contexto utilizado. Esse é um benefício em se utilizar estilo de interface orientado a documentos.

\subsection{O Context Kernel em uso por aplicações de aprendizado eletrônico}

Nesta sessão, são descritas três aplicações de aprendizado eletrônico, iClass |Cattelan et al., 2003c;a|b], AutorE [Sante et al., 2004; Pimentel et al., 2003], e CoWeb |Pimentel et al., 2001| e como elas foram integradas utilizando o Context Kernel. Embora essas aplicações tenham sido desenvolvidas no mesmo grupo de pesquisa, elas tiveram desenvolvedores independentes associados a projetos diferentes. A primeira implementação da CoWeb foi obtida em 2001, do iClass em 2002 e do AutorE foi em 2003. O trabalho de integração, os resultados obtidos e lições aprendidas foram reportados nos artigos:

- Jardim, C. H. O., Neto, R. F. B., Godoy, R. P., Ribas, H. M. B., Arruda Jr., C. R. E., Munson, E. V., and Pimentel, M. G. C. (2005). Web Services Enabling Ubiquitous Computing Applications: Lessons Learned by Integrating Ubiquitous e-Learning Applications. International Journal of Web Services Practices, 1(12):142-152. ISSN: 1738-6535. 
- Jardim, C. H. O., Bulcão Neto, R. F., Ribas, H. M. B., Munson, E. V., and Pimentel, M. G. C. (2005). Web Services Enabling Context-aware Applications: Lessons Learned by Integrating e-Learning Applications. In International Conference on Next Generation Web Services Practices, pages 400-405, Seoul, Korea. IEEE Computer Society Press. ISBN: 0-7695-2452-4.

- Macedo, A. A., Bulcão Neto, R. F., Camacho-Guerrero, J. A., Jardim, C. H. O., Cattelan, R. G., Inácio Jr, V. R., and Pimentel, M. G. C. (2005). Linking everyday presentations through context information. In 3rd IW3C2 Latin American Web Conference, pages 130-139, Buenos Aires, Argentina. IEEE Computer Society Press.

\subsection{1 iClass}

O iClass [Cattelan et al., 2003c] é um exemplo de aplicação no domínio de aprendizado eletrônico e é uma evolução do eClass |Abowd, 1999|. O iClass é uma aplicação de computação ubíqua construída sobre uma infra-estrutura de software que apóia o desenvolvimento de aplicações de captura e acesso [Cattelan, 2004; Baldochi Jr et al., 2004|. Usualmente o iClass é utilizado durante sessões de aula para: gravar informações capturadas em uma aula ao vivo e automaticamente gerar documentos Web multimídia para revisão posterior.

O iClass tem componentes para capturar áudio, vídeo, navegação Web e anotações baseadas em caneta em uma lousa eletrônica. A Figura 6.4(a) ilustra um instrutor usando o iClass para anotar sobre um conjunto de slides preparados antes da aula. Todas as informaçõe capturadas são usadas para produzir automaticamente documentos multimídia para a Web, que podem ser revisados após a aula. A Figura 6.4(b) mostra um documento HTML contendo todos os slides apresentados ou anotados em uma aula. Uma versão multimídia é apresentada na Figura 6.4(c), na qual a tinta eletrônica é reproduzida sincronamente com o áudio capturado.

Uma visão detalhada do componente para captura de anotação em tinta eletrônica é apresentada na Figura 6.5. A figura mostra a interface do iClass com uma barra de ferramentas para navegação e criação de slides, e com ferramentas de desenho. Neste caso o slide está associado a uma imagem de fundo preparada antes da aula e que foi enviado para o servidor durante a criação da aula. O iClass é usado em aulas ao vivo e demanda a preparação da sessão com informações sobre o instrutor, o curso e da própria aula. Estas informações podem ser fornecidas pela aplicação AutorE antes da captura ao vivo, como detalhado a seguir. 


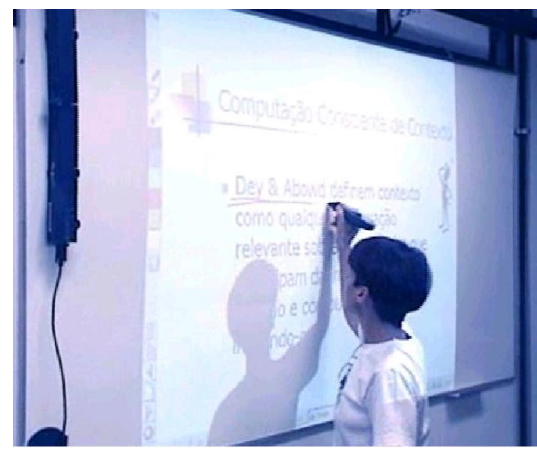

(a)

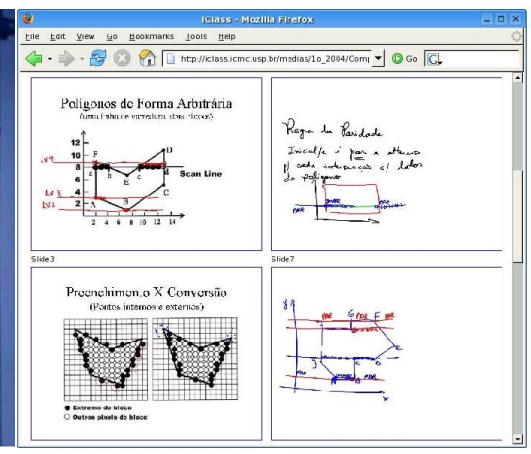

(b)

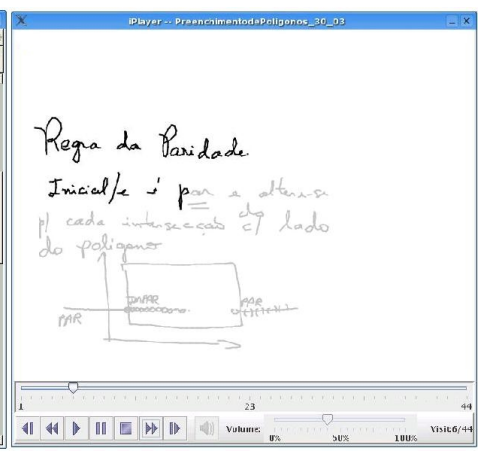

(c)

Figura 6.4: Aplicação iClass: (a) um instrutor usando o iClass para anotar sobre slides previamente preparados; (b) um documento HTML contento todos os slides apresentados e/ou anotados em uma aula; (c) tinta eletrônica sendo reproduzida sincronamente com o áudio capturado.

\subsubsection{AutorE}

Para usar o AutorE [Sante et al., 2004; Pimentel et al., 2003], o instrutor se autentica com o sistema e tem como resultado a lista de todos os cursos associados com o instrutor. O AutorE é utilizado pelos instrutores antes da aula com o intuito de prepará-la para a captura. Para preparar a aula, o instrutor seleciona um curso e cria uma nova aula fornecendo o título e outras informações opcionais tais como uma descrição da aula e um arquivo com os slides preparados para serem utilizados na aula ao vivo, como ilustrado na Figura 6.6. Uma vez que a preparação da sessão demanda somente acesso Web, isso pode ser feito pelo instrutor fora da sala de aula em qualquer momento antes da sessão começar. Quando a aula está para iniciar, o instrutor, na sala de aula, se autentica com o AutorE e ativa o iClass para iniciar a aula preparada. O AutorE direciona as informações para a aplicação alvo, por exemplo aulas preparadas para o iClass, mas não fornece uma interface de software para as aplicações acessarem sua base de dados.

\subsubsection{CoWeb}

Independente do iClass e do AutorE, a CoWeb [Pimentel et al., 2001] é um sistema baseado na autoria colaborativa de documentos em formulários Web, no qual instrutores e estudantes compartilham informações (por exemplo, documentação de projetos e critérios de avaliação). A Figura 6.7 ilustra uma página Web gerenciada pela $\mathrm{CoWeb}$. Qualquer um pode selecionar a opção de edição no topo da página para editar seu conteúdo. Embora a CoWeb e o iClass possam ser usados para apoiar o mesmo curso, eles não estão integrados. É importante mencionar que o AutorE e o 


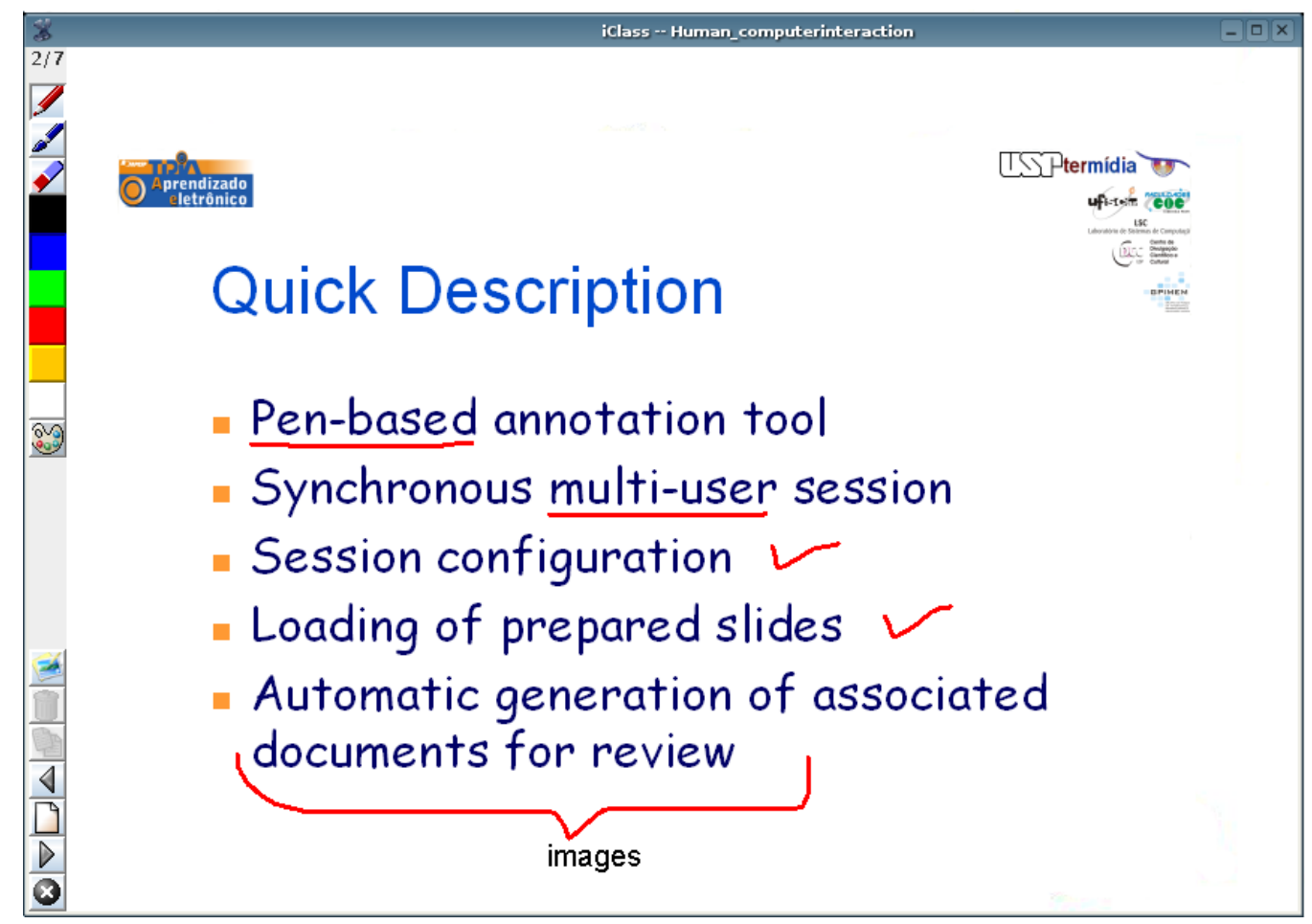

Figura 6.5: Exemplo de um slide sendo anotado durante uma aula com o iClass.

iClass usam linguagens de programação e tecnologias de banco de dados distintas das utilizadas pela CoWeb: o AutorE e o iClass utilizam Java ${ }^{T M}$ e um banco de dados XML, enquanto a CoWeb utiliza PHP e um banco de dados SQL. Além disso, iClass e AutorE usam modelos de dados distintos e complementares. Ao utilizar-se o Serviço Web Context Kernel, a CoWeb, o iClass e o AutorE podem trocar informações de contexto de forma padronizada e independente de suas infra-estruturas subjacentes.

A integração das três aplicações por meio do Serviço Web Context Kernel permite: (a) o registro de cursos e a preparação de aulas usando informações de contexto; (b) a captura de aulas usando informações de contexto; (c) a integração das informações preparadas antes da aula com informações capturadas durante a aula e as informações criadas após a aula - antes, durante e após usando uma CoWeb associada ao curso.

\subsubsection{Integrando aplicações de aprendizado eletrônico}

Uma vez que cada aplicação tem seu próprio modelo de dados, os quais foram criados independente de informações de contexto, a integração das aplicações por meio do CK tem duas motivações:

- permitir o intercâmbio de informações de contexto relevante para o domínio de aprendizado eletrônico sem explicitamente fazer chamadas de uma aplicação 


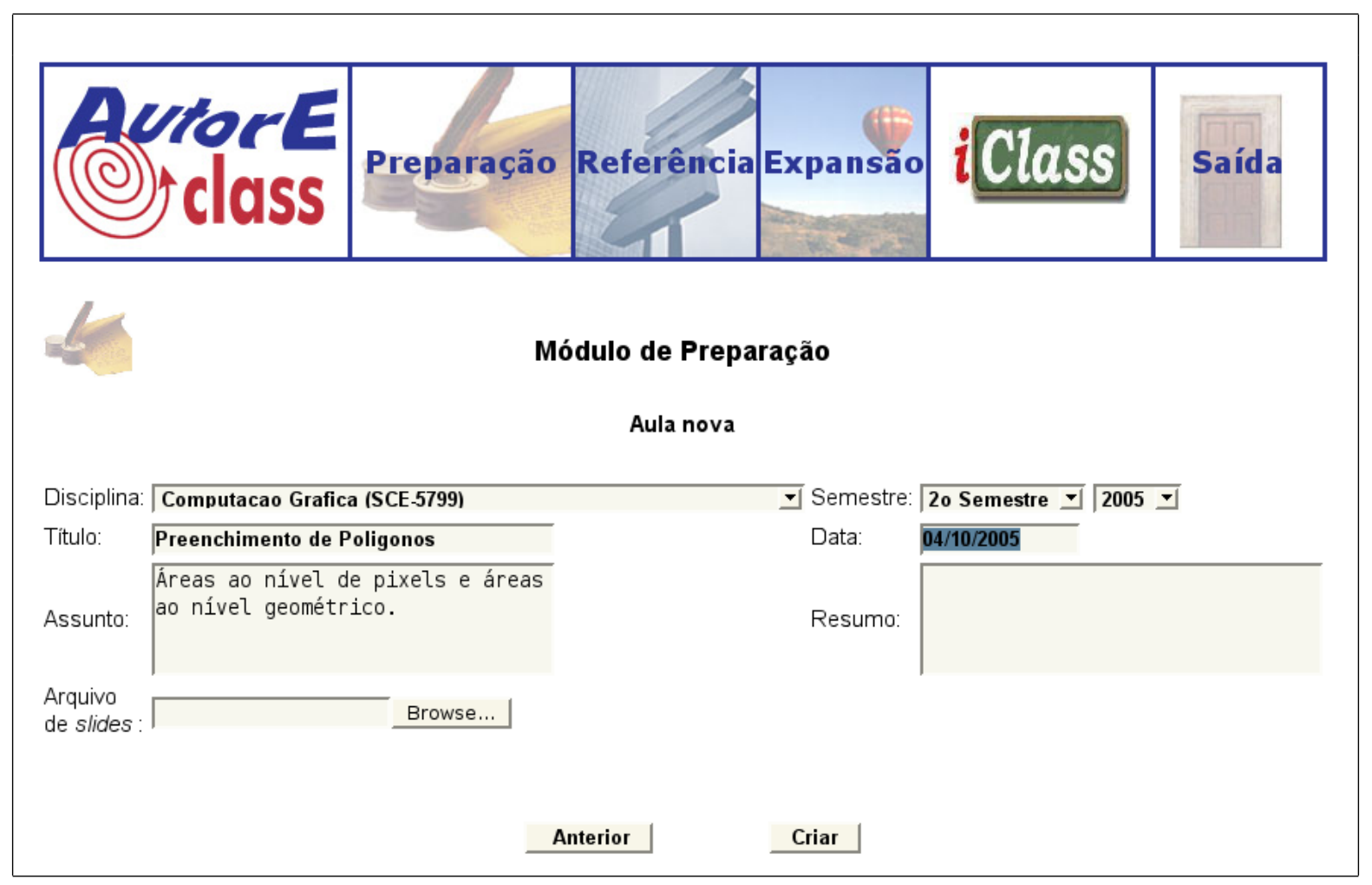

Figura 6.6: Exemplo de uma aula sobre Computação Gráfica sendo criada usando o AutorE.

para outra - por exemplo permitindo que uma página da CoWeb seja atualizada com informações de uma aula recentemente capturada no iClass;

- melhorar cada aplicação ao explorar informações de contexto - por exemplo permitindo que o módulo responsável por iniciar uma aula utilize informações de contexto tais como onde a aula está para ocorrer e quando está sendo iniciada.

Há um ponto importante a ser destacado aqui: a integração das três aplicações exemplifica como aplicações podem tornar-se cientes de contexto com baixo custo de implementação ao explorar a abordagem de Serviços Web. Nesta seção é discutido como a integração ocorreu.

A Figura 6.8 mostra o fluxo de informação entre o CK e as três aplicações. Os fluxos 1 e 2 indicam que o AutorE registra metadados sobre cursos e aulas, no momento da criação de cursos, tais como quem é o instrutor, quando as aulas ocorrem (como por exemplo, segunda-feira) e onde elas ocorrem (como por exemplo, na sala 3009). Na figura, o fluxo 1, que é bidirecional, indica que o AutorE também consulta metadados de cursos, por exemplo para iniciar uma aula ativando o iClass, considerando a sala de aula (where) e o dia (when). O fluxo 3 indica que a CoWeb consulta metadados de aulas, por exemplo quando há uma demanda para atualizar a lista de aulas (what) 


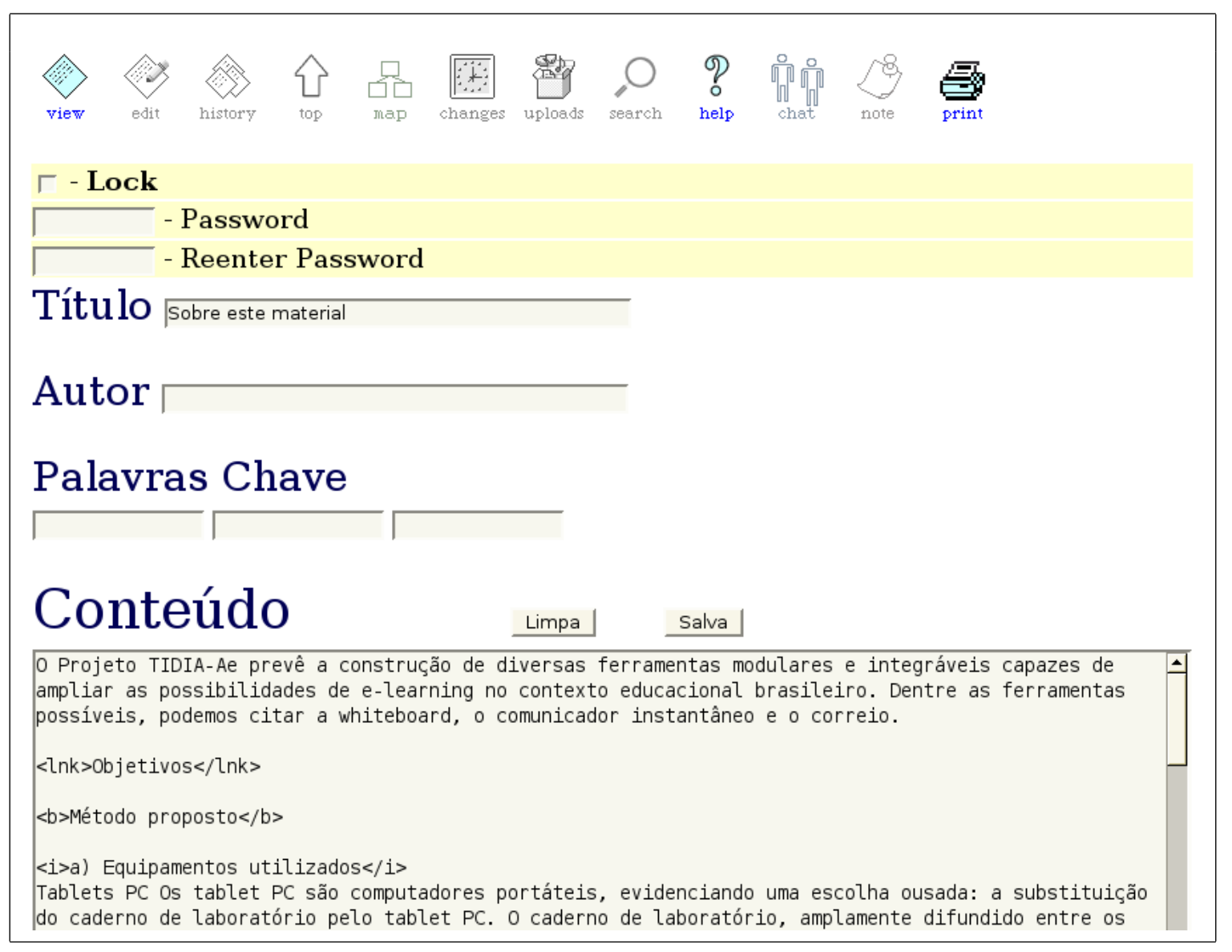

Figura 6.7: Exemplo de uma aula sendo documentada usando a CoWeb.

que foram capturadas por um dado curso por meio do iClass. Os fluxos 4 e 5 indicam que o iClass consulta metadados de cursos e aulas, os quais são necessários para suportar a autoria de objetos de aprendizagem com o conteúdo relativo a quem foi o instrutor, qual curso e qual aula o objeto de aprendizagem corresponde, entre outros.

\section{AutorE: criação de cursos}

No momento da criação do curso, o AutorE usa a operação PutRules para registrar uma regra contendo o login do instrutor, uma identificação da sala de aula, os dias da semana quando as aulas são ministradas, e a URL da página correspondente da CoWeb para o curso. O Exemplo 10 ilustra uma regra descrevendo um curso (what) identificado por SCE-5176, o login do instrutor é "Ethan" (who); as aulas ocorrem toda segunda-feira (when) na sala 3009 (where). O curso tem uma página CoWeb (how) em coweb.icmc.usp.br/sce5176.

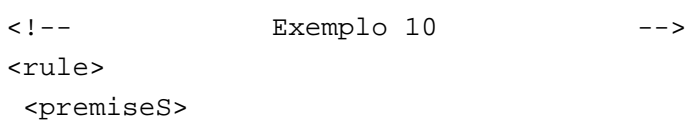






Figura 6.8: Fluxo de informação: AutorE, iClass, CoWeb e o Serviço Web Context Kernel trocando metadados sobre registro e consultas de cursos e aulas.



\section{AutorE: recuperando informações de cursos}

Uma vez que as regras estão registradas para um curso, o AutorE pode invocar a operação GetAny para obter somente os cursos contendo aulas que serão ministradas na sala e no dia atual - isso significa que o instrutor inicia uma aula baseada em informações de contexto daquele momento. O Exemplo 11 descreve como o AutorE consulta todas os cursos (what) contendo aulas a serem capturadas pelo instrutor cujo login é "Ethan" (who) na segunda-feira (when) na sala 3009 (where). O operador booleano AND combinando as premissas é usado para obter a inferência correspondente. Dessa forma, o instrutor não precisa ficar procurando pela aula planejada para aquele dia. O sistema informa o usuário usando informações de contexto. A Figura 6.9 ilustra as informações mostradas para o instrutor ao iniciar o curso planejado.

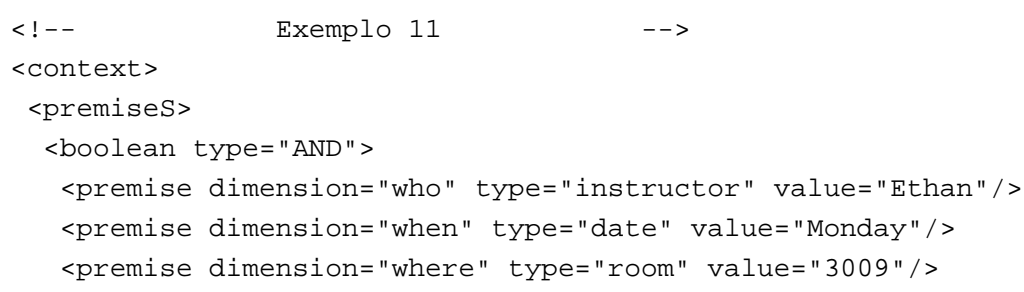



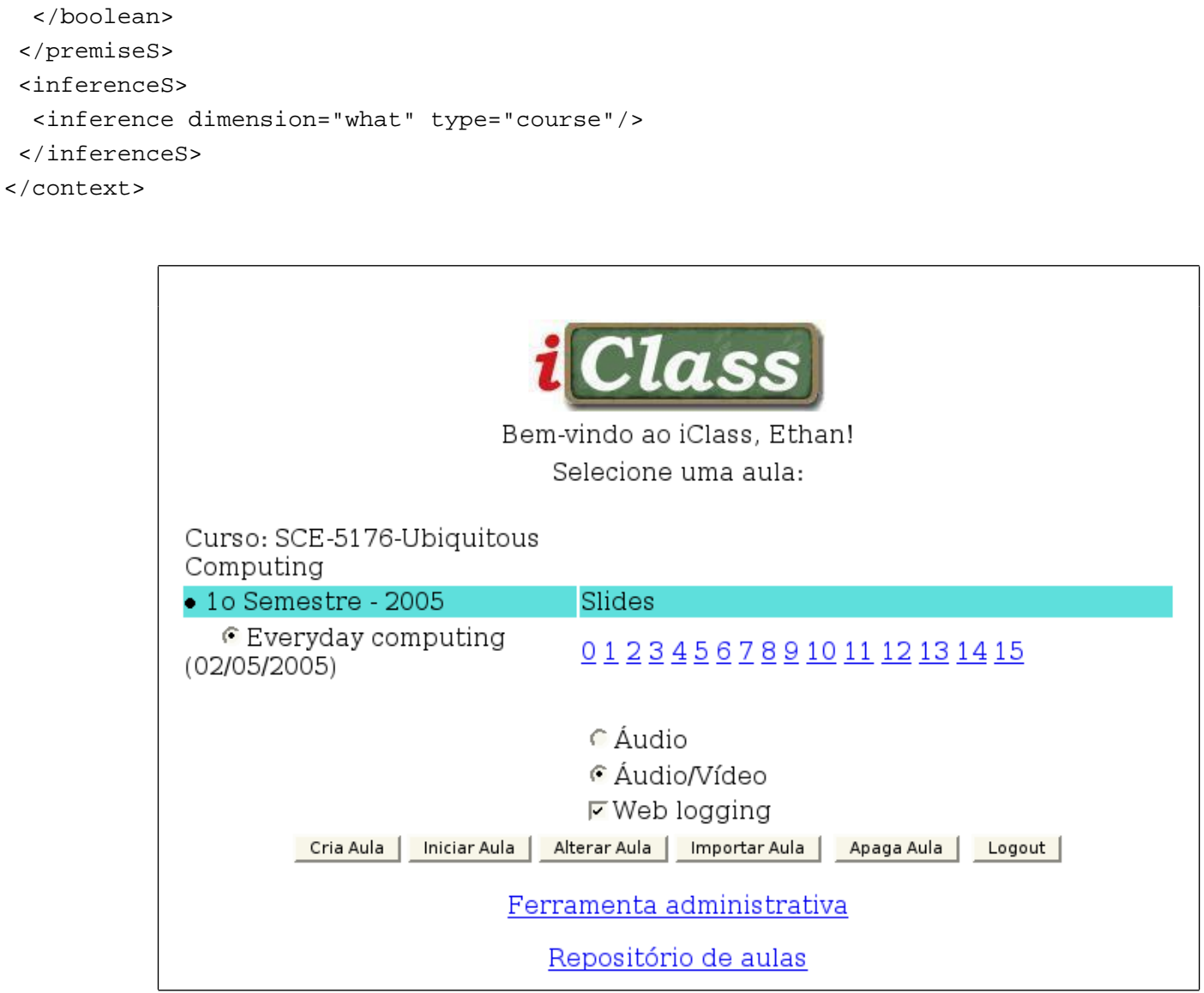

Figura 6.9: As informações consultadas no Exemplo 11 são usadas pelo iClass para iniciar a aula entitulada "Everyday computing" para o curso "Ubiquitous Computing" que é ministrada às segundas-feiras pelo instrutor Ethan.

\section{AutorE: utilizando informações de contexto para iniciar uma aula com o iClass}

Na criação de aula, o AutorE registra no CK (via PutRules): a identificação do curso, o semestre, a data, o título e o assunto da aula. O Exemplo 12 ilustra que a aula sobre "Everyday computing" (what) foi criada para o curso SCE-5176 no primeiro semestre de 2005 (when). No Exemplo 10, o curso foi modelado como uma atividade (what), e as premissas são modeladas como metadados de curso. O Exemplo 12 representa o curso como assunto (who) do contexto que queremos descrever, neste caso, a relação entre aulas e cursos.

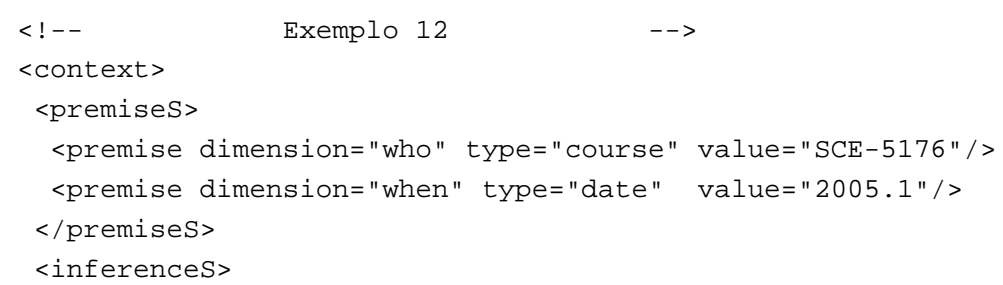




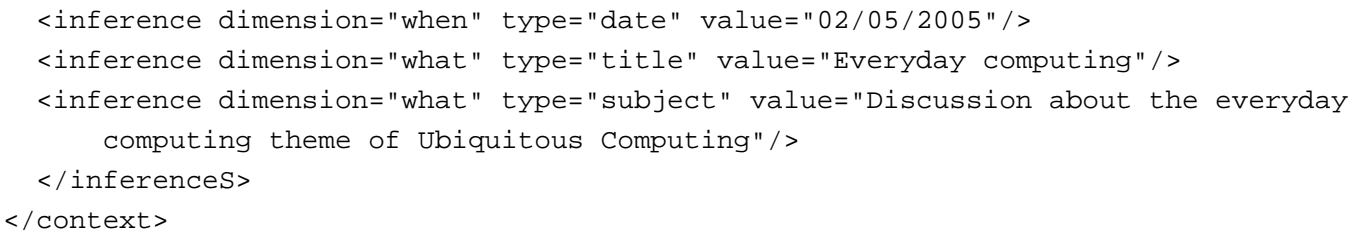

Ao obter informações de contexto do Serviço Web Context Kernel, aplicações podem trocar metadados que podem ser utilizados de várias forma, como ilustrado a seguir.

\section{CoWeb: criando referências para aulas capturadas no iClass}

Considerando o caso onde um curso é suportado tanto pelo iClass quanto pela $\mathrm{CoWeb}$, qualquer referência desse último para um documento gerado pelo primeiro tem que ser editada explicitamente em uma página na CoWeb. Como exemplo de como aplicações podem trocar informações de contexto por meio de um Serviço Web, a seguir é ilustrado como a CoWeb pode obter informações do iClass via CK para atualizar a lista de aulas capturadas.

Usando o identificador público do AutorE obtido via StatusApps, a CoWeb consulta o CK de modo a obter o título, a data e o assunto de uma aula. Essas informações são utilizadas para criar uma lista das aulas para o curso correspondente (veja a Figura 6.10. Este é um exemplo de como aplicações podem trocar informações de contexto relevante por meio de um Serviço Web. O Exemplo 13 ilustra uma mensagem usada pela CoWeb para reunir metadados (via GetAny) de todas as aulas do curso SCE-5176 no primeiro semestre de 2006.

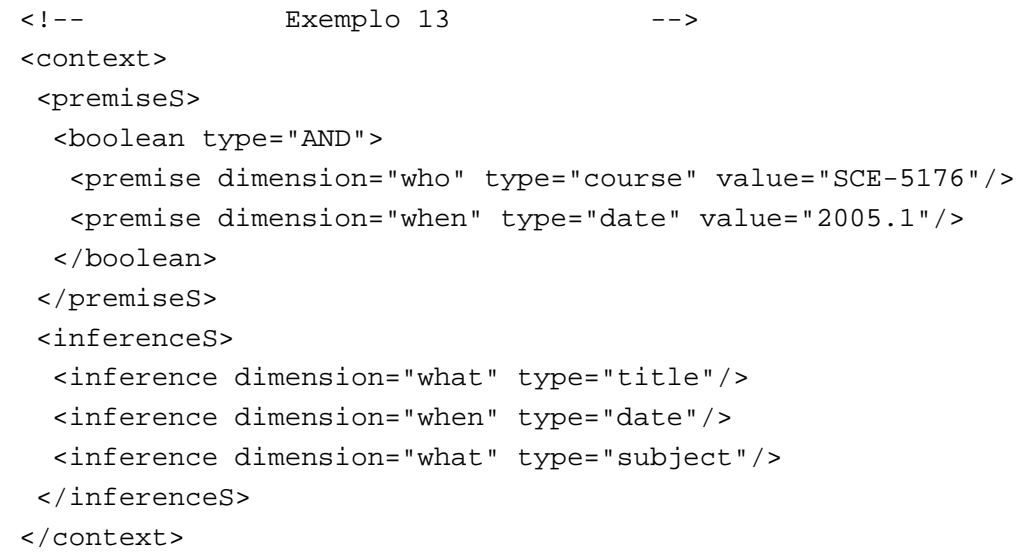

\section{iClass: criando objetos de aprendizagem}

Para ilustrar a praticidade de se compartilhar informações de contexto entre as aplicações iClass, AutorE e CoWeb, a seguir é descrito o uso de informações de contexto armazenadas no CK em objetos de aprendizagem. 


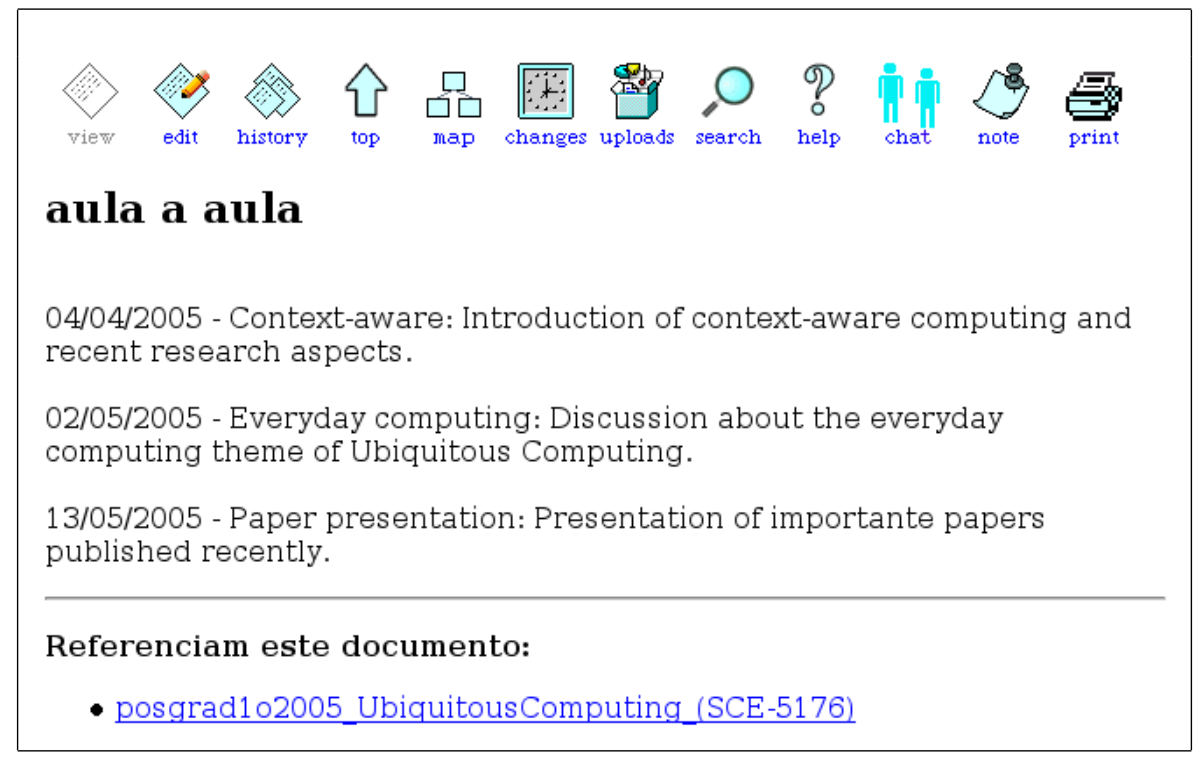

Figura 6.10: Lista de aulas do curso "Ubiquitous Computing" criado na CoWeb consultando o Context Kernel. A lista contém a data, o título e o assunto das aulas capturadas.

Considerando que a autoria de metadados de objetos de aprendizagem é um problema importante na literatura de aprendizado eletrônico Cardinaels et al., 2005; Fait and Hsi, 2005] e considerando que o iClass produz um repositório com conteúdo multimídia associado com uma aula, há uma oportunidade para suportar a produção de objetos de aprendizagem com conteúdos armazenados no iClass e com metadados obtidos do CK.

No trabalho de Ribas [2004, o iClass foi estendido de tal forma que o conteúdo capturado pode ser melhorado com metadados associados com objetos de aprendizagem. O conjunto de elementos SCORM ${ }^{T M}$ Advanced Distributed Learning (ADL), 2004] para os objetos de aprendizagem foi definido no trabalho de Godoy [2005]. Com tal extensão, o iClass apresenta ao usuário interfaces Web para a criação de objetos de aprendizagem descrevendo aulas capturadas (tal como a da Figura 6.11). O processo de criação de objetos de aprendizagem é usualmente uma tarefa difícil dada a grande quantidade de metadados a serem preenchidos.

Tendo o autor desta dissertação definido as mensagens de consulta de informações de contexto a serem utilizadas pelo iClass, Ribas estendeu o seu trabalho, citado no parágrafo anterior, para obter algumas informações para os metadados a serem associados a objetos de aprendizagem. Acessando o CK, o iClass invoca as operações GetAny e Getlnverse para obter metadados sobre aulas e cursos, respectivamente. Uma consulta similar àquela ilustrada no Exemplo 13 é executada para obter informações necessárias para o elemento General (Figura 6.11) - o título e a descrição da aula - que demanda informações para descrever o objeto de aprendizagem como 


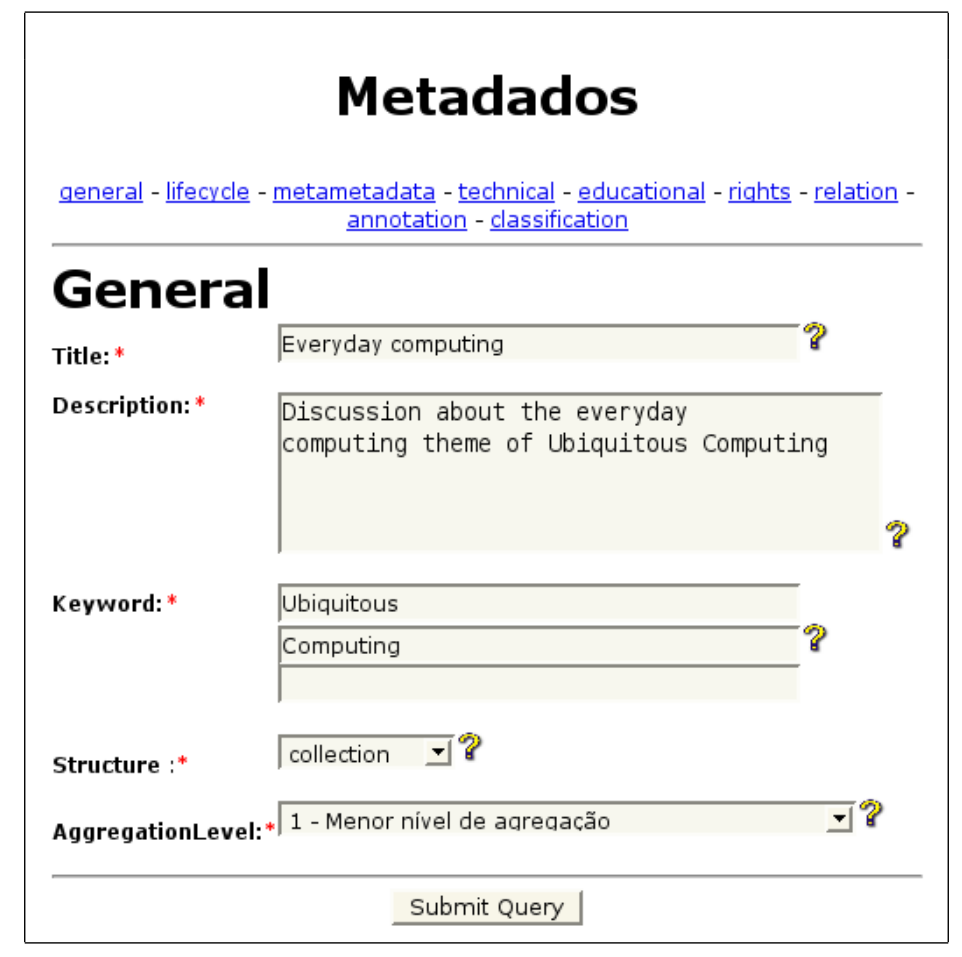

Figura 6.11: Elemento SCORM ${ }^{T M}$ General com informações obtidas do Context Kernel. O iClass invoca as operações GetAny e Getlnverse para obter metadados sobre aulas e cursos, respectivamente.

um todo. O Exemplo 14 ilustra uma consulta (via Getlnverse) para obter o login do instrutor, a identificação da sala/data onde/quando a aula ocorre, e a URL da CoWeb para o curso SCE-5176. Nesse caso, as informações são usadas para preencher o elemento Relation (Figura 6.12), que representa os tipos das relações entre o recurso sendo descrito (por exemplo, os slides capturados durante uma aula) e um outro recurso (por exemplo, uma página da CoWeb relativa ao curso).

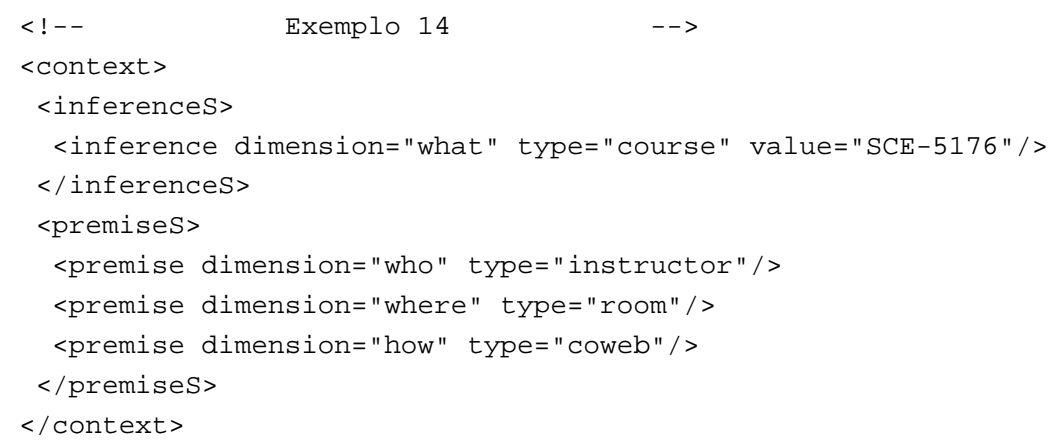

\subsubsection{Discussão sobre a integração}

O trabalho de integração das aplicações AutorE, iClass e CoWeb discutido nas sub-seções anteriores, foi viabilizado devido ao uso dos Serviços Web. Mesmo usando 


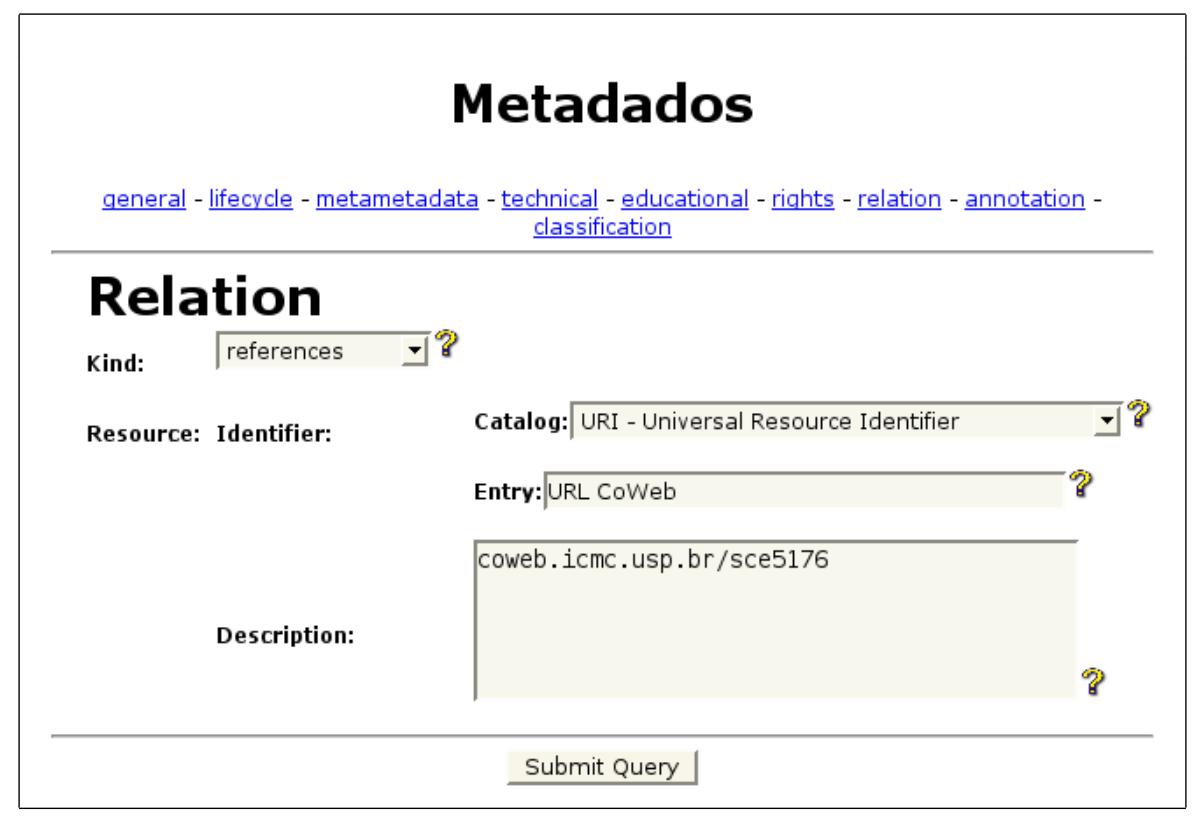

Figura 6.12: Elemento SCORM ${ }^{T M}$ Relation com informações obtidas do Context Kernel. Este elemento representa relações de referência entre os slides capturados durante uma aula e as páginas correspondentes na CoWeb para o curso "Ubiquitous Computing".

diferentes linguagens de programação e modelos de dados, as aplicações puderam trocar informações de contexto via o Serviço Web Context Kernel sem modificações nos modelos de dados das aplicações.

A aplicação AutorE é um exemplo de aplicação que não privilegia a separação entre a lógica de apresentação e a lógica do negócio ao utilizar uma arquitetura em duas camadas: uma camada contém apresentação e lógica de negócio e outra camada contém o modelo de dados, o que torna custosa a evolução da lógica do negócio. Entretanto, utilizar as operações do CK é facilitada devido ao fraco acoplamento dos Serviços Web. A etapa mais importante passa, então, a ser como modelar as informações na representação em dimensões de contexto proposta pelo CK, o que é o mais interessante do ponto de vista da ciência de contexto. Nesse sentido, o estilo de interface orientado a documento adotado pelo Context Kernel facilita o intercâmbio e a representação das informações de contexto, uma vez que permite estruturar e relacionar as dimensões de contexto e seus dados.

A utilização do Serviço Web Context Kernel pelas aplicações AutorE, iClass e CoWeb, ilustra como aplicações podem se tornar cientes de contexto com baixo custo de desenvolvimento. Além disso, a integração realizada ilustra como diferentes softwares podem ser combinados para fornecer um serviço integrado, no caso, para intercâmbio de informações de aprendizado eletrônico, com fraco acoplamento e sem quebra de coesão. Cada aplicação continua com suas responsabilidades - AutorE na prepara- 
ção de aula, iClass na captura e produção de objetos de aprendizagem e CoWeb na produção colaborativa de conteúdo pós aula - de modo a privilegiar uma coesão não originalmente possível no conjunto de aplicações exploradas.

\subsection{Lições aprendidas ao utilizar Serviços Web}

Como resultado do trabalho realizado e detalhado nas seções anteriores, um conjunto de lições aprendidas foi abstraído e é reportado nesta seção.

Aplicações de computação ubíqua podem se beneficiar das características de fraco acoplamento dos Serviços Web. As operações fornecidas pelo CK escondem as complexidades envolvidas no gerenciamento das informações de contexto, o que facilita o desenvolvimento de aplicações de computação ubíqua uma vez que desenvolvedores não precisam implementar funções recorrentes de gerenciamento de contexto.

Os Serviços Web viabilizam o intercâmbio de informações de contexto em ambientes de computação ubíqua. Nestes ambientes, aplicações devem cooperar entre si para abstrair a localização e a recuperação de informações de contexto. Ao disponibilizar informações de contexto, deve-se considerar como promover o intercâmbio de informações de contexto, como garantir a padronização na representação de informações de contexto e na comunicação com aplicações e/ou serviços. Os padrão abertos, que são as bases dos Serviços Web, facilitam a troca de informações de contexto entre aplicações de computação ubíqua. A facilidade de integração de aplicações alcançada com o Context Kernel é grande devido ao reuso e ao fraco acoplamento, além dos benefício provenientes dele como flexibilidade e interoperabilidade. Para integrar aplicações e fazê-las ciente de contexto, os desenvolvedores devem: (a) escolher a relevância da informação de contexto a ser compartilhada; (b) mapear essas informações nos termos das dimensões de contexto para estruturar a informação mapeada de acordo com o modelo XML do Context Kernel.

Serviços Web exigem menos esforços em novos trabalhos de integração, devido ao uso de protocolos padronizados. O meio padronizado pelo qual o processo de integração é realizado, facilita a utilização por outras aplicações. A experiência adquirida (e documentada) ao se integrar um conjunto de aplicações, é facilmente utilizada por outros desenvolvedores. Os protocolos padronizados aliviam o desenvolvedor dos detalhes da tecnologia e permite a eles focar nas informações de contexto em si, nos termos descritos no parágrafo anterior.

Os Serviços Web facilitam lidar com mudanças de requisitos em aplicações já em uso. Durante a integração das aplicações novos requisitos foram identificados para a infra-estrutura CK: (a) operação para consulta das premissas dada uma inferência (Getlnverse); (b) acréscimo do atributo type a inferência, de modo a identificar o tipo da dimensão; (c) acréscimo do atributo notify a regra, de modo a selecionar as regras 
que seriam utilizadas pelo serviço de notificação; (d) modificação das operações de consulta para utilizar caracteres coringas. O acréscimo de uma nova operação de consulta, embora modifique a descrição do Serviço Web, não afeta a assinatura das demais operações. O estilo orientado a documento, permite modificações nas informações utilizadas pelas operações sem prejudicar o uso destas. O estilo orientado a documento ainda permite validar a estrutura do documento contra um esquema (XML Schema, por exemplo). Dessa forma, as características da flexibilidade em lidar com modificações e o fraco acoplamento proveniente das especificações e tecnologias envolvidas, colocam os Serviços Web como solução interessante em cenários com diversidade de aplicações.

Os Serviços Web podem ser localizados por meio de registros, mas não ainda da forma como é necessário em computação ubíqua. Uma necessidade dos ambientes de computação ubíqua é a disponibilização de serviços de descoberta, que devem localizar o recurso mais apropriado para uma tarefa. Embora os Serviços Web utilizem uma linguagem para descrição de serviços (a WSDL), esta é uma representação de baixo nível, que dificulta o raciocínio a nível semântico para a análise da adequação do serviço de acordo com o que foi requisitado. Em outras palavras, aplicações de computação ubíqua necessitam determinar qual o melhor serviço entre os disponíveis para determinada tarefa, mas informações sobre a interface do serviço e protocolos de aplicação, não são adequadas para automatizar o processo de descoberta.

A segurança em Serviços Web é uma questão que demanda análise mais aprofundada, pois há um número considerável de especificações em andamento, principalmente as dos consórcios OASIS e W3C. Algumas delas se completam e podem ser utilizadas em conjunto. Do ponto de vista da computação ciente de contexto, privacidade e segurança tem ganhado mais atenção, pois tem algumas particularidades (ver Sub-seção 2.4.4) que vão além de segurança no nível de comunicação e mensagem. Um estudo extenso precisa ser feito para determinar quais das especificações atuais podem ser utilizadas em cenários de ciência de contexto.

\subsection{Considerações finais}

O aprendizado e os resultados obtidos neste trabalho são importantes no desenvolvimento do Projeto TIDIA-Ae ${ }^{1}$, que objetiva desenvolver e aplicar uma infra-estrutura que explora uma rede Internet de alta velocidade. O TIDIA-Ae é um projeto colaborativo envolvendo várias equipes de pesquisa com o intuito de projetar e construir uma infra-estrutura integrada com ferramentas para suportar o aprendizado eletrônico. Ferramentas com muitas funções - incluindo aquelas do iClass, CoWeb e Sistema de Gerenciamento de Objetos de Aprendizagem - têm sido planejadas e estão em de-

\footnotetext{
${ }^{1}$ http://tidia-ae.incubadora.fapesp.br/portal
} 
senvolvimento, suportadas por um núcleo comum e integrado de conceitos e componentes de software. Entretanto, já se sabe de muitas outras aplicações que deveriam ser integradas e disponibilizadas para os usuários. Muitas dessas aplicações são aplicações de terceiros que executam em ambientes heterogêneos. Tal cenário demanda a facilidade de integração de aplicações possivel por meio de Serviços Web. O fato é que não importa quanto planejamento ocorra durante a construção da infra-estrutura de software, deve ser necessário integrar aplicações de terceiros independentemente. Como ilustrado neste capítulo, a abordagem dos Serviços Web é viável de ser considerada na investigação de soluções para aprendizado eletrônico no escopo do Projeto TIDIA-Ae. 


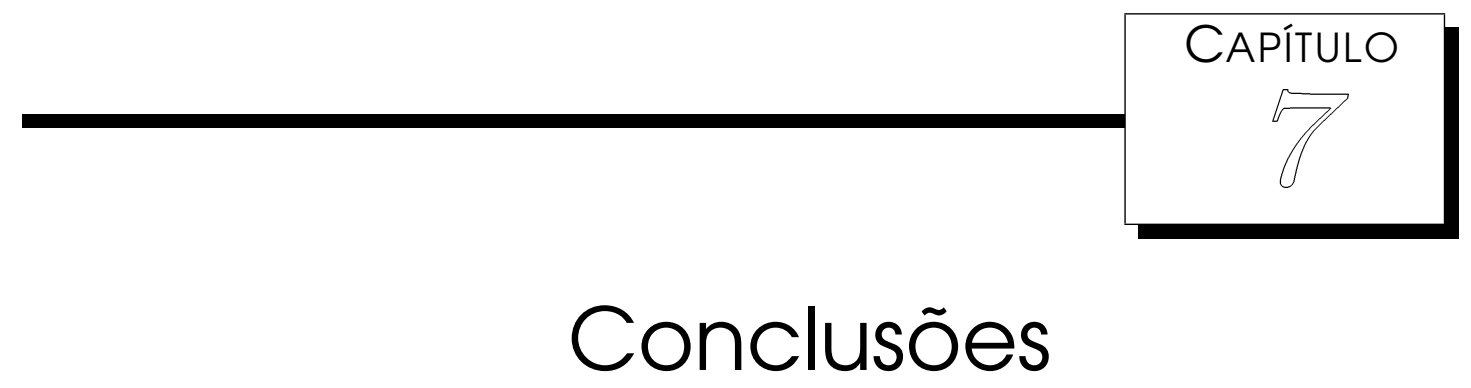

$\mathcal{A}$ s áreas de Computação Ciente de Contexto e de Serviços Web são alvos de intenso esforço em pesquisa. Em computação ciente de contexto, várias pesquisas têm resultado em propostas de infra-estruturas para suportar o desenvolvimento de aplicações que antecipem as necessidades dos usuários e reajam automaticamente de forma pouco intrusiva diante de uma situação. Em Serviços Web, as pesquisas tem resultado em especificações para a concepção de uma plataforma distribuída, aberta, interoperável, robusta, segura e padronizada.

Os trabalhos reportados na literatura para suportar a construção de aplicações cientes de contexto e que foram descritos no Capítulo 5 não exploram as especificações e tecnologias da Web. A infra-estrutura Context Kernel, desenvolvida no mesmo grupo de pesquisa que este trabalho está inserido, propõe o uso de Serviços Web como abordagem para suportar o compartilhamento de informações de contexto por meio de uma plataforma padronizada e aberta. Grimm [2004], destaca as limitações de se adotar, em um sistema distribuído, modelos de dados centrados em códigos e soluções específicas de uma plataforma de execução. Serviços Web, por sua vez, fornecem vários mecanismos para interoperabilidade entre aplicações e promovem o compartilhamento de informações em plataformas diferentes e heterogêneas.

O trabalho aqui apresentado objetivou a análise da utilização de Serviços Web em computação ciente de contexto, por meio do emprego da infra-estrutura Context Kernel para integração de aplicações em cenários de trabalho colaborativo e aprendizado eletrônico. Como resultado, foi obtido um conjunto de lições aprendidas provenientes do estudo e do emprego das especificações para Serviços Web. Outros resultados foram as especificações de informações de contexto de grupo e de metadados educa- 
cionais em dimensões de contexto e os exemplos de utilização do Context Kernel para tornar as aplicações cientes de contexto.

\subsection{Contribuições}

As lições aprendidas (Seção 6.3) na utilização de Serviços Web para a integração e interação entre aplicações cientes de contexto é a principal contribuição do trabalho. Tais lições discutem algumas vantagens e desvantagens dos Serviços Web. Esse aprendizado é útil para o desenvolvimento de outros cenários que demandem colaboração, interação e interoperabilidade entre aplicações heterogêneas, bem como quanto ao intercâmbio de informações de contexto a serem compartilhadas. As lições também atentam para a restrição quanto ao nível da descrição dos Serviços Web, que precisa ser melhor explorada considerando a demanda por análise em alto nível por serviços de descoberta.

A integração da aplicação AutorE contribuiu com uma especificação de informações de contexto para representar aulas e cursos, que pode ser utilizado por outras aplicações além das descritas na Seção 6.2. Macedo et al. [2005] utilizaram o resultado dessa integração em parte do trabalho para a concepção de um serviço de ligações realçados com informações de contexto. O trabalho de Macedo et al. [2005] ainda considerou essa especificação para definir regras de contexto para a aplicação iClass, de modo a utilizar informações de contexto para a geração de ligações entre aulas capturadas.

Para a evolução da infra-estrutura Context Kernel, este trabalho contribuiu com a inclusão de novas funções e a melhoria em algumas já existentes: (a) operação para consulta das premissas dada uma inferência (Getlnverse); (b) acréscimo do atributo type ao elemento inferência, de modo a identificar o tipo da dimensão; (c) acréscimo do atributo notify a regra de contexto, de modo a selecionar as regras que seriam utilizadas pelo serviço de notificação; (d) modificação das operações de consulta para utilizar caracteres coringas. É importante destacar também que houve contribuição em exemplos de como proceder na integração de aplicações utilizando o Context Kernel e na modelagem de informações de grupos e de informações de aprendizado eletrônico em dimensões de contexto.

\subsection{Publicações}

As publicações obtidas foram as seguintes:

- Jardim, C. H. O., Neto, R. F. B., Godoy, R. P., Ribas, H. M. B., Arruda Jr., C. R. E., Munson, E. V., and Pimentel, M. G. C. (2005). Web Services enabling 
Ubiquitous Computing Applications: Lessons Learned by Integrating Ubiquitous e-Learning Applications. International Journal of Web Services Practices, 1(12):142-152. ISSN: 1738-6535.

- Jardim, C. H. O., Bulcão Neto, R. F., Ribas, H. M. B., Munson, E. V., and Pimentel, M. G. C. (2005). Web Services Enabling Context-aware Applications: Lessons Learned by Integrating e-Learning Applications. In International Conference on Next Generation Web Services Practices, pages 400-405, Seoul, Korea. IEEE Computer Society Press. ISBN: 0-7695-2452-4.

- Macedo, A. A., Bulcão Neto, R. F., Camacho-Guerrero, J. A., Jardim, C. H. O., Cattelan, R. G., Inácio Jr, V. R., and Pimentel, M. G. C. (2005). Linking everyday presentations through context information. In 3rd IW3C2 Latin American Web Conference, pages 130-139, Buenos Aires, Argentina. IEEE Computer Society Press.

- Bulcão Neto, R. F., Jardim, C. H. O., Camacho-Guerrero, J. A., and Pimentel, M. G. C. (2004). A Web Service Approach for Providing Context Information to CSCW Applications. In Proceedings of 2nd IW3C2 Latin American Web Congress, pages 78-85, Ribeirão Preto, Brasil. IEEE Computer Society Press.

- Bulcão Neto, R. F., Jardim, C. H. O., Camacho-Guerrero, J. A., Lobato, D. C., and Pimentel, M. G. C. (2004). A Context-based Web Service Approach to Communities of Practice. XXXI Seminário Integrado de Software e Hardware, SEMISH. 15 pages.

- Bulcão Neto, R. F., Jardim, C. H. O., Camacho-Guerrero, J. A., and Pimentel, M. G. C. (2004). Provision of context information to CSCW Applications: A Web Service Approach. Technical report 227, Instituto de Ciências Matemáticas e de Computação - USP. 26 pages.

\subsection{Trabalhos futuros}

A seguir estão descritas algumas sugestões de trabalhos futuros para a infraestrutura Context Kernel, e principalmente sugestões e referências de temas de pesquisa relativo a abordagem dos Serviços Web.

\section{Descrever o Serviço Web Context Kernel utilizando uma ontologia}

A linguagem WSDL especifica os detalhes particulares do formato das mensagens, protocolos e endereços de rede no qual um Serviço Web está instanciado. O W3C recebeu a submissão de uma proposta de linguagem de marcação para Serviços Web, a 
ontologia OWL-S |W3C, 2005a|. A adoção de um descrição de alto nível, como complemento a linguagem WSDL, tem como objetivo automatizar a descoberta, a invocação, a composição e a interoperação de Serviços Web.

A OWL-S [DAML Program, 2004], originalmente denominada DAML-S, é uma ontologia para descrever Serviços Web dentro de um arcabouço baseado em OWL |W3C, 2004d] da Web Semântica [Berners-Lee et al., 2001]. Entre seus principais objetivos estão automatizar o descobrimento e a utilização de serviços na Web, tanto para pessoas quanto para agentes de software |The OWL Services Coalition, 2003|. A ontologia está estruturada nas classes "perfil de serviço", "modelo de serviço" e "bases do serviço” (respectivamente do inglês Service Profile, Service Model e Service Grounding), que fornecem informações essenciais sobre o serviço descrito, pois representam, respectivamente "o que o serviço faz", "como o serviço trabalha" e "como o serviço pode ser acessado”. A OWL-S não restrínge o perfil de serviço a uma forma de registro, podendo-se adotar modelos de registros centralizados semelhantes ao UDDI e mesmo as arquiteturas puramente Peer-to-Peer (normalmente abreviada por P2P) nas quais não haveriam registros. A OWL-S pode ser utilizada pelos serviços de descoberta de recursos tanto em registros centralizados quanto em uma infra-estrutura P2P.

\section{Descoberta de recursos}

Para o processo de descoberta de serviços em instâncias do Context Kernel, seria possivel utilizar registros centralizados como os da especificação UDDI OASIS, 2004a). O UDDI baseia sua arquitetura em diretórios centralizados de modo que cada Serviço Web anuncia sua existência e sua descrição, e todo serviço que precisar utilizar um Serviço Web deve consultar esses registros procurando pelo serviço mais apropriado. Balke and Wagner |2004| propõem integrar descobrimento baseado em ontologias diretamente dentro de diretórios UDDI. Uma outra abordagem a ser investigada poderia considerar uma representação baseada na ontologia OWL-S (descrita anteriormente) e comunicação P2P. O uso de redes P2P é mais apropriado em ambiente dinâmicos como os de computação ubíqua |W3C, 2004e].

Um exemplo de aplicação de P2P em Web Semântica Berners-Lee et al. 2001] é o Projeto Edutella Nejdl et al., 2002|. Este projeto desenvolve uma infra-estrutura com representação própria de metadados baseados em RDF |W3C, 2004c| para redes P2P utilizando a tecnologia JXTA ${ }^{1}$ (conjunto de protocolos para comunicação e colaboração em um rede P2P). Essa infra-estrutura visa a descoberta de conteúdos e não de serviços, cuja representação própria limita o uso do metadado se comparada a ontologia OWL-S |Paolucci et al., 2003|. A adoção de uma infra-estrutura de rede P2P com descrição em OWL-S poderia ser investigada como abordagem para descoberta

\footnotetext{
${ }^{1}$ http://www.jxta.org/
} 
de recursos fornecidos pela infra-estrutura Context Kernel.

\section{Notificação de eventos em Serviços Web}

Há um trabalho, ainda em fase inicial, de produção de especificações para a notificação de eventos em Serviço Web sendo conduzido por um conjunto de empresas |OASIS, 2006]. O objetivo deste grupo de trabalho é definir um conjunto de especificações que padronizem a forma como Serviços Web lidam com notificação de eventos. A arquitetura orientado a eventos sendo proposta empregará o modelo produtor/consumidor para notificar clientes dos serviços.

Acompanhar a evolução desse trabalho e investigar seu uso seria interessante, pois embora a solução atual do Context Kernel para notificação de eventos seja funcional, ela tem um importante limitação: a operação responsável pela notificação não pode ser adequadamente representada no documento WSDL. Isto ocorre, porque a infra-estrutura envia diretamente a notificação para um endereço fornecido pela aplicação usuária. Na abordagem de produtor/consumidor, um tópico pode ser disponibilizado na interface do Serviço Web e as aplicações interessadas em receber notificações da infra-estrutura Context Kernel assinariam esse tópico.

\subsection{Considerações finais}

O trabalho reportado aqui contribuiu para novas pesquisas em Computação Ciente de Contexto e em Serviços Web. Ambos os temas de pesquisa tem muito a contribuir um com outro em novos requisitos, indagações e sugestões. As novas tendências em pesquisas para a Web com o advento da Web Semântica motivam investigar os problemas não supridos pelos Serviços Web quanto aos desafios em Computação Ciente de Contexto.

Um ponto interessante deste trabalho é que ele envolveu trabalhos realizados por outros membros do grupo e contribuiu com lições aprendidas sobre os Serviços Web. Espera-se que essas lições sejam úteis para tais trabalhos e também para os novos, principalmente os relacionados ao Projeto TIDIA-Ae. 


\section{Referências Bibliográficas}

Abowd, G. D. (1999). Classroom 2000: an experiment with the instrumentation of a living educational environment. IBM Systems Journal, 38(4):508-530.

Abowd, G. D. and Mynatt, E. D. (2000). Charting past, present, and future research in ubiquitous computing. ACM Transactions on Computer-Human Interaction (TOCHI), 7(1):29-58.

Abowd, G. D., Mynatt, E. D., and Rodden, T. (2002). The human experience. IEEE Pervasive Computing, 1(1):48-57.

Advanced Distributed Learning (ADL) (2004). Sharable Content Object Reference Model (SCORM ${ }^{T M}$ ) Content Aggregation Model Version 1.3.1. Disponivel na Internet em http://www.adlnet.org/scorm/. Visitado em 11/02/2006.

Amann, P. and Quirchmayr, G. (2003). Foundation of a framework to support knowledge management in the field of context-aware and pervasive computing. In Proceedings of the Australasian Information Security Workshop Conference on ACSW Frontiers 2003, pages 119-131. Australian Computer Society, Inc.

Arruda Jr., C. R. E. (2003). Context Kernel: um Web Service baseado nas dimensões de informação de contexto. Master's thesis, aprovada pelo Programa de Mestrado do ICMC-USP. 85 páginas.

Arruda Jr., C. R. E., Bulcão Neto, R. F., and Pimentel, M. G. C. (2003). Open ContextAware Storage as a Web Service. In International Workshop on Middleware for Pervasive and Ad-Hoc Computing as part of the ACM/IFIP/USENIX International Middleware Conference, pages 81-87.

Baldochi Jr, L. A., Andrade, A. R., Cattelan, R. G., and Pimentel, M. G. C. (2004). Architecture and components for capture and access applications. In Proceedings 
of the 2nd IW3C2 Latin American Web Congress, pages 150-157. IEEE Computer Society Press.

Balke, W. and Wagner, M. (2004). Through different eyes: assessing multiple conceptual views for querying web services. In Proceedings of the 13th International World Wide Web Conference Alternate Track, pages 196-205. ACM Press.

Bardram, J. E. (2004). Applications of context-aware computing in hospital work: examples and design principles. In SAC '04: Proceedings of the 2004 ACM Symposium on Applied Computing, pages 1574-1579. ACM Press.

Berners-Lee, T., Hendler, J., and Lassila, O. (2001). The Semantic Web. Scientific American, 284(5):35-43. Disponivel na Internet em http://www.sciam.com/article.cfm?articleID=00048144-10D2-1C7084A9809EC588EF21. Visitado em 11/02/2006.

Bond, J., Law, D., D., A. L., and Roxburgh, H. P. (2004). Teach Yourself J2EE in 21 Days. SAMS. 1002 pages. Second Edition.

Borriello, G., Chalmers, M., LaMarca, A., and Nixon, P. (2005). Delivering real-world ubiquitous location systems. Communications of the ACM, 48(3):36-41.

Bulcão Neto, R. F. (2003). Interoperabilidade semântica entre aplicações cientes de contexto: uma abordagem ontológica. Monografia de qualificação aprovada pelo Programa de Doutorado do ICMC-USP. 84 páginas.

Bulcão Neto, R. F., Jardim, C. H. O., Camacho-Guerrero, J. A., Lobato, D. C., and Pimentel, M. G. C. (2004a). A Context-based Web Service Approach to Communities of Practice. XXXI Seminário Integrado de Software e Hardware, SEMISH. 15 pages.

Bulcão Neto, R. F., Jardim, C. H. O., Camacho-Guerrero, J. A., and Pimentel, M. G. C. (2004b). Provision of context information to CSCW Applications: A Web Service Approach. Technical Report 227, Instituto de Ciências Matemáticas e de Computação - USP. 26 pages.

Bulcão Neto, R. F., Jardim, C. H. O., Camacho-Guerrero, J. A., and Pimentel, M. G. C. (2004c). A Web Service Approach for Providing Context Information to CSCW Applications. In Proceedings of 2nd IW3C2 Latin American Web Congress, pages 78-85, Ribeirão Preto, Brasil. IEEE Computer Society Press.

Burner, M. (2003). The Deliberate Revolution. ACM Queue, 1(1):28-37.

Burrell, J., Gay, G. K., Kubo, K., and Farina, N. (2002). Context-Aware Computing: A Test Case. In Proceeding of the International Conference on Ubiquitous Computing 
(UbiComp), pages 1-15. Springer-Verlag. Lecture Notes In Computer Science; Vol. 2498.

Cardinaels, K., Meire, M., and Duval, E. (2005). Automating metadata generation: the simple indexing interface. In $W W W$ '05: Proceedings of the 14th International Conference on World Wide Web, pages 548-556. ACM Press.

Cattelan, R. C., Andrade, A. R., Rocha, C. F. P., and Pimentel, M. G. C. (2003a). iClass: um sistema para captura e acesso de sessões em ambiente educacional. Revista Eletrônica de Iniciação Científica (REIC) da Sociedade Brasileira de Computação, 3(1):10-18. Disponível na Internet em http://www.sbc.org.br/reic/edicoes/2003e1/cientificos/iClassUmSistemaParaCapturaEAcessoDeSessoesEmAmbienteEducacional.pdf. Visitado em 11/02/2006.

Cattelan, R. G. (2001). ChatServer 2.0. Relatório do primeiro semestre de 2001 Grupo PET Computação - USP São Carlos.

Cattelan, R. G. (2004). Construção de aplicações de captura e acesso baseada em recorrência de funcionalidades. Master's thesis, Universidade de São Paulo, São Carlos-SP, Brasil. 100 páginas. Disponível na Internet em http://www.teses.usp.br/teses/disponiveis/55/55134/tde-06052004180541/. Visitado em 11/02/2006.

Cattelan, R. G., Baldochi Jr, L. A., and Pimentel, M. G. C. (2003b). Experiences on Building Capture \& Access Applications. In Anais do Simpósio Brasileiro de Sistemas Multimídia e Web (WebMídia), pages 213-228.

Cattelan, R. G., Baldochi Jr, L. A., and Pimentel, M. G. C. (2003c). Processing and storage middleware support for capture and access applications. In Companion Proceedings of the 2003 ACM/IFIP/USENIX International Middleware Conference, page 315.

Chen, H., Finin, T., and Joshi, A. (2004). An Ontology for Context-Aware Pervasive Computing Environments. Special Issue on Ontologies for Distributed Systems, Knowledge Engineering Review, 18(3):197-207.

Cheng, S., Garlan, D., Schmerl, B., Sousa, J. P., Spitznagel, B., Steenkist, P., and $\mathrm{Hu}$, N. (2002). Software architecture-based adaptation for pervasive systems. In International Conference on Architeture of Computing Systems (ARC'SO2): Trends in Network and Pervasive Computing, pages 67-82. 
Chiu, P., Boreczky, J., Girgensohn, A., and Kimber, D. (2001). LiteMinutes: an Internet-based system for multimedia meeting minutes. In WWW '01: Proceedings of the 1Oth International Conference on World Wide Web, pages 140-149. ACM Press.

Czerwinski, S. E., Zhao, B. Y., Hodes, T. D., Joseph, A. D., and Katz, R. H. (1999). An architecture for a secure service discovery service. In MobiCom '99: Proceedings of the 5th annual ACM/IEEE International Conference on Mobile Computing and Networking, pages 24-35. ACM Press.

DAML Program (2004). OWL-based Web Service Ontology (OWL-S). Disponivel na Internet em http://www.daml.org/services/owl-s/. Visitado em 11/02/2006.

Davis II, J. J., Sow, D. M., Blount, M., and Ebling, M. R. (2003a). Context Tailor: Towards a Programming Model for Context-Aware Computing. In 1st International ACM Workshop on Middleware for Pervasive and Ad-Hoc Computing, pages 68-75. PUC-RIO.

Davis II, J. S., Sow, D. M., Dalton, A. B., and Ebling, M. R. (2003b). Context-sensitive Invocation Using the Context Tailor Infrastructure. In System Support for Ubiquitous Computing Workshop at the Fifth Annual Conference on Ubiquitous Computing. 8 pages.

Dey, A. K. (2000). Providing Architectural Support for Building Context-Aware Applications. PhD thesis, College of Computing, Georgia Institute of Technology.

Dey, A. K. (2001). Understanding and Using Context. Personal and Ubiquitous Computing, 5(1):4-7.

Dey, A. K., Abowd, G., and Salber, D. (1999a). A Context-based Infrastructure for Smart Environments. In Proceedings of the 1st International Workshop on Managing Interactions in Smart Environments (MANSE '99), pages 114-128.

Dey, A. K., Abowd, G. D., and Salber, D. (2001). A Conceptual Framework and a Toolkit for Supporting the Rapid Prototyping of Context-Aware Applications. HumanComputer Interaction (HCI) Journal, 16(2-4):97-166.

Dey, A. K., Salber, D., Abowd, G. D., and Futakawa, M. (1999b). The Conference Assistant: Combining Context-Awareness with Wearable Computing. In ISWC '99: Proceedings of the 3rd IEEE International Symposium on Wearable Computers. IEEE Computer Society. 21 pages.

Dey, A. K., Salber, D., Abowd, G. D., and Futakawa, M. (1999c). The Conference Assistant: Combining Context-Awareness with Wearable Computing. In ISWC '99: 
Proceedings of the 3rd IEEE International Symposium on Wearable Computers, pages 21-28. IEEE Computer Society.

Doulkeridis, C., Zafeiris, V., and Vazirgiannis, M. (2005). The role of caching and context-awareness in P2P service discovery. In MEM '05: Proceedings of the 6th International Conference on Mobile Data Management, pages 142-146. ACM Press.

Ebling, M., Hunt, G., and Lei, H. (2001). Issues for Context Services for Pervasive Computing. In Middleware'01 Advanced Workshop on Middleware for Mobile Computing, Heidelberg, Germany. 6 pages.

Fait, H. and Hsi, S. (2005). From playful exhibits to LOM: lessons from building an exploratorium digital library. In JCDL '05: Proceedings of the 5th ACM/IEEE-CS Joint Conference on Digital Libraries, pages 207-212. ACM Press.

Forstadius, J., Lassila, O., and Seppanen, T. (2005). RDF-Based Model for ContextAware Reasoning in Rich Service Environment. In Proceedings of the 3rd International Conference on Pervasive Computing and Communications Workshops (PerCom Workshops), pages 15-19.

Friday, A., Davies, N., and Catterall, E. (2001). Supporting service discovery, querying and interaction in ubiquitous computing environments. In MobiDe '01: Proceedings of the 2nd ACM International Workshop on Data Engineering for Wireless and Mobile Access, pages 7-13. ACM Press.

Fu, X., Bultan, T., and Su, J. (2004). Analysis of interacting BPEL Web Services. In WWW '04: Proceedings of the 13th International Conference on World Wide Web, pages 621-630. ACM Press.

Fuchs, L. (1999). AREA: a cross-application notification service for groupware. In Proceedings of the Sixth European Conference on Computer Supported Cooperative Work, pages 61-80. Kluwer Academic Publishers.

Garlan, D., Siewiorek, D., Smailagic, A., and Steenkist, P. (2002). Project Aura: Toward distraction-free pervasive computing. IEEE Pervasive Computing, 1(2):2231.

Godoy, R. P. (2005). Contribuições para a extensão de informação capturada no iClass: metadados e Web Services. Master's thesis, aprovada pelo Programa de Mestrado do ICMC-USP. 171 páginas.

Goularte, R., Cattelan, R. G., Camacho-Guerrero, J. A., Inácio Jr., V. R., and Pimentel, M. G. C. (2004). Interactive multimedia annotations: enriching and extending 
content. In DocEng '04: Proceedings of the 2004 ACM Symposium on Document Engineering, pages 84-86. ACM Press.

Grimm, R. (2004). One.world: Experiences with a Pervasive Computing Architecture. IEEE Pervasive Computing, 3(3):22-30.

Grimm, R., Davis, J., Lemar, E., Macbeth, A., Swanson, S., Anderson, T., Bershad, B., Borriello, G., Gribble, S., and Wetherall, D. (2004). System support for pervasive applications. ACM Transactions on Computer Systems (TOCS), 22(4):421-486.

Harrison, B. L., Fishkin, K. P., Gujar, A., Mochon, C., and Want, R. (1998). Squeeze me, hold me, tilt me! An exploration of manipulative user interfaces. In CHI '98: Proceedings of the ACM SIGCHI Conference on Human Factors in Computing Systems, pages 17-24. ACM Press/Addison-Wesley Publishing Co.

Heer, J., Newberger, A., Beckmann, C., and Hong, J. I. (2003). liquid: Context-Aware Distributed Queries. In Proceedings of the International Conference on Ubiquitous Computing (UbiComp), pages 140-148. Springer-Verlag. Lecture Notes in Computer Science; Vol. 2864.

Hess, C. K., Román, M., and Campbell, R. H. (2002). Building Applications for Ubiquitous Computing Environments. In Pervasive '02: Proceedings of the First International Conference on Pervasive Computing, pages 16-29, London, UK. Springer-Verlag.

Hong, J. I. (2002). The Context Fabric: an infrastructure for context-aware computing. In CHI 'O2 Extended Abstracts on Human Factors in Computing Systems, pages 554555. ACM Press.

Hong, J. I. and Landay, J. A. (2001). An Infrastructure Approach to Context-Aware Computing. Human-Computer Interaction (HCI) Journal, 16(2-3):287-303.

Ishii, H. and Ullmer, B. (1997). Tangible bits: towards seamless interfaces between people, bits and atoms. In CHI '97: Proceedings of the ACM SIGCHI Conference on Human Factors in Computing Systems, pages 234-241. ACM Press.

Jardim, C. H. O. (2003). Context Daemon: um serviço de notificação de eventos para aplicações cientes de contexto. Monografia de Projeto de Graduação do curso Bacharelado em Ciências de Computação do Departamento de Ciências de Computação do ICMC-USP. Disponivel na Internet em http://coweb.icmc.usp.br/coweb/upload/5/ProjetoGradII_Patrao-revisado.pdf. Visitado em 12/02/2006. 40 páginas.

Jardim, C. H. O., Bulcão Neto, R. F., Ribas, H. M. B., Munson, E. V., and Pimentel, M. G. C. (2005a). Web Services Enabling Context-aware Applications: Lessons Learned by Integrating e-Learning Applications. In International Conference on Next 
Generation Web Services Practices, pages 400-405, Seoul, Korea. IEEE Computer Society Press. ISBN: 0-7695-2452-4.

Jardim, C. H. O., Neto, R. F. B., Godoy, R. P., Ribas, H. M. B., Munson, E. V., Arruda Jr., C. R. E., and Pimentel, M. G. C. (2005b). Web Services enabling Ubiquitous Computing Applications: Lessons Learned by Integrating Ubiquitous e-Learning Applications. International Journal of Web Services Practices, 1(1-2):142-152. ISSN: 1738-6535.

Johanson, B., Fox, A., and Winograd, T. (2002). The Interactive Workspaces Project: Experiences with Ubiquitous Computing Rooms. IEEE Pervasive Computing, 1(2):71-78.

Kidd, C. D., Orr, R., Abowd, G. D., Atkeson, C. G., Essa, I. A., MacIntyre, B., Mynatt, E. D., Starner, T., and Newstetter, W. (1999). The Aware Home: A Living Laboratory for Ubiquitous Computing Research. In CoBuild '99: Proceedings of the Second International Workshop on Cooperative Buildings, Integrating Information, Organization, and Architecture, pages 191-198. Springer-Verlag. Lecture Notes In Computer Science; Vol. 1670.

Lahlou, S., Langheinrich, M., and Röcker, C. (2005). Privacy and trust issues with invisible computers. Communications of the ACM, 48(3):59-60.

Lei, H., Sow, D. M., Davis II, J. S., Banavar, G., and Ebling, M. R. (2002). The Design and Applications of a Context Service. Mobile Computing and Communications Review, ACM SIGMOBILE Mobile Computing and Communications Review, 6(4):45-55.

Liberty Alliance Project (2004). Specifications. Disponivel na Internet em http://www.projectliberty.org/resources/specifications.php. Visitado em $17 / 01 / 2006$.

Macedo, A. A., Bulcão Neto, R. F., Camacho-Guerrero, J. A., Jardim, C. H. O., Cattelan, R. G., Inácio Jr, V. R., and Pimentel, M. G. C. (2005). Linking everyday presentations through context information. In 3rd IW3C2 Latin American Web Conference, pages 130-139, Buenos Aires, Argentina. IEEE Computer Society Press.

Macedo, A. A., Truong, K. N., Camacho-Guerrero, J. A., and Pimentel, M. G. C. (2003). Automatically Sharing Web Experiences through a Hyperdocument Recommender System. In Proceeding of the ACM Conference on Hypertext and Hypermedia, pages 48-56. ACM Press.

McBride, B. (2002). Jena: A Semantic Web Toolkit. IEEE Internet Computing, 6(6):5559. 
McNee, S. M., Albert, I., Cosley, D., Gopalkrishnan, P., Lam, S. K., Rashid, A. M., Konstan, J. A., and Riedl, J. (2002). On the recommending of citations for research papers. In CSCW '02: Proceedings of the 2002 ACM Conference on Computer Supported Cooperative Work, pages 116-125. ACM Press.

Microsoft (1999). COM: Component Object Model Technologies. Disponivel na Internet em http://www.microsoft.com/com/default.mspx. Visitado em 20/01/2006.

Müller, R. and Ottmann, T. (2000). The "Authoring on the Fly" system for automated recording and replay of (tele)presentations. Multimedia Systems, 8(3):158-176.

Nagel, K., Kidd, C. D., O’Connell, T., Dey, A., and Abowd, G. D. (2001). The Family Intercom: Developing a Context-Aware Audio Communication System. In Proceedings of the International Conference on Ubiquitous Computing (UbiComp), pages 176-183. Springer-Verlag. Lecture Notes in Computer Science. Vol. 2201.

Nejdl, W., Wolf, B., Qu, C., Decker, S., Sintek, M., Naeve, A., Nilsson, M., Palmér, M., and Risch, T. (2002). EDUTELLA: a P2P networking infrastructure based on RDF. In Proceedings of the Eleventh International Conference on World Wide Web, pages 604-615. ACM Press.

Nurmi, P. and Floréen, P. (2004). Reasoning in ContextAware Systems. Position paper. Disponível na Internet em http://www.cs.helsinki.fi/u/ptnurmi/papers/positionpaper.pdf. Visitado em $11 / 01 / 2005$.

OASIS (2004a). Introduction to UDDI: Important Features and Functional Concepts. Disponível na Internet em http://uddi.org/pubs/uddi-tech-wp.pdf. Visitado em 09/12/2005.

OASIS (2004b). Web Services Security: SOAP Message Security 1.0 (WSSecurity 2004), OASIS Standard. Disponivel na Internet em http://docs.oasisopen.org/wss/2004/01/oasis-200401-wss-soap-message-security-1.0.pdf. Visitado em 22/01/2006.

OASIS (2005a). OASIS Security Services (SAML). Disponível na Internet em http://www.oasis-open.org/committees/tc_home.php?wg_abbrev=security. Visitado em 16/01/2006.

OASIS (2005b). Web Services Business Process Execution Language (WSBPEL). Disponivel na Internet em http://www.oasisopen.org/committees/tc_home.php?wg_abbrev=wsbpel. Visitado em 16/01/2006. 
OASIS (2005c). Web Services Distributed Management. Disponível na Internet em http://www.oasis-open.org/committees/tc_home.php?wg_abbrev=wsdm. Visitado em 16/01/2006.

OASIS (2005d). Web Services Distributed Management: Management of Web Services (WSDM-MOWS) 1.0. Disponivel na Internet em http://docs.oasisopen.org/wsdm/2004/12/wsdm-mows-1.0.pdf. Visitado em 16/01/2006.

OASIS (2005e). Web Services Distributed Management: Management Using Web Services (MUWS 1.0) Part 1. Disponivel na Internet em http://docs.oasisopen.org/wsdm/2004/12/wsdm-muws-part1-1.0.pdf. Visitado em 16/01/2006.

OASIS (2006). Web Services Notification (WSN) Technical Committee. Disponivel na Internet em http://www.oasisopen.org/committees/tc_home.php?wg_abbrev=wsn. Visitado em 25/01/2006.

Object Management Group (2004). CORBA/IIOP Specification. Disponível na Internet em http://www.omg.org/technology/documents/formal/corba_iiop.htm. Visitado em 24/01/2006.

Orti, E. (2005). Service-Oriented Architecture and Web Services: Concepts, Technologies, and Tools. Disponivel na Internet em http://java.sun.com/developer/technicalArticles/WebServices/soa2/index.html. Visitado em 16/01/2006.

Paolucci, M., Sycara, K., Nishimura, T., and Srinivasan, N. (2003). Using DAML-S for P2P Discovery. In First International Conference on Web Services, ICWS 2003, pages 203-207, Las Vegas, Nevada, USA.

Papazoglou, M. P. and Heuvel, W. (2005). Web Services Management: A Survey. IEEE Internet Computing, 9(6):58-64.

Pedersen, E. R., McCall, K., Moran, T. P., and Halasz, F. G. (1993). Tivoli: an electronic whiteboard for informal workgroup meetings. In CHI '93: Proceedings of the ACM SIGCHI Conference on Human Factors in Computing Systems, pages 391-398. ACM Press.

Pimentel, M. G. C., Izeki, C. A., and Arruda Jr., C. R. E. (2001). An XML-based infrastructure supporting collaborative annotations as first-class hyperdocuments. In Proceedings of the VII Brazilian Symposium on Multimedia and Hypermedia Systems, pages 173-186.

Pimentel, M. G. C., Sante, D. G., Bulcão Neto, R. F., Izeki, C., and Fortes, R. P. M. (2003). Preparing and Extending captured-based documents. In IT2S'O3 - International Information Technology Simposium, pages 1-8, Florianópolis, SC, Brasil. 
Przybilski, M. and Nurmi, P. (2005). An Architecture to Enable Remote Context Reasoning. In Proceedings of the International Conference on Pervasive Systems and Computing (PSC), pages 111-116, Las Vegas.

Ranganathan, A., Campbell, R. H., Ravi, A., and Mahajan, A. (2002). ConChat: A Context-aware Chat Program. IEEE Pervasive Computing, 1(3):51-57.

Ribak, A., Jacovi, M., and Soroka, V. (2002). Ask before you search: peer support and community building with reachout. In CSCW'02: Proceedings of the $2002 \mathrm{ACM}$ Conference on Computer Supported Cooperative Work, pages 126-135. ACM Press.

Ribas, H. M. B. (2004). Geração de Metadados SCORM para documentos de aula do iClass. Monografia de Projeto de Graduação do curso Bacharelado em Ciências de Computação do Departamento de Ciências de Computação do ICMC-USP. 30 páginas.

Román, M. and Campbell, R. H. (2003). A Middleware-base Application Framework for Active Spaces Applications. In Proceedings of the ACM/IFIP/USENIX International Middleware Conference, pages 433-454.

Román, M., Hess, C., Cerqueira, R., Ranganathan, A., Campbell, R. H., and Nahrstedt, K. (2002). A middleware infrastructure for active spaces. IEEE Pervasive Computing, 1(4):74-83.

Salber, D., Dey, A. K., and Abowd, G. A. (1999a). The Context Toolkit: aiding the development of context-enabled applications. In Proceedings of the ACM SIGCHI conference on Human factors in computing systems, pages 434-441. ACM Press.

Salber, D., Dey, A. K., and Abowd, G. D. (1999b). The Context Toolkit: aiding the development of context-enabled applications. In CHI '99: Proceedings of the ACM SIGCHI Conference on Human Factors in Computing Systems, pages 434-441. ACM Press.

Sante, D. G., Camacho-Guerrero, J. A., Macedo, A. A., and Fortes, R. P. M. (2004). Preparing, Extending and Retrieving Captured Information. In LA-WEBMEDIA 'O4: Proceedings of the WebMedia \& LA-Web 2004 Joint Conference, pages 158-160. IEEE Press.

Schilit, B. N., Golovchinsky, G., and Price, M. N. (1998). Beyond paper: supporting active reading with free form digital ink annotations. In $\mathrm{CHI}$ '98: Proceedings of the ACM SIGCHI Conference on Human Factors in Computing Systems, pages 249-256. ACM Press/Addison-Wesley Publishing Co. 
Shi, Y., Xie, W., Xu, G., Shi, R., Chen, E., Mao, Y., and Liu, F. (2003). The smart classroom: Merging Technologies for Seamless Tele-education. IEEE Pervasive Computing, 2(2):47-55.

Siewiorek, D. P. (2002). New frontiers of application design. Communications of the ACM, 45(12):79-82.

Sousa, J. P. and Garlan, D. (2002). Aura: an Architectural Framework for User Mobility in Ubiquitous Computing Environments. In Proceedings of 3rd Working IEEE/IFIP Conference on Software Architecture, pages 29-43. Kluwer Academic Publishers.

Spence, M., Driver, C., and Clarke, S. (2005). Sharing Context History in Mobile, Context-Aware Trails-Based Applications. In 1st International Workshop on Exploiting Context Histories in Smart Environments, (ECHISE 2005) Pervasive 2005, Munich, Germany. 5 pages.

Stal, M. (2002). Web services: beyond component-based computing. Communications of the ACM, 45(10):71-76.

Sun Microsystems (2003). Java RMI Specification. Disponivel na Internet em http://java.sun.com/j2se/1.4.2/docs/guide/rmi/spec/rmiTOC.html. Visitado em $24 / 01 / 2006$.

Sun Microsystems (2006). Jini Network Technology. Disponível na Internet em http://www.sun.com/software/jini/. Visitado em 24/01/2006.

The OWL Services Coalition (2003). OWL-S Semantic Markup for Web Services. Disponível na Internet em http://www.daml.org/services/owl-s/1.0/. Visitado em 12/02/2006.

Truong, K. N., Abowd, G. D., and Brotherton, J. A. (2001). Who, What, When, Where, How: Design issues of capture \& access applications. In Proceedings of the International Conference on Ubiquitous Computing, pages 209-224.

Vieira, V. H. (2004a). Integração de Agenda e Suporte a Documentação de Projetos para Grupos ao Sistema de Computação Ubíqua iClass. Monografia de qualificação aprovada pelo Programa de Mestrado do ICMC-USP.

Vieira, V. H. (2004b). Integração de aplicações web: intercâmbio de funcionalidades e informações de contexto usando Web Services. IV Workshop de Teses e Dissertações em Multimídia, Hipermidia e Web (WTDWeb 2004). 
W3C (2000). SOAP Messages with Attachments. Disponivel na Internet em http://www.w3.org/TR/2000/NOTE-SOAP-attachments-20001211. Visitado em $24 / 01 / 2006$.

W3C (2001). Semantic Web Activity. Disponivel na Internet em http://www.w3.org/2001/sw/. Visitado em 12/02/2006.

W3C (2002). Web Services Activity. Disponivel na Internet em http://www.w3.org/2002/ws. Visitado em 23/01/2006.

W3C (2003a). Extensible Markup Language. Disponível na Internet em http://www.w3.org/XML/. Visitado em 25/01/2006.

W3C (2003b). Simple Object Access Protocol (SOAP) 1.2, W3C Recommendation. Disponível na Internet em http://www.w3.org/TR/soap12-part0/. Visitado em $25 / 01 / 2006$.

W3C (2004a). Annotated List of Web Services Specs. Disponivel na Internet em http://lists.w3.org/Archives/Public/www-ws-arch/2004Feb/0022.html. Visitado em 24/01/2006.

W3C (2004b). Namespaces in XML 1.1. Disponível na Internet em http://www.w3.org/TR/xml-names11/. Visitado em 24/01/2006.

W3C (2004c). Resource Description Framework (RDF). Disponivel na Internet em http://www.w3.org/RDF/. Visitado em 12/02/2006.

W3C (2004d). Web Ontology Language (OWL). Disponivel na Internet em http://www.w3.org/2004/OWL/. Visitado em 12/02/2006.

W3C (2004e). Web Services Architecture. Disponivel na Internet em http://www.w3.org/TR/2004/NOTE-ws-arch-20040211/. Visitado em $24 / 01 / 2006$.

W3C (2004f). XML Schema Part 0: Primer, W3C Recommendation. Disponivel na Internet em http://www.w3.org/TR/xmlschema-0/. Visitado em 25/01/2006.

W3C (2005a). OWL-S: Semantic Markup for Web Services. Disponivel na Internet em http://www.w3.org/Submission/OWL-S/. Visitado em 09/01/2006.

W3C (2005b). XSL Transformations (XSLT) Version 2.0, W3C Candidate Recommendation. Disponível na Internet em http://www.w3.org/TR/xslt20/. Visitado em 25/01/2006. 
W3C (2006). Web Services Description Language (WSDL) 2.0, W3C Candidate Recommendation. Disponível na Internet em http://www.w3.org/TR/wsdl20/. Visitado em 25/01/2006.

Wang, X., Dong, J. S., Chin, C., Hettiarachchi, S. R., and Zhang, D. (2004). Semantic Space: An Infrastructure for Smart Spaces. IEEE Pervasive Computing, 03(3):32-39.

Want, R., Hopper, A., Falcão, V., and Gibbons, J. (1992). The active badge location system. ACM Transactions on Information Systems, 10(1):91-102.

Web Service Interoperability Organization (2004). Basic profile version 1.1. Disponíel na Internet em http://www.ws-i.org/Profiles/BasicProfile-1.1.html. Visitado em 23/01/2006.

Weiser, M. (1991). The computer for the 21 st century. Scientific American, 265(3):94104.

Weiser, M. (1993). Some Computer Science Issues in Ubiquitous Computing. Communications of the ACM, 36(7):75-84.

Witbrock, M. J. and Hauptmann, A. G. (1998). Speech Recognition for a Digital Video Library. Journal of the American Society of Information Science, 49(7):619-632.

Zimmer, T. (2004). Towards a Better Understanding of Context Attributes. In 2nd IEEE Conference on Pervasive Computing and Communications Workshops (PerCom 2004 Workshops), pages 23-27. IEEE Computer Society. 


\section{Glossário}

Acoplamento: No desenvolvimento de software refere-se ao grau no qual módulos ou componentes de software dependem um do outro.

Ad hoc: Solução para um propósito particular.

API: Acrônimo para Application Programming Interface. Um conjunto padrão de formato de dados, métodos, chamadas e interrupções de software que pode ser utilizado por uma aplicação para acessar serviços de rede, dispositivos ou sistemas operacionais.

Arcabouço: Uma estrutura na qual um outro software pode ser organizado e desenvolvido.

Cache: O armazenamento temporário no qual valores recentes ou freqüentemente utilizado são armazenados para evitar a sobrecarga de obter esse valores.

Callback: Quando um programa registra o tratamento de certo evento a outro programa (controlador de eventos). O programa controlador do evento pode avisar o programa que o registrou quando o evento ocorrer. Esse processo é denominado callback.

CORBA: Acrônimo para Common Object Request Broker Architecture. Um conjunto de serviços fornecendo conectividade, segurança, transações, persistência, entre outros, para a definição de um ambiente distribuído.

CPA: Acrônimo para Collaboration Protocol Agreements. Informação acordada entre os envolvidos no negócio que descreve o protocolo específico de colaboração a ser utilizado.

CPP: Acrônimo para Collaboration Protocol Profile. Protocolo utilizado com serviços de mensagens para configurar o acesso a repositórios ebXML. 
CSCW: Acrônimo para Computer Supported Cooperative Work. Área que estuda como atividades colaborativas e sua coordenação podem ser apoiadas por sistemas computacionais.

DCOM: Acrônimo para Distributed Component Object Model. É uma extensão do COM (Component Object Model) da Microsoft, para suportar objetos distribuídos através de uma rede.

Driver: Uma porção de software utilizada para padronizar e abstrair detalhes do acesso a um programa.

E/S: Acrônimo para Entrada e Saída.

FTP: Acrônimo para File Transfer Protocol. Um protocolo para troca de arquivos em qualquer rede que suporte o protocolo TCP/IP.

HTTP: Acrônimo para Hypertext Transfer Protocol. Um conjunto de regras (protocolo) para transferir arquivos (texto, gráfico, som, vídeo e outros arquivos multimídia) na World Wide Web.

IDC: Empresa de consultoria em tecnologia da informação.

IIOP: Acrônimo para Internet Inter-ORB Protocol. Protocolo abstrato por meio do qual os ORBs se comunicam.

Interoperabilidade: A habilidade do software ou do hardware de fabricantes diferentes interagirem.

Java: Uma linguagem de programação orientada a objetos.

Jini: É uma arquitetura aberta de rede para a construção de sistemas distribuídos.

JMS: Acrônimo para Java Message Service. Fornece os modelos ponto-a-ponto e produtor consumidor para a passagem de mensagens na plataforma J2EE.

JXTA: Um conjunto de protocolos abertos para permitir que dispositivos se conectem e colaborem em uma rede P2P.

Kerberos: Um protocolo de autenticação de redes de computadores na qual usuários e serviços verificam a identidade um do outro.

Lógica Fuzzy: Lógica na qual há valores intermediários entre verdadeiro e falso, de modo a representar situações onde não se pode apenas afirmar ou negar algo sobre uma proposição.

Middleware: Agentes de software que atuam como intermediários entre componentes de aplicação. 
Namespace: um documento unicamente identificado na Web que é utilizado para estabelecer a estrutura lógica de outro documento.

OASIS: Acrônimo para Organization for the Advancement of Structured Information Standards. Um consórcio internacional que guia o desenvolvimento, a convergência e a adoção de padrões de negócios eletrônico.

Objetos de aprendizagem: Gualquer entidade, digital ou não digital, que pode ser usada para aprendizado, educação e treinamento.

Ontologia: Uma especificação formal de como representar objetos, conceitos e entidades em alguma área de interesse e os relacionamentos entre eles.

ORB: Acrônimo para Object Request Broker. Um middleware que permite aos programadores realizar chamadas de um computador a outro via rede.

OWL-S: É uma ontologia para descrever Serviços Web dentro de um arcabouço baseado em OWL.

OWL: Acrônimo para Web Ontology Language. Uma linguagem de ontologia para descrever classes e relacionamentos entre informações e aplicações na Web.

P2P: Acrônimo para Peer-to-Peer. Uma rede de computadores baseada no conceito de nós que atuam simultaneamente como clientes e servidores para outros nós na rede.

PHP: É uma linguagem de programação utilizada principalmente em aplicações servidoras para manipular conteúdo dinâmico na Web.

PKI: Acrônimo para Public Key Infrastructure. Infra-estruturas de chave pública permitem aos usuários autenticarem um ao outro e usar certificados de identidade para encriptar e decriptar mensagens.

Proxy: Um servidor que atua como intermediário entre uma aplicação cliente e a Internet normalmente para controle administrativo, segurança, cache e registro de informações.

RDF: Acrônimo para Resource Descriptor Framework. Um conjunto de especificações para um modelo de metadados em grafos com o objetivo de fazer sentenças sobre um recurso.

RMI: Acrônimo para Java Remote Method Invocation. É uma API Java para realizar chamada a procedimentos remotos. 
RPC: Acrônimo para Remote Procedure Call. Método para comunicação entre processos no qual o cliente envia uma mensagem de requisição para um sistema remoto como se estivesse chamando um procedimento local.

SAML: Acrônimo para Security Assertion Markup Language. Um padrão que permite que usuários autenticados uma única vez possam acessar serviços separados.

SCM: Acrônimo para Service Control Manager. Um servidor RPC no qual programas para controle e configuração de serviços podem manipular serviços em máquinas remotas.

SCORM: Acrônimo para Sharable Content Object Reference Model. Uma coleção de padrões e especificações para aprendizado eletrônico para a Web.

Sensor: Qualquer dispositivo que receba sinais ou estímulos.

SMTP: Acrônimo para Simple Mail Transfer Protocol. Padrão que define como servidores de email enviam mensagem um para o outro.

SOAP: Acrônimo para Simple Object Access Protocol. É um protocolo que especifica exatamente como codificar uma mensagem HTTP em um documento XML de forma que um programa em um computador pode chamar um programa em outro computador e passar informações a este último.

SQL: Acrônimo para Structured Query Language. Linguagem para criar, modificar e recuperar dados de um sistema gerenciador de banco de dados.

SSL: Acrônimo para Secure Socket Layer. Define um meio de usar encriptação assimétrica por intermédio de conexões com socket.

TIDIA-Ae: Acrônimo para Tecnologia da Informação para o Desenvolvimento da Internet Avançada - Aprendizagem Eletrônica. Um projeto colaborativo, financiado pela FAPESP, para pesquisa e desenvolvimento na área de aprendizado eletrônico suportado por uma rede de alta velocidade.

TLS: Acrônimo para Transport Layer Security. É o sucessor do SSL, e assim como este é um protocolo para criptografia que fornece comunicação segura na Internet.

Toolkit: Conjunto de elementos básicos para a construção de um software.

UDDI: Acrônimo para Universal Description, Discovery, and Integration. Um registro baseado em XML para serviços na Internet.

URI: Acrônimo para Universal Resource Identifier. O conjunto genérico de todos os nomes e endereços que referem-se a objetos (tipicamente na Internet). 
w3C: Acrônimo para World Wide Web Consortium. Um consórcio internacional que objetiva garantir a padronização e interoperabilidade para a evolução da Web.

Web Semântica: É uma extensão da Web atual por meio do uso de padrões, linguagens de marcação e ferramentas de processamento, com o objetivo de dar significado ao conteúdo dos documentos para Web para que possam ser entendidos por máquinas.

WS-BPEL: Acrônimo para Web Services Business Process Execution Language. Uma especificação para descrever as atividades de um processo de negócio como Serviços Web.

WS-I: Acrônimo para Web Services Interoperability. Uma especificação que define um núcleo principal de tecnologias que mesmo implementadas em plataformas e sistemas diferentes, ajudam a garantir a interoperabilidade entre os serviços que utilizem estas tecnologias.

WS-Security: Acrônimo para Web Services Security. Um padrão proposto para garantia de segurança em dados trocados em Serviços Web.

WSDL: Acrônimo para Web Services Description Language. Uma linguagem para descrever Serviços Web que é baseada na linguagem XML. Essa linguagem é utilizada para descrever a interface de serviços de um Serviço Web, ou seja, o formato das suas mensagens de requisição e resposta.

WSDM: Acrônimo para Web Services Distributed Management. Um conjunto de especificações para definir uma arquitetura de Serviços Web para gerenciamento de recursos distribuídos.

XML: Acrônimo para eXtensible Markup Language. É um formato de texto simples e muito flexível derivado do SGML. Originalmente projetado para o desafio de publicação eletrônica de grande escala, o XML é um importante padrão para intercâmbio de dados na Web e em qualquer outra aplicação.

XSLT: Acrônimo para eXtensible Style Sheet Language. Uma linguagem declarativa e um modelo de processamento usado para converter um dialeto XML em outro dialeto XML ou outro formato textual. 